\title{
Projecting genetic associations through gene expression patterns highlights disease etiology and drug mechanisms
}

This manuscript (permalink) was automatically generated from greenelab/phenoplier manuscript@다c4a3 on August 4, 2021.

\section{Authors}

\section{- Milton Pividori}

\section{(D) $\underline{0000-0002-3035-4403} \cdot$ ? miltondp $\cdot$ miltondp}

Department of Genetics, Perelman School of Medicine, University of Pennsylvania, Philadelphia, PA 19104, USA .

Funded by The Gordon and Betty Moore Foundation GBMF 4552; The National Human Genome Research Institute (R01 HG010067)

\section{- Sumei Lu}

Center for Spatial and Functional Genomics, Children's Hospital of Philadelphia, Philadelphia, PA, 19104, USA

\section{- Binglan Li}

\section{(iD) 0000-0002-0103-6107}

Department of Biomedical Data Science, Stanford University, Stanford, CA, USA

\section{- Chun Su}

\section{(iD) 0000-0001-6388-8666 · (O) sckinta}

Center for Spatial and Functional Genomics, Children's Hospital of Philadelphia, Philadelphia, PA, 19104, USA

\section{- Matthew E. Johnson}

Center for Spatial and Functional Genomics, Children's Hospital of Philadelphia, Philadelphia, PA, 19104, USA

\section{- Wei-Qi Wei}

Vanderbilt University Medical Center

\section{- Qiping Feng}

(iD) $\underline{0000-0002-6213-793 X}$

Vanderbilt University Medical Center

\section{- Bahram Namjou}

Cincinnati Children's Hospital Medical Center

- Krzysztof Kiryluk

(D) 0000-0002-5047-6715 · kirylukk

Department of Medicine, Division of Nephrology, Vagelos College of Physicians \& Surgeons, Columbia University, New York, New York 
bioRxiv preprint doi: https://doi.org/10.1101/2021.07.05.450786; this version posted August 5, 2021. The copyright holder for this preprint (which was not certified by peer review) is the author/funder, who has granted bioRxiv a license to display the preprint in perpetuity. It is made available under aCC-BY 4.0 International license.

\section{- Iftikhar Kullo}

Mayo Clinic

\section{- Yuan Luo}

Northwestern University

\section{- Blair D. Sullivan}

School of Computing, University of Utah, Salt Lake City, UT, USA

\section{- Benjamin F. Voight}

\section{(D) 0000-0002-6205-9994 · (P) bvoight · bvoight28}

Department of Systems Pharmacology and Translational Therapeutics, Perelman School of Medicine, University of Pennsylvania, Philadelphia, PA 19104, USA; Department of Genetics, Perelman School of Medicine, University of Pennsylvania, Philadelphia, PA 19104, USA; Institute for Translational Medicine and Therapeutics, Perelman School of Medicine, University of Pennsylvania, Philadelphia, PA 19104, USA

\section{- Carsten Skarke}

\section{(i) 0000-0001-5145-3681 · CarstenSkarke}

Institute for Translational Medicine and Therapeutics, Department of Medicine, University of Pennsylvania, Philadelphia, PA 19104, USA

\section{- Marylyn D. Ritchie}

\section{(iD) 0000-0002-1208-1720 · MarylynRitchie}

Department of Genetics, Perelman School of Medicine, University of Pennsylvania, Philadelphia, PA 19104, USA

\section{- Struan F.A. Grant}

\section{(D) 0000-0003-2025-5302 · STRUANGRANT}

Center for Spatial and Functional Genomics, Children's Hospital of Philadelphia, Philadelphia, PA, 19104, USA; Department of Pediatrics, Perelman School of Medicine, University of Pennsylvania, Philadelphia, PA, 19104, USA; Division of Human Genetics, Children's Hospital of Philadelphia, Philadelphia, PA, 19104, USA

\section{- Casey S. Greene}

\section{(D) 0000-0001-8713-9213 · c cgreene $\cdot$ GreeneScientist}

Center for Health Al, University of Colorado School of Medicine, Aurora, CO 80045, USA; Department of Biochemistry and Molecular Genetics, University of Colorado School of Medicine, Aurora, CO 80045, USA · Funded by The Gordon and Betty Moore Foundation (GBMF 4552); The National Human Genome Research Institute (R01 HG010067); The National Cancer Institute (R01 CA237170) 


\section{Abstract}

Understanding how dysregulated transcriptional processes result in tissue-specific pathology requires a mechanistic interpretation of expression regulation across different cell types. It has been shown that this insight is key for the development of new therapies. These mechanisms can be identified with transcriptome-wide association studies (TWAS), which have represented a significant step forward to test the mediating role of gene expression in GWAS associations. However, it is hard to disentangle causal cell types using eQTL data alone, and other methods generally do not use the large amounts of publicly available RNA-seq data. Here we introduce PhenoPLIER, a polygenic approach that maps both gene-trait associations and pharmacological perturbation data into a common latent representation for a joint analysis. This representation is based on modules of genes with similar expression patterns across the same tissues. We observed that diseases were significantly associated with gene modules expressed in relevant cell types, and our approach was accurate in predicting known drug-disease pairs and inferring mechanisms of action. Furthermore, using a CRISPR screen to analyze lipid regulation, we found that functionally important players lacked TWAS associations but were prioritized in phenotype-associated modules by PhenoPLIER. By incorporating groups of coexpressed genes, PhenoPLIER can contextualize genetic associations and reveal potential targets within associated processes that are missed by single-gene strategies.

\section{Introduction}

Human diseases have tissue-specific etiologies and manifestations $[1,2, \underline{3}]$. In this context, determining how genes influence these complex phenotypes requires mechanistically understanding expression regulation across different cell types $[\underline{4}, \underline{5}, \underline{6}]$, which in turn should lead to improved treatments $[\underline{7}, \underline{8}]$. Previous studies have described regulatory DNA elements, including chromatinstate annotations $[\underline{9}, \underline{10}]$, high-resolution enhancers [11, 12], DNase I hypersensitivity maps [ㄷ], and genetic effects on gene expression across different tissues [4]]. Integrating functional genomics data and GWAS data [13] has improved the identification of these transcriptional mechanisms that, when dysregulated, commonly result in tissue- and cell lineage-specific pathology.

Given the availability of gene expression data across several tissues $[\underline{4}, \underline{14}, \underline{15}, \underline{16}]$, a popular approach to identify these biological processes is the transcription-wide association study (TWAS), which integrates expression quantitative trait loci (eQTLs) data to provide a mechanistic interpretation for GWAS findings. TWAS relies on testing whether perturbations in gene regulatory mechanisms mediate the association between genetic variants and human diseases $[17,18,19,20]$. However, TWAS has not reliably detected tissue-specific effects because eQTLs are commonly shared across tissues [21,22]. This sharing makes it challenging to identify the tissue or tissues that are etiologically relevant. Existing methods that connect GWAS findings with gene expression data can infer disease-relevant tissues and cell types $[\underline{22}, \underline{23}, \underline{24}, \underline{25}, \underline{26}, \underline{27}]$, but they generally rely on small sets of expression data compared with the total number of RNA-seq samples that are increasingly available $[14,15]$.

Moreover, widespread gene pleiotropy across complex traits reveals the highly interconnected nature of transcriptional networks $[\underline{28}, \underline{29}]$, where potentially all genes expressed in disease-relevant cell types have a non-zero effect $[\underline{30}, 31]$. Consequently, this complicates the interpretation of genetic effects and hampers translational efforts.

We propose PhenoPLIER, a polygenic approach that infers how groups of functionally-related genes influence complex traits, and how pharmacological perturbations affect these genes' activity to exert their effects. The approach maps both gene-trait associations and drug-induced transcriptional responses into a common representation for a joint analysis. For this, we integrated more than 4,000 gene-trait associations (using TWAS from PhenomeXcan [32]) and transcriptional profiles of drugs (LINCS L1000 [33]) into a low-dimensional space learned from public gene expression data on tens of 
thousands of RNA-seq samples (recount2 $[14,34]$ ). We used a latent representation defined by a computational approach [35] that learns recurrent gene co-expression patterns with certain sparsity constraints and preferences for those that align with prior knowledge (pathways). This low-

dimensional space comprised features representing groups of genes (gene modules) with coordinated expression across different tissues and cell types. When mapping gene-trait associations to this reduced expression space, we observed that diseases were significantly associated with gene modules expressed in relevant cell types, such as hypothyroidism with T cells and thyroid, corneal endothelial cells with keratometry measurements, hematological assays on specific blood cell types, plasma lipids with adipose tissue, and neuropsychiatric disorders with different brain cell types. Moreover, since we rely on a large and heterogeneous RNA-seq dataset, we were also able to identify modules associated with cell types under specific stimuli or disease states. We replicated gene module associations with cardiovascular and autoimmune diseases in the Electronic Medical Records and Genomics (eMERGE) network phase III [36]. Furthermore, we performed a CRISPR screen to analyze lipid regulation in HepG2 cells and observed more robust trait associations with modules than with individual genes, even when single genes known to be involved in lipid metabolism did not reach genome-wide significance. Compared to a single-gene approach, our module-based method also better predicted FDA-approved drug-disease links by capturing tissue-specific pathophysiological mechanisms linked with the mechanism of action of drugs (e.g., niacin with cardiovascular traits via a known immune mechanism), suggesting that modules may provide a better means to examine drug-disease relationships than individual genes. Finally, exploring the phenotype-module space also revealed stable trait clusters associated with relevant tissues, including a complex branch involving lipids with cardiovascular, autoimmune, and neuropsychiatric disorders. In summary, instead of considering single genes associated with different complex traits, PhenoPLIER incorporates groups of genes that act together to carry out different functions in specific cell types. This improves robustness to detect and interpret genetic associations, and here we show how it can prioritize alternative and potentially more promising candidate targets when important single gene associations are not detected. The approach represents a conceptual shift in the interpretation of genetic studies, and has the potential to extract mechanistic insight from statistical associations to enhance the understanding of complex diseases and their therapeutic modalities.

\section{Results}

\section{PhenoPLIER: an integration framework based on gene co-expression patterns}



made available under aCC-BY 4.0 International license.

a)

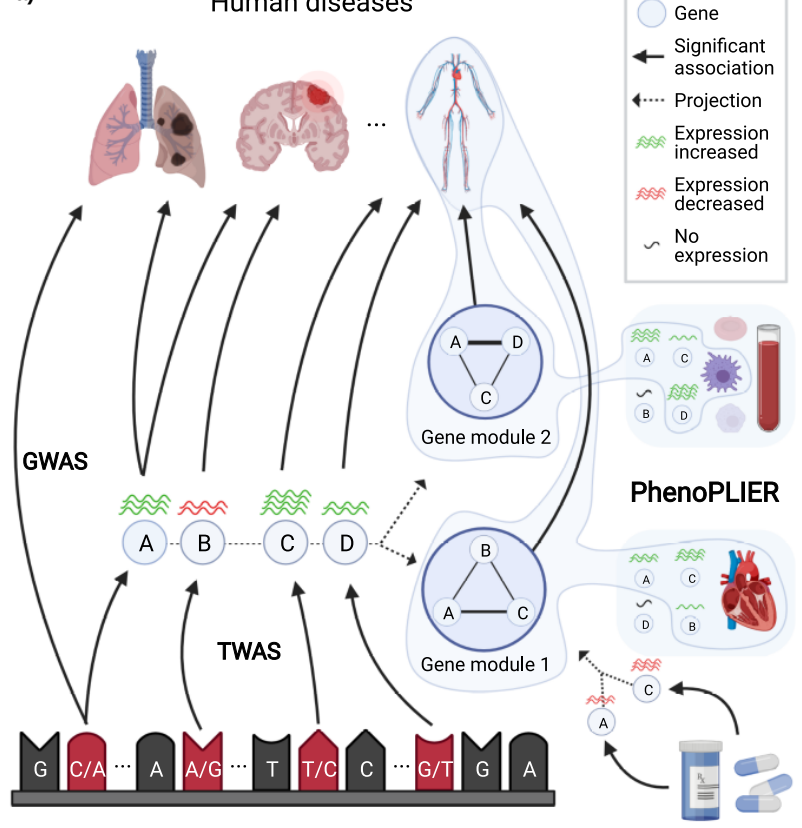

b)
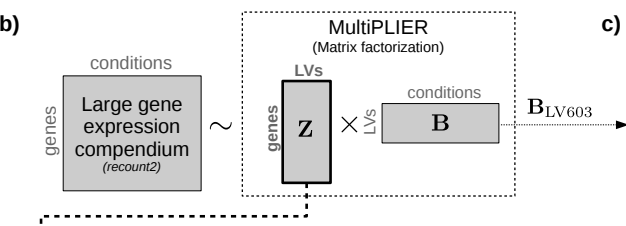

$i^{2}$
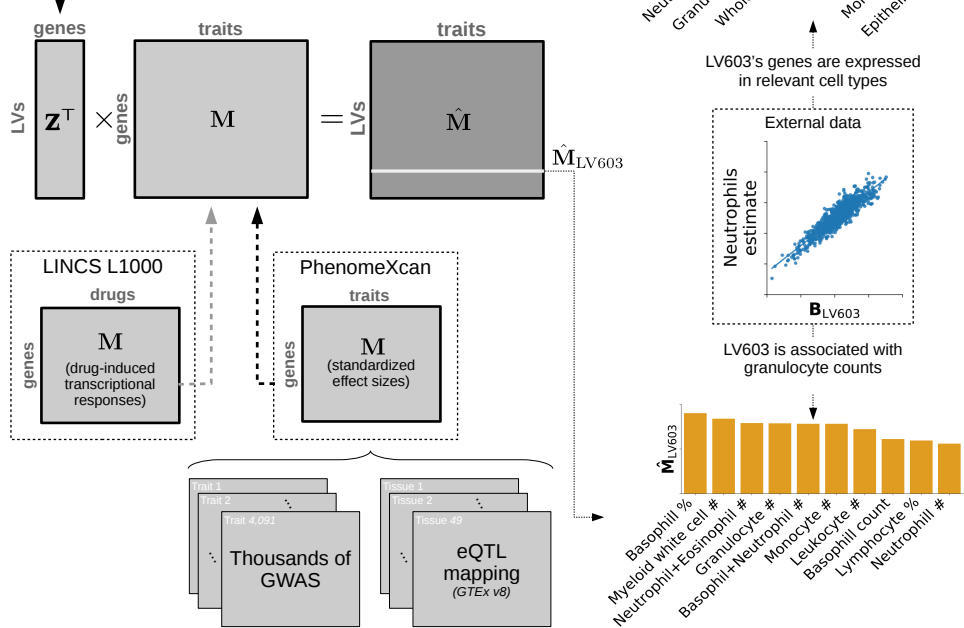

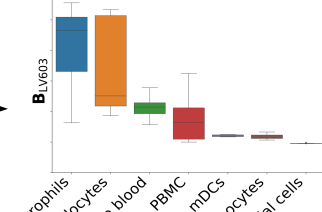

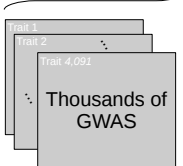

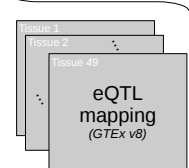
V603's genes are expressed in relevant cell types External data

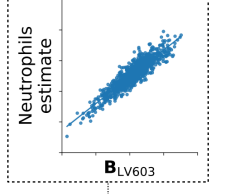
LV603 is associated with 603 is associated wi

Figure 1: Schematic of the PhenoPLIER framework. a) High-level schematic of PhenoPLIER (a gene module-based method) in the context of TWAS (single-gene) and GWAS (genetic variants). PhenoPLIER integrates groups of genes coexpressed in specific cell types (gene modules) with gene-trait and gene-drug associations. b) The integration consists of projecting gene-trait/gene-drug associations from PhenomeXcan/LINCS L1000 (bottom) to a latent space based on gene modules (represented by latent variables/LVs) from MultiPLIER (top). The process generates matrix $\hat{\mathbf{M}}$, where each trait/drug is now described by LVs (only traits are shown). c) LV603, termed as a neutrophil signature in the original MultiPLIER study, was associated in PhenoPLIER with neutrophil counts and other white blood cells (bottom, showing the top 10 traits for LV603). Genes in LV603 were expressed in relevant cell types (top). PBMC: peripheral blood mononuclear cells; mDCs: myeloid dendritic cells.

PhenoPLIER combines TWAS and drug-induced transcriptional responses with gene co-expression patterns by projecting gene-trait and gene-drug associations onto a latent gene expression representation (Figure 1). We used PhenomeXcan [32], a TWAS resource for the UK Biobank [37] and other cohorts with 4,091 different diseases and traits, and the transcriptional responses to small molecule perturbations from LINCS L1000 [33] comprising 1,170 compounds. We obtained a latent gene expression representation from MultiPLIER [34], an unsupervised learning approach applied to recount2 [14] - a uniformly-curated collection of transcript-level gene expression quantified by RNAseq in a large, diverse set of samples collected across a range of disease state, cell types differentiation stages, and various stimuli (Methods). MultiPLIER extracted 987 latent variables (LV) by optimizing data reconstruction but also the alignment of LVs with prior knowledge/pathways (Methods). Each LV or gene module represents a group of weighted genes expressed together in the same tissues and cell types as a functional unit. Since LVs might represent a functional set of genes regulated by the same transcriptional program $[38,39]$, we conjecture that the projection of TWAS and pharmacologic perturbations data into this latent space could provide context for their interpretation. PhenoPLIER converts gene associations to an LV score: all genes' standardized effect sizes for a trait (from TWAS) or differential expression values for a drug (from pharmacologic perturbation data) are multiplied by the LV genes' weights and summed, producing a single value. This process links different traits and drugs to LVs representing cell types and tissues, even at specific developmental stages or under distinct stimuli. Examining these LVs is possible because the MultiPLIER's models link to samples, which may be annotated for experimental conditions (represented by matrix $\mathbf{B}$ in Figure 1 b, top) in which genes in an LV are expressed. To further analyze LV-trait associations, we adapted the gene-property approach from MAGMA [40] to compute an LVtrait $p$-value by fitting a regression model with LV weights as predictors of a trait's gene associations. Thus PhenoPLIER allows the user to address specific questions, namely: do disease-associated genes belong to modules expressed in specific tissues and cell types? Are these cell type-specific modules associated with different diseases (thus, potentially representing a "network pleiotropy" example from 
an omnigenic point of view [30])? Is there a subset of module's genes that is closer to the definition of "core" genes (i.e., directly affecting the trait with no mediated regulation of other genes [31]) and thus represent alternative and potentially better candidate targets? Are drugs perturbing these transcriptional mechanisms, and if so, can they suggest potential mechanisms of action?

In the original MultiPLIER study, the authors reported that one of the latent variables, identified as LV603, was associated with a known neutrophil pathway and highly correlated with neutrophil count estimates from whole blood RNA-seq profiles [41]. We analyzed LV603 using PhenoPLIER (Figure $1 \mathrm{c}$ ) and found that 1) neutrophil counts and other white blood cell traits were ranked among the top 10 traits out of 4,091 (Figure 1 c, bottom) and significantly associated with this LV (Supplementary Table 3) when using the gene-property approach, and 2) LV603's genes were expressed in highly relevant cell types (Figure $1 \mathrm{c}$, top). These results suggested that groups of functionally related and coexpressed genes tend to correspond to groups of trait-associated genes. Thus, the gene expression space (which has no GTEx samples) and the TWAS space (with gene models trained using GTEx v8) contained shared patterns, and the approach can link transcriptional mechanisms from large and diverse dataset collections to complex traits.

\section{LVs link genes that alter lipid accumulation with relevant traits and tissues}

Our first experiment attempted to answer whether genes in a disease-relevant LV could represent potential therapeutic targets. For this, the first step was to obtain a set of genes strongly associated with a phenotype of interest. Therefore, we performed a fluorescence-based CRISPR-Cas9 in the HepG2 cell line and identified 462 genes associated with lipid regulation (Methods). From these, we selected two high-confidence gene-sets that either caused a decrease or increase of lipids: a lipidsdecreasing gene-set with eight genes: BLCAP, FBXW7, INSIG2, PCYT2, PTEN, SOX9, TCF7L2, UBE2J2; and a lipids-increasing gene-set with six genes: ACACA, DGAT2, HILPDA, MBTPS1, SCAP, SRPR (Supplementary File 1). 
a

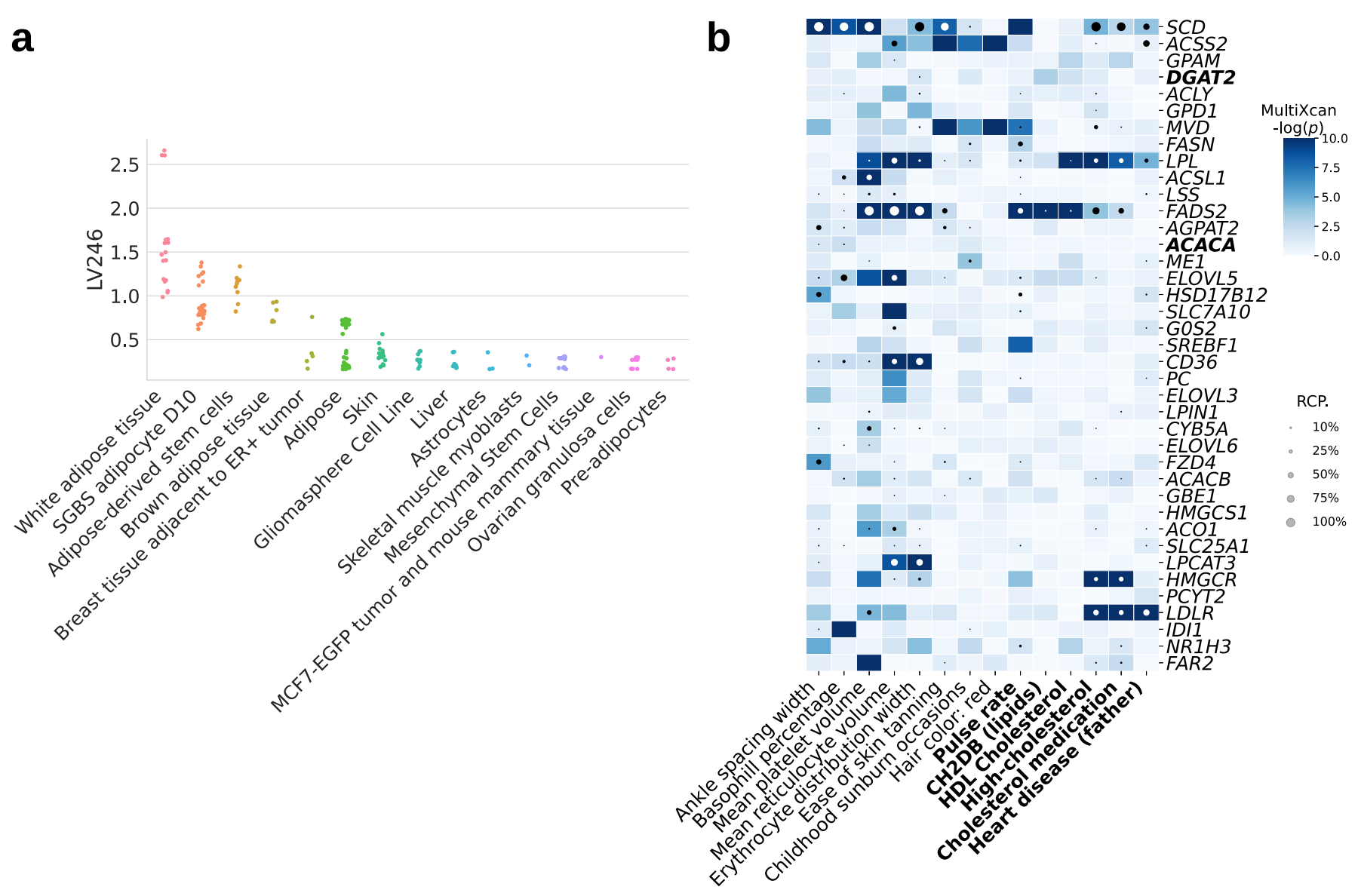

Figure 2: Tissues and traits associated with a gene module related to lipid metabolism (LV246). a) Top cell types/tissues where LV246's genes are expressed in. Values in the $y$-axis come from matrix $\mathbf{B}$ in the MultiPLIER models (Figure $1 \mathrm{~b}$, see Methods). In the $x$-axis, cell types/tissues are sorted by the maximum sample value. b) Gene-trait associations (S-MultiXcan; threshold at $-\log (p)=10$ ) and colocalization probability (fastENLOC) for the top traits in LV246. The top 40 genes in LV246 are shown, sorted by their LV weight (matrix Z), from largest (the top gene $S C D$ ) to smallest (FAR2); DGAT2 and ACACA, in boldface, are two of the six high-confidence genes in the lipids-increasing gene-set from the CRISPR-screen. Cardiovascular-related traits are in boldface. SGBS: Simpson Golabi Behmel Syndrome; CH2DB: $\mathrm{CH}_{2}$ groups to double bonds ratio; HDL: high-density lipoprotein; RCP: locus regional colocalization probability.

Next, we analyzed all 987 LVs using Fast Gene Set Enrichment Analysis (FGSEA) [42], and found 15 LVs nominally enriched (unadjusted $P<0.01$ ) with these lipid-altering gene-sets (Supplementary Tables $\underline{5}$ and 6 ). Among those with reliable sample metadata, LV246, the top LV associated with the lipidsincreasing gene-set, contained genes mainly co-expressed in adipose tissue (Figure $\underline{2}$ a), which plays a key role in coordinating and regulating lipid metabolism. Using the gene-property analysis method, we found that gene weights for this LV were predictive of gene associations for plasma lipids and high cholesterol (Supplementary Table $\underline{8}$ ). Two high-confidence genes from our CRISPR screening, DGAT2 and $A C A C A$, are responsible for encoding enzymes for triglycerides and fatty acid synthesis and were among the highest-weighted genes of LV246 (Figure $2 \mathrm{~b}$, in boldface). However, in contrast to other members of this LV, DGAT2 and ACACA were not strongly associated nor colocalized with any of the cardiovascular-related traits and thus would not have been prioritized by TWAS alone; other members of LV246, such as SCD, LPL, FADS2, HMGCR, and $L D L R$, were instead significantly associated and colocalized with lipid-related traits. This lack of association/colocalization of two high-confidence genes from our CRISPR-screen might be explained from an omnigenic point of view [31]. Assuming that the TWAS models for DGAT2 and ACACA capture all common cis-eQTLs (the only genetic component of gene expression that TWAS can capture) and there are no rare cis-eQTLs, these two genes might represent "core" genes (i.e., they directly affect the trait with no mediated regulation of other genes), and many of the rest in the LV are "peripheral" genes that trans-regulate them. These results suggested that our LV-based approach can contextualize genetic associations and prioritize alternative therapeutic targets, mainly when TWAS cannot detect them or hits are not druggable. 


\section{PhenoPLIER with LVs predicts drug-disease pairs better than single genes}

We next determined the extent to which substituting LVs in place of individual genes predicted known treatment-disease relationships. For this, we used the transcriptional responses to small molecule perturbations profiled in LINCS L1000 [33], which were further processed and mapped to DrugBank IDs $[43, \underline{44}, \underline{45}]$. Based on an established drug repurposing strategy that matches reversed transcriptome patterns between genes and drug-induced perturbations $[46,47]$, we adopted a previously described framework that uses imputed transcriptomes from TWAS to prioritize drug candidates [48]. For this, we computed a drug-disease score by calculating the negative dot product between the $z$-scores for a disease (from TWAS) and the $z$-scores for a drug (from LINCS) across sets of genes of different size (see Methods). Therefore, a large score for a drug-disease pair indicated that a higher (lower) predicted expression of disease-associated genes are down (up)-regulated by the drug, thus predicting a potential treatment. Similarly, for the LV-based approach, we estimated how pharmacological perturbations affected the gene module activity by projecting expression profiles of drugs into our latent representation (Figure 1 b). We used a manually-curated gold standard set of drug-disease medical indications [44,49] for 322 drugs across 53 diseases to evaluate the prediction performance.
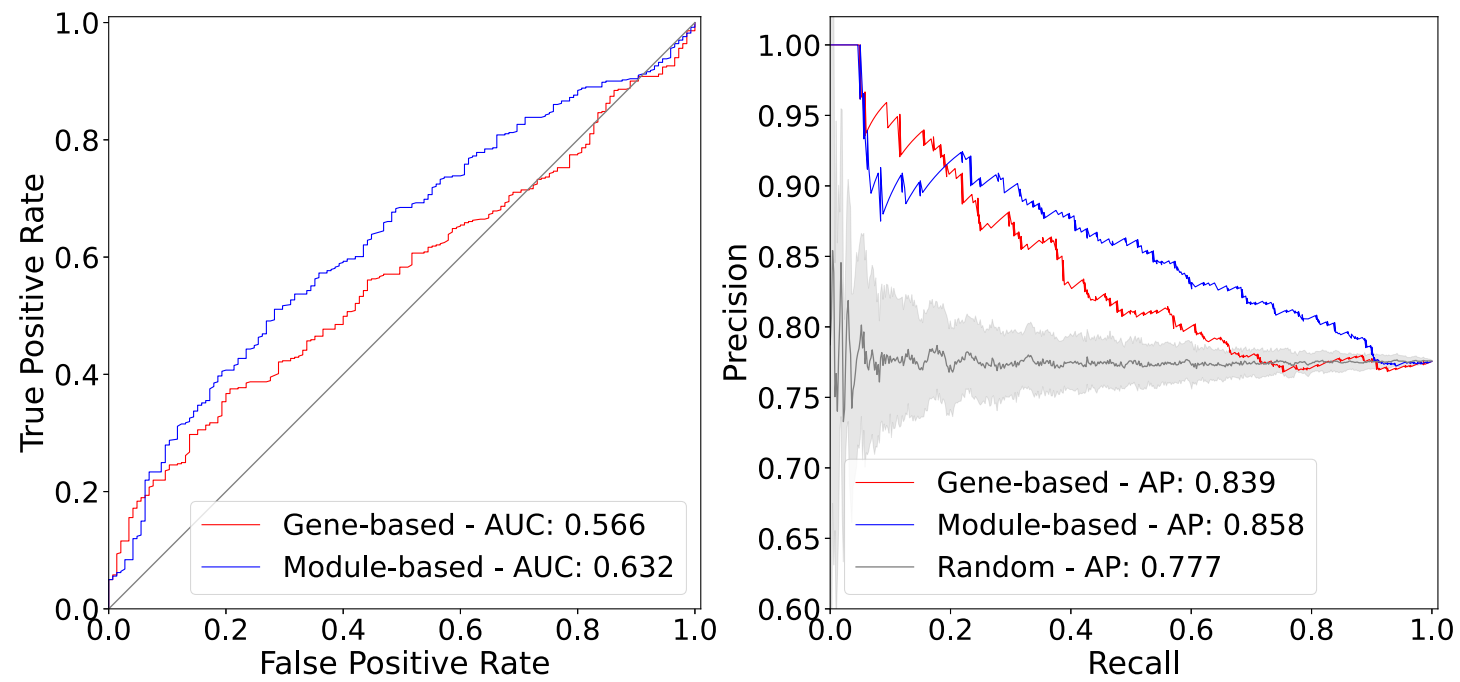

Figure 3: Drug-disease prediction performance for gene-based and module-based approaches. The receiver operating characteristic (ROC) (left) and the precision-recall curves (right) for a gene-based and our module-based approach. AUC: area under the curve; AP: average precision.

The gene-trait associations and drug-induced expression profiles projected into the latent space represent a compressed version of the entire set of results. Despite this information loss, the LVbased method outperformed the gene-based one with an area under the curve of 0.632 and an average precision of 0.858 (Figure 3 ). The prediction results suggested that this low-dimensional space captures biologically meaningful patterns that can link pathophysiological processes with the mechanism of action of drugs.

We examined a specific drug-disease pair to determine whether the LVs driving the prediction were biologically plausible. Nicotinic acid (niacin) is a B vitamin widely used clinically to treat lipid disorders, although there is controversy on its clinical utility to prevent cardiovascular disease [50,51, 52]. Niacin exerts its effects on multiple tissues, although its mechanisms are not well understood $[\underline{53}, \underline{54}, \underline{55}, \underline{56}]$. This compound can increase high-density lipoprotein (HDL) by inhibiting an HDL catabolism receptor in the liver. Niacin also inhibits diacylglycerol acyltransferase-2 (DGAT2), which decreases the production of low-density lipoproteins (LDL) by modulating triglyceride synthesis in hepatocytes or by inhibiting adipocyte triglyceride lipolysis [53]. Niacin was one of the drugs in the gold standard set indicated for atherosclerosis (AT) and coronary artery disease (CAD). We observed that this compound 
was predicted by the gene-based and LV-based approach as a medical indication for coronary artery disease (CAD), with scores above the mean ( 0.51 and 0.96 , respectively). For AT, the LV-based approach predicted niacin as a therapeutic drug with a score of 0.52 , whereas the gene-based method assigned a negative score of -0.01 (below the mean). Since LVs represent interpretable features associated with specific cell types, we analyzed which LVs were positively contributing to these predictions (i.e., with an opposite direction between niacin and the disease). Notably, LV246 (Figure 2), expressed in adipose tissue and liver and associated with plasma lipids and high cholesterol (Supplementary Table $\underline{8}$ ), was the 16th most important module in the prediction of niacin as a therapeutic drug for AT. Besides the gold standard set, LV246 was among the top modules for other cardiovascular diseases, such as ischaemic heart disease (wide definition, 15th module) and high cholesterol (7th module).

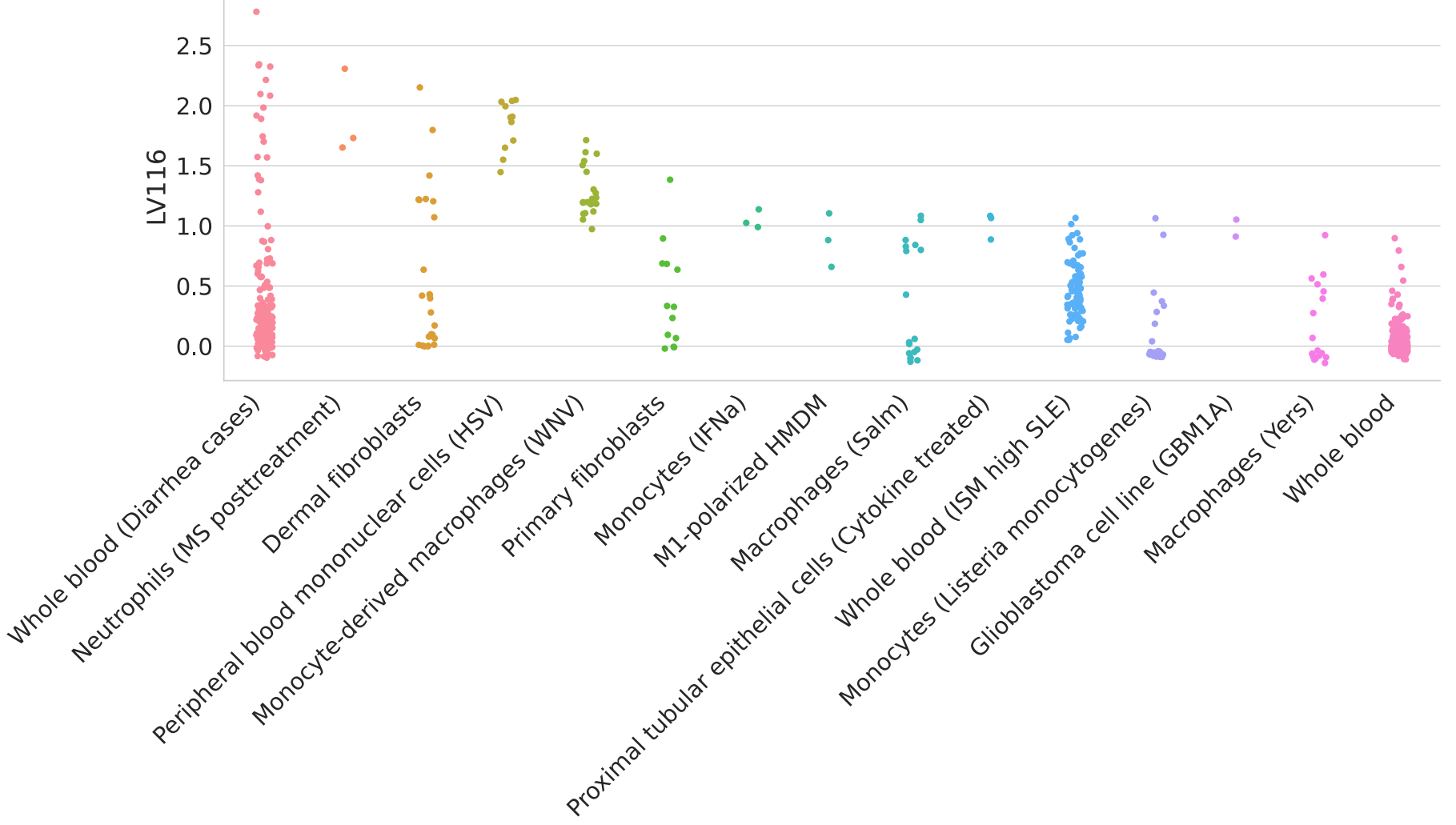

Figure 4: Top cell types/tissues where LV116's genes are expressed in. Values in the $y$-axis come from matrix B in the MultiPLIER models (Figure $1 \mathrm{~b}$ ). In the $x$-axis, cell types/tissues are sorted by the maximum sample value. The figure shows a clear immune response with cell types under different stimuli. MS: multiple sclerosis; HSV: treated with herpes simplex virus; WNV: infected with West Nile virus; IFNa: treated with interferon-alpha; HMDM: human peripheral blood mononuclear cell-derived macrophages; Salm: infected with Salmonella typhimurium; Yers: infected with Yersinia pseudotuberculosis, ISM: Interferon Signature Metric; SLE: Systemic lupus erythematosus.

The analysis of other top niacin-contributing LVs across different cardiovascular diseases revealed additional mechanisms of action. For example, GPR109A/HCAR2 encodes a G protein-coupled highaffinity niacin receptor in adipocytes and immune cells, including monocytes, macrophages, neutrophils and dendritic cells $[57,58]$. It was initially thought that the antiatherogenic effects of niacin were solely due to inhibition of lipolysis in adipose tissue. However, it has been shown that nicotinic acid can reduce atherosclerosis progression independently of its antidyslipidemic activity through the activation of GPR109A in immune cells [59], thus boosting anti-inflammatory processes [60]. In addition, flushing, a common adverse effect of niacin, is also produced by the activation of GPR109A in Langerhans cells (macrophages of the skin). This alternative mechanism for niacin could have been hypothesized by examining the cell types where the top-contributing modules are expressed: for instance, LV116 and LV931 (Figure 4, Supplementary Figure 13, and Supplementary Tables 10 and 11 ) were the top two modules for AT, with a strong signature in monocytes, macrophages, neutrophils, dendritic cells, among others. In Figure $\underline{4}$, it can be seen that LV116's 
bioRxiv preprint doi: https://doi.org/10.1101/2021.07.05.450786; this version posted August 5, 2021. The copyright holder for this preprint (which was not certified by peer review) is the author/funder, who has granted bioRxiv a license to display the preprint in perpetuity. It is made available under aCC-BY 4.0 International license.

genes are expressed as an immune response when these cell types are under different stimuli, such as diarrhea caused by different pathogens [61], samples from multiple sclerosis or systemic lupus erythematosus $[\underline{62}, \underline{63}]$, or infected with different viruses (such as herpes simplex [64], West Nile virus [65], Salmonella typhimurium [6] ], among others). These three LVs (LV246, LV116 and LV931) were among the top 20 modules contributing to the niacin prediction across different cardiovascular traits (Table 1). Given the current controversy around this compound and its effect on cardiovascular disease, our approach may help to better understand different pathophysiological mechanisms linked with the mechanism of action of niacin.

Table 1: LVs among the top 20 contributors of prediction of niacin for five cardiovascular diseases. "Heart attack, angina, stroke or hypertension" refers to the UK Biobank data-field 6150. GWAS sample size: Atherosclerosis $(361,194$ in total and 566 cases), Chronic ischaemic heart disease (361,194 in total and 12,769 cases), Heart attack, angina, stroke or hypertension (360,420 in total and 253,565 cases), Ischaemic heart disease/wide definition (361,194 in total and 20,857 cases), High cholesterol/self-reported (361,141 in total and 43,957 cases).

\begin{tabular}{|l|l|l|}
\hline LV & Cell type & Disease \\
\hline LV116 & Immune cells, skin & Atherosclerosis (ICD10 I70) \\
\hline & & Chronic ischaemic heart disease (ICD10 I25) \\
\hline & & Heart attack, angina, stroke or hypertension \\
\hline LV931 & Immune cells & Ischaemic heart disease (wide definition) \\
\hline & & Atherosclerosis (ICD10 I70) \\
\hline & & Heart attack, angina, stroke or hypertension \\
\hline LV246 & Adipose tissue, liver & Ischaemic heart disease (wide definition) \\
\hline & & Atherosclerosis (ICD10 I70) \\
\hline & & High cholesterol (self-reported) \\
\hline
\end{tabular}

The LV-based method was able to integrate different data types to provide an interpretable approach for drug repositioning research based on genetic studies. Additionally, our approach could also be helpful to understand better the mechanism of pharmacological effect of known or experimental drugs. For example, LV66, one of the top LVs affected by niacin (Supplementary Figure 14) was mainly expressed in ovarian granulosa cells. This compound has been very recently considered as a potential therapeutic for ovarian diseases $[67,68]$, as it was found to promote follicle growth and inhibit granulosa cell apoptosis in animal models. Our LV-based approach could be helpful to generate novel hypotheses to evaluate potential mechanisms of action, or even adverse effects, of different drugs.

\section{LV projections reveal trait clusters with shared transcriptomic properties}


bioRxiv preprint doi: https://doi.org/10.1101/2021.07.05.450786; this version posted August 5, 2021. The copyright holder for this preprint (which was not certified by peer review) is the author/funder, who has granted bioRxiv a license to display the preprint in perpetuity. It is made available under aCC-BY 4.0 International license.

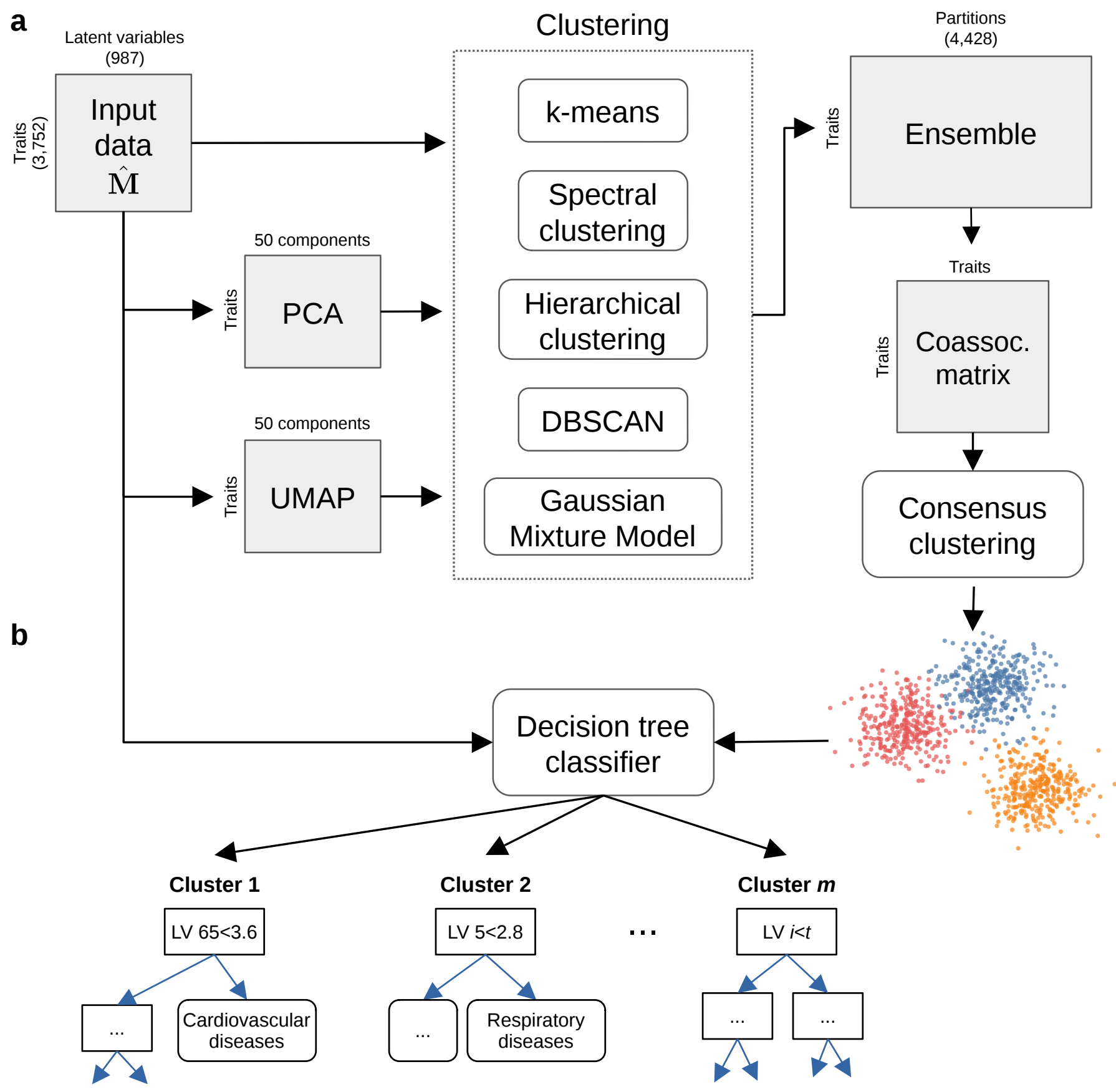

Figure 5: Cluster analysis on traits using the latent gene expression representation. a) The projection of TWAS results on $n=3,752$ traits into the latent gene expression representation is the input data to the clustering process. A linear (PCA) and non-linear (UMAP) dimensionality reduction techniques were applied to the input data, and the three data versions were processed by five different clustering algorithms. These algorithms derive partitions from the data using different sets of parameters (such as the number of clusters), leading to an ensemble of 4,428 partitions. Then, a distance matrix is derived by counting how many times a pair of traits were grouped in different clusters across the ensemble. Finally, a consensus function is applied to the distance matrix to generate consolidated partitions with different numbers of clusters (from 2 to $\sqrt{n} \approx 60$ ). These final solutions were represented in the clustering tree (Figure $\underline{6})$. b) The clusters found by the consensus function were used as labels to train a decision tree classifier on the original input data, which detects the LVs that better differentiate groups of traits.

The previous results suggested that the compression into $\hat{\mathbf{M}}$ increases the signal-to-noise ratio. Thus, we analyzed $\hat{\mathbf{M}}$ to find groups of traits that were affected by the same transcriptional processes. To identify relationships that were robust to the selection of a specific clustering algorithm (each of which makes particular assumptions about the structure of data), we employed a consensus clustering approach. Therefore, we applied different methods with varying sets of parameters and later combined these into a consolidated solution (Methods). Our clustering pipeline generated 15 final consensus clustering solutions with 5 to 29 clusters (Supplementary Figure $\underline{15}$ ). Instead of selecting a 
specific number of clusters, we used a clustering tree [69] (Figure $\underline{6}$ ) to examine stable groups of traits across multiple resolutions. To understand which latent variables differentiated the group of traits, we trained a decision tree classifier on the input data $\hat{\mathbf{M}}$ using the clusters found as labels.

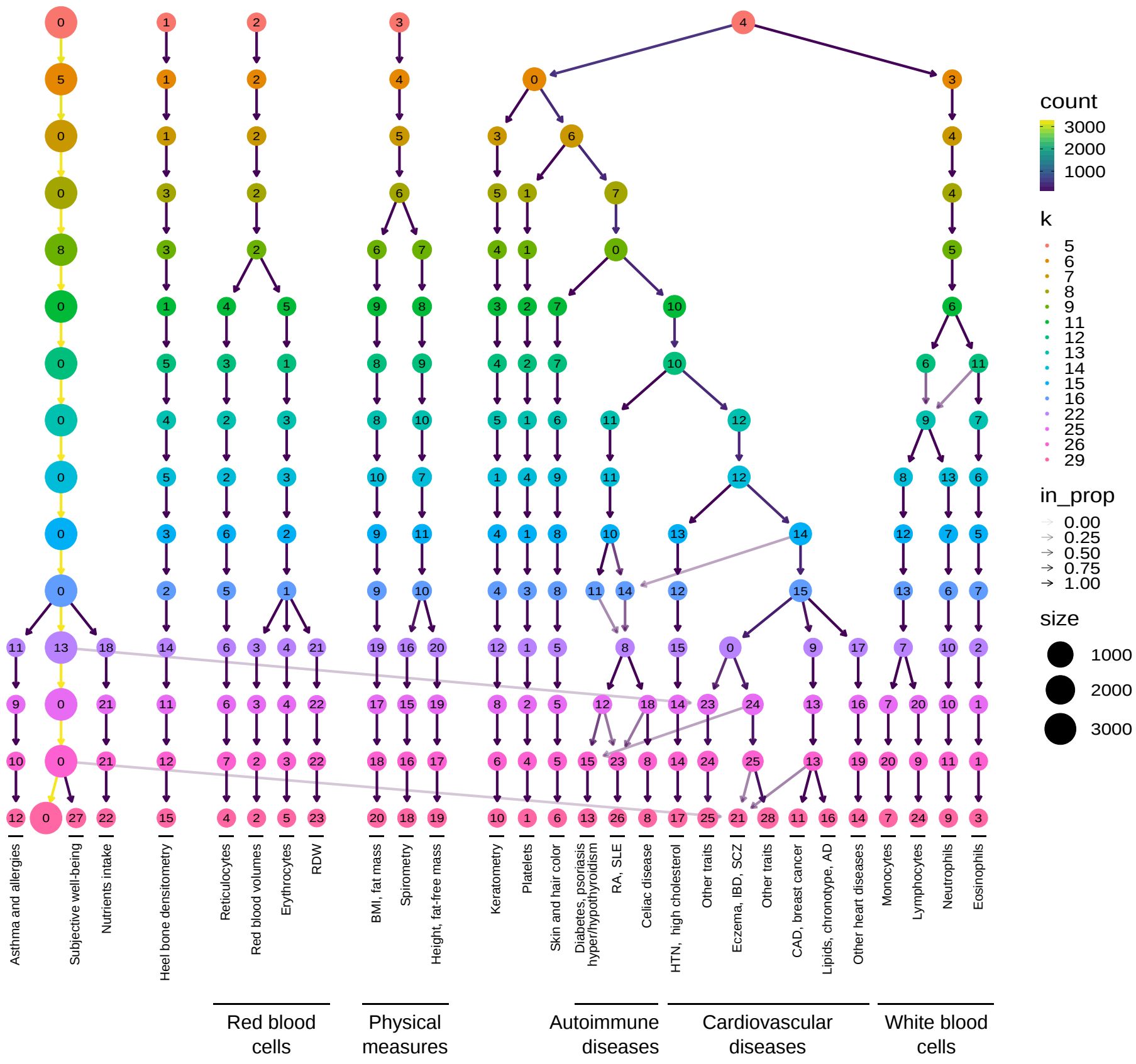

Figure 6: Clustering tree using multiple resolutions for clusters of traits. Each row represents a partition/grouping of the traits, and each circle is a cluster from that partition. The number of clusters goes from 5 to 29 . Arrows indicate how traits in one cluster move across clusters from different partitions. Most of the clusters are preserved across different resolutions, showing highly stable solutions even with independent runs of the clustering algorithm. RDW: red cell (erythrocyte) distribution width; BMI: body mass index; WC: waist circumference; HC: hip circumference; RA: rheumatoid arthritis; SLE: systemic lupus erythematosus; HTN: Hypertension; IBD: inflammatory bowel disease; SCZ: Schizophrenia; CAD: Coronary artery disease; AD: Alzheimer's disease; Descriptions of traits by cluster ID (from left to right): 12: also includes lymphocyte count and allergies such as allergic rhinitis or eczema; 4: includes reticulocyte count and percentage, immature reticulocyte fraction, and high light scatter reticulocytes count and percentage; 2 : includes mean corpuscular volume, mean corpuscular hemoglobin, mean reticulocyte volume, mean sphered cell volume; 5 : includes erythrocyte count, hemoglobin concentration, and hematocrit percentage; 20: also includes weight, waist and hip circumference; 18: also includes body impedance measures and ankle spacing width; 19: also includes basal metabolic rate; 1 : includes platelet count, crit, mean volume, and distribution width; 13: diabetes refers to age when diabetes was first diagnosed; 25: also includes vascular problems such as angina, deep vein thrombosis (DVT), intraocular pressure, eye and mouth problems, pulse rate, hand-grip strength, several measurements of physical activity, jobs involving heavy physical work, types of transport used, intake of vitamin/mineral supplements, and various types of body pain and medications for pain relief; 21: also includes attention deficit hyperactivity disorder (ADHD), number of years of schooling completed, bone density, and intracranial volume measurement; 28: includes diabetes, 
gout, arthrosis, and respiratory diseases (and related medications such as ramipril, allopurinol, and lisinopril), urine assays, female-specific factors (age at menarche, menopause, first/last live birth), and several environmental/behavioral factors such as intake of a range of food/drink items including alcohol, time spent outdoors and watching TV, smoking and sleeping habits, early-life factors (breastfed as a baby, maternal smoking around birth), education attainment, psychological and mental health, and health satisfaction; 11: also includes fasting blood glucose and insulin measurement; 16: lipids include high and low-density lipoprotein (HDL and LDL) cholesterol, triglycerides, and average number of methylene groups per a double bond; 14: includes myocardial infarction, coronary atherosclerosis, ischaemic heart disease (wide definition); 7: includes monocyte count and percentage; 24: includes lymphocyte count and percentage; 9: includes neutrophil count, neutrophil+basophil count, neutrophil+eosinophil count, granulocyte count, leukocyte count, and myeloid cell count; 3: includes eosinophil count, eosinophil percentage, and eosinophil+basophil count.

We found that phenotypes were grouped into five clear branches (Figure $\underline{6}$ ). These were 0) a "large" branch that includes most of the traits subdivided only starting at $k=16$ (with asthma, subjective wellbeing traits, and nutrient intake clusters), 1) heel bone-densitometry measurements, 2) hematological assays on red blood cells, 3) physical measures, including spirometry and body impedance, and anthropometric traits with fat-free and fat mass measures in separate sub-branches, and 4) a "complex" branch including keratometry measurements, assays on white blood cells and platelets, skin and hair color traits, autoimmune disorders (type 1 diabetes, psoriasis, hyper/hypothyroidism, rheumatoid arthritis, systemic lupus erythematosus, celiac disease), and cardiovascular diseases (hypertension, coronary artery disease, myocardial infarction, hypercholesterolemia, and other cardiovascular-related traits such hand-grip strength [70], and environmental/behavioral factors such as physical activity and diet) (See Supplementary Files 2-6 for clustering results). Within these branches, results were relatively stable. The same traits were often clustered together across different resolutions, even with the consensus algorithm using random initializations at each level. Arrows between different clusters show traits moving from one group to another across different resolutions. This mainly happens between clusters within the "complex" branch, and between clusters from the "large" branch to the "complex" branch. We would expect that continuing to explore higher dimensionalities would result in further subdivisions of these large groupings. This behavior was expected since complex diseases are usually associated with shared genetic and environmental factors and are thus hard to categorize into a single cluster. We would also expect that exploring solutions with a larger number of clusters would result in further subdivisions of these large groupings. 


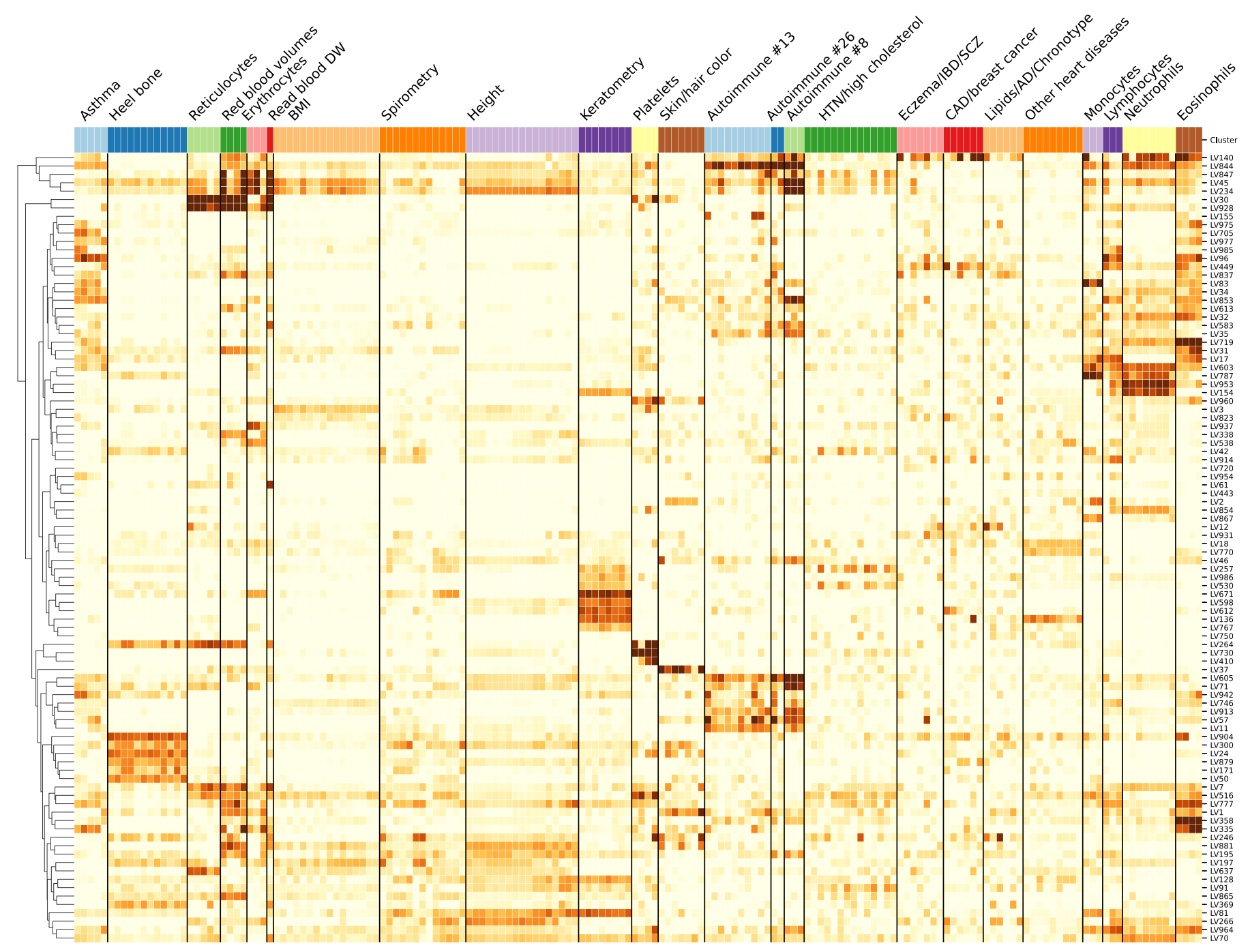

Figure 7: Cluster-specific and general transcriptional processes associated with disease. The plot shows a submatrix of $\hat{\mathbf{M}}$ for the main trait clusters at $k=29$, considering only LVs (rows) that are well-aligned with at least one pathway. Standardized values from -5 (lighter color) to 16 (darker color).

Next, we analyzed which LVs were driving these clusters of traits. We trained decision tree classifiers on the input data (Figure $\underline{5}$ ) using each cluster at $k=29$ (bottom of Figure $\underline{6}$ ) as labels (see Methods). This yielded for each cluster the top LVs, where several of them were well-aligned to existing pathways (Figure 7), and others were novel and expressed in relevant tissues (Supplementary Figure 16). In Figure $\underline{7}$, it can be seen that some LVs were highly specific to certain types of traits, while others were associated with a wide range of different phenotypes, thus potentially involved in more general biological functions. For example, LVs such as LV928 and LV30, which were well-aligned to early progenitors of the erythrocytes lineage [71] (Supplementary Tables $\underline{13}$ and 16), were predominantly expressed in early differentiation stages of erythropoiesis (Supplementary Figures 17 and 18) and strongly associated with different assays on red blood cells (FDR < 0.05; Supplementary Tables $\underline{14}, \underline{15}$, and 18). In contrast, other LVs were highly specific, such as LV730, which is expressed in thrombocytes from different cancer samples (Supplementary Figures 19 and Supplementary Table 19), and strongly associated with hematological assays on platelets (FDR < 2e-4, Supplementary Table 20); or LV598, whose genes were expressed in corneal endothelial cells (Supplementary Figures 20 and Supplementary Table 22) and associated with keratometry measurements (FDR < 4e-05; Supplementary Table $\underline{23}$ ).

The autoimmune diseases sub-branch also had significant LVs associations expressed in relevant cell types. LV844 was the most strongly associated gene module with autoimmune disorders in both PhenomeXcan (FDR < 7e-16; Supplementary Tables 26) and eMERGE (FDR < 2e-6, 27), and was expressed in a wide range of cell types, including blood, breast organoids, myeloma cells, lung 

made available under aCC-BY 4.0 International license.

fibroblasts, and different cell types from the brain (Supplementary Figures 21 and Supplementary Table 25). LV155 was strongly expressed in the thyroid (Supplementary Figures 22 and

Supplementary Table 28) and significantly associated with hypothyroidism both in PhenomeXcan (FDR $<0.05$, Supplementary Table $\underline{29}$ ) and eMERGE (FDR < 0.10, Supplementary Table $\underline{30}$ ). Other important LVs associated with autoimmunity in both PhenomeXcan and eMERGE were LV57, expressed in T cells (Supplementary Figure $\underline{23}$ and Supplementary Tables 31, 32, 33), and LV54, expressed in different soft tissue tumors, breast, lung, pterygia and epithelial cells (Supplementary Figure $\underline{24}$ and Supplementary Tables $\underline{34}, \underline{35}, \underline{36})$.

The cardiovascular sub-branch also exhibited significant associations. LV847 (Supplementary Figure $\underline{25}$ and Supplementary Table $\underline{37}$ ) was strongly associated with hypertension in PhenomeXcan (FDR < 2e-13, Supplementary Tables $\underline{38}$ ) and several cardiovascular diseases, type 1 diabetes, prostate cancer, and others in eMERGE (FDR < 0.05, Supplementary Table 39). LV847 was expressed in CD19 (B cells) (which are related to preeclampsia [72]), Jurkat cells (T lymphocyte cells), and cervical carcinoma cell lines (the uterus was previously reported to be linked to blood pressure through a potential hormonal pathway $[\underline{73}, 74])$. LV136 was aligned with known collagen formation and muscle contraction pathways (Supplementary Table 40 ), and it was associated with coronary artery disease (FDR < 2e-8), myocardial infarction (FDR < 6e-4) and keratometry measurements (FDR < 1e-7) in PhenomeXcan (Supplementary Tables 41), but with no strong associations in eMERGE (FDR $<0.20$, Supplementary Table 42 ). This LV was expressed in a wide range of cell types, including fibroblasts, mesenchymal stem cells, osteoblasts, pancreatic stellate cells, cardiomyocytes, and adipocytes (Supplementary Figure 26). Lipids, clustered with chronotype and Alzheimer's disease, were significantly associated with several modules expressed mainly in brain cell types, including LV93 (Supplementary Figure 27 and Supplementary Tables 43, 44, 45), LV206 (Supplementary Figure 28 and Supplementary Tables $\underline{46}$, 47, 48), and LV260 (Supplementary Figure 29 and Supplementary Tables $\underline{49}, \underline{50}$ and $\underline{51}$ ). These modules were associated mainly with cardiovascular traits in eMERGE.

Within the cardiovascular sub-branch, we found neuropsychiatric and neurodevelopmental disorders such as Alzheimer's disease, schizophrenia, and attention deficit hyperactivity disorder (ADHD). These disorders were previously linked to the cardiovascular system $[\underline{75}, \underline{76}, \underline{77}, \underline{78}]$ and share several risk factors, including hypertension, high cholesterol, obesity, smoking, among others [ $\underline{79}, \underline{80}]$. In our results, however, these diseases were grouped by potentially shared transcriptional processes expressed in specific tissues/cell types. Alzheimer's disease, for example, was significantly associated with LV21 in PhenomeXcan (FDR < 2e-19, Supplementary Table 53) and with LV5 (FDR < 3e-3, Supplementary Table $\underline{56}$ ). LV21 was strongly expressed in a variety of soft tissue sarcomas, monocytes/macrophages (including microglia from cortex samples), and aortic valves (Supplementary Figure 30 and Supplementary Table 52). This LV was also associated with lipids: LDL cholesterol (FDR $<1 \mathrm{e}-4$ ) and triglycerides (FDR < 0.02). As discussed previously, macrophages play a key role in the reverse cholesterol transport and thus atherogenesis [81], and lipid metabolism in microglia has been recently identified as an important factor in the development of neurodegenerative diseases [82]. On the other hand, LV5 was expressed in breast cancer and brain glioma samples, microglia (cortex), liver, and kidney, among other cell types (Supplementary Figure 31 and Supplementary Table $\underline{55}$ ). In addition to lipids, LV5 was also associated with depression traits from the UK Biobank (FDR $<0.05$, Supplementary Table 56). Since Alzheimer's disease was not present in eMERGE, we could not replicate this association. ADHD was the only significantly associated trait for LV434 (FDR < 6e-3) (Supplementary Table 59), which was expressed in breast cancer and glioma cells, cerebral organoids, and several different cell populations from the brain: fetal neurons (replicating and quiescence), microglia, and astrocytes (Supplementary Figure 32 and Supplementary Table 58). Schizophrenia was not significantly associated (FDR $<0.05)$ with any gene module tested in our analysis. None of these LVs were significantly aligned to prior pathways, which might represent potentially novel transcriptional processes affecting the cardiovascular and central nervous systems.

\section{Discussion}


We have introduced a novel computational strategy that integrates statistical associations from TWAS with groups of genes (gene modules) that have similar expression patterns across the same cell types. Our key innovation is that we project gene-trait associations through a latent representation derived not strictly from measures of normal tissue but also cell types under a variety of stimuli and at various developmental stages. This improves interpretation by going beyond statistical associations to infer cell type-specific features of complex phenotypes. We found that our approach can identify diseaserelevant cell types from summary statistics, and several disease-associated gene modules were replicated in eMERGE. Using a CRISPR screen to analyze lipid regulation, we found that our gene module-based approach can prioritize causal genes even when single gene associations are not detected. We interpret these findings with an omnigenic perspective of "core" and "peripheral" genes, suggesting that the approach can identify genes that directly affect the trait with no mediated regulation of other genes, and thus prioritize alternative and potentially more attractive therapeutic targets. Using our gene module perspective, we also integrated drug-induced transcriptional profiles, which allowed us to connect diseases, drugs, and cell types. Furthermore, and beyond statistical prediction, we focused on a particular drug (niacin) and set of traits (cardiovascular diseases) to show that the approach connects disease-relevant transcriptional processes with known mechanisms of action. This suggests that the conceptual approach may reveal the mechanisms of pharmacological effect of known or experimental drugs. Finally, we found that the analysis of associations through latent representations provided reasonable groupings of diseases and traits affected by shared and distinct transcriptional mechanisms expressed in highly relevant tissues.

In some cases, the features/LVs linked to phenotypes appear to be associated with specific cell types. Associations with such cell type marker genes may reveal potentially causal cell types for a phenotype with more precision. We observed modules expressed primarily in one tissue (such as adipose in LV246, thyroid in LV155, or ovary in LV66). Others appeared to be expressed in many contexts, and these may capture pathways associated with a set of related complex diseases. For example, LV136 is associated with cardiovascular disease and measures of corneal biomechanics, and expressed in fibroblasts, osteoblasts, pancreas, liver, and cardiomyocytes, among others. Another example is LV844, expressed in whole blood samples and strongly associated with a range of autoimmune diseases. From an omnigenic point of view, these patterns might represent cases of "network pleiotropy," where the same cell types mediate molecularly related traits. To our knowledge, projection through a representation learned on complementary but distinct datasets is a novel approach to identify cell type and pathway effects on complex phenotypes that is computationally simple to implement.

Our approach rests on the assumption that gene modules with coordinated expression patterns will also manifest coordinated pathological effects. Our implementation in this work integrates two complementary approaches. The first is MultiPLIER, which extracts latent variables from large expression datasets, and these LVs could represent either real transcriptional processes or technical factors ("batch effects"). We used a previously published model derived from recount2, which was designed to analyze rare disorders but might not be the optimal latent representation for the wide range of complex diseases considered here. Also, the underlying factorization method rests on linear combinations of variables, which could miss important and more complex co-expression patterns. In addition, recount2, the training dataset used, has since been surpassed in size and scale by other resources $[15,83]$. The second approach we used in this study is TWAS, where we are only considering the hypothesis that GWAS loci affect traits via changes in gene expression, and other effects such as coding variants disrupting protein-protein interactions are not captured. Additionally, TWAS has several limitations that can lead to false positives $[\underline{84}, \underline{85}]$. Like GWAS, which generally detects groups of associated variants in linkage disequilibrium (LD), TWAS usually identifies several genes within the same locus $[20,86]$. This is due to sharing of GWAS variants in gene expression models, correlated expression of nearby genes, or even correlation of their predicted expression due to eQTLs in LD, among others [84]. Larger datasets and methods designed to learn representations with this application in mind could further refine the approach and are a promising avenue for future research. 
Our findings are concordant with previous studies showing that drugs with genetic support are more likely to succeed through the drug development pipeline $[\underline{7}, \underline{48}]$. In this case, projecting association results through latent variables better prioritized disease-treatment pairs than considering singlegene effects alone. An additional benefit is that the latent variables driving predictions can be examined to infer potential mechanisms of action. Here we prioritized drugs for diseases with very different tissue etiologies, and a challenge of the approach is to select the most appropriate tissue model from TWAS to find reversed transcriptome patterns between genes and drug-induced perturbations. We also demonstrated that clustering trees, introduced initially as a means to examine developmental processes in single-cell data, provide a multi-resolution grouping of phenotypes based on latent variable associations. We employed hard-partitioning algorithms (one trait belongs exclusively to one cluster) where the distance between two traits takes into account all gene modules. However, it is also plausible for two complex diseases to share only a few biological processes instead of being similar across most of them. In this portion, we used S-MultiXcan associations, which only provide the association strength between a gene and a trait, but with no direction of effect. This does mean that traits are grouped based on associated genes, but genes could have opposite effects on traits within the same cluster. Considering groups of related diseases was previously shown to be more powerful to detect shared genetic etiology $[\underline{87}, 88]$, and clustering trees provide a way to explore such relationships in the context of latent variables. Finally, our TWAS results were derived from a large set of GWAS of different sample sizes and qualities. Although the potential issues derived from this data heterogeneity were addressed before performing cluster analysis of traits, data preprocessing steps are always challenging and might not avoid bias altogether.

Ultimately, the quality of the representations is essential to performance. Here we used a representation derived from a factorization of bulk RNA-seq data. Detailed perturbation datasets and single-cell profiling of tissues, with and without perturbagens, and at various stages of development provide an avenue to generate higher quality and more interpretable representations. On the other hand, the key to interpretability is driven by the annotation of sample metadata. New approaches to infer and annotate with structured metadata are promising and can be directly applied to existing data [89]. Rapid improvements in both areas set the stage for latent variable projections to be widely applied to disentangle the genetic basis of complex human phenotypes. By providing a new perspective for a mechanistic understanding of statistical associations from TWAS, our method can generate testable hypotheses for the post-GWAS functional characterization of complex diseases, which will likely be an area of great importance in the coming years.

\section{Methods}

\section{PhenomeXcan: gene-based associations on 4,091 traits}

We used TWAS results from PhenomeXcan [32] on 4,091 traits for 22,515 genes. PhenomeXcan was built using publicly available GWAS summary statistics to compute 1) gene-based associations with the PrediXcan family of methods $[\underline{19}, \underline{20}, \underline{90}]$, and 2) a posterior probability of colocalization between GWAS loci and cis-eQTL with fastENLOC $[32,91]$. The PrediXcan family of methods first builds prediction models using data from the Genotype-Tissue Expression project (GTEx v8) [4] for gene expression imputation and then correlate this predicted expression with the phenotype of interest. This family is comprised of S-PrediXcan [이 (which computes a gene-tissue-trait association using GWAS as input) and S-MultiXcan [19] (which computes a gene-trait association by aggregating evidence of associations across all tissues).

We refer to the standardized effect sizes ( $z$-scores) of S-PrediXcan across $n$ traits and $m$ genes in tissue $t$ as $\mathbf{M}^{t} \in \mathbb{R}^{n \times m}$. For S-MultiXcan, we do not have the direction of effect, and we used the $p$ values converted to $z$-scores $\mathbf{M}=\Phi^{-1}(1-p / 2)$, where $\Phi^{-1}$ is the probit function. Higher $z$-scores correspond to stronger associations. 


\section{MultiPLIER and Pathway-level information extractor (PLIER)}

MultiPLIER [34] extracts patterns of co-expressed genes from recount2 [14], a large gene expression dataset. The approach applies the pathway-level information extractor method (PLIER) [35], which performs unsupervised learning using prior knowledge (canonical pathways) to reduce technical noise. Via a matrix factorization approach, PLIER deconvolutes the gene expression data into a set of latent variables (LV), where each represents a gene module. This reduced the data dimensionality into 987 latent variables or gene modules.

Given a gene expression dataset $\mathbf{Y}^{m \times c}$ with $m$ genes and $c$ experimental conditions and a prior knowledge matrix $\mathbf{C} \in\{0,1\}^{m \times p}$ for $p$ MSigDB pathways [르] (so that $\mathbf{C}_{i j}=1$ if gene $i$ belongs to pathway $j$ ), PLIER finds $\mathbf{U}, \mathbf{Z}$, and $\mathbf{B}$ minimizing

$$
\|\mathbf{Y}-\mathbf{Z B}\|_{F}^{2}+\lambda_{1}\|\mathbf{Z}-\mathbf{C U}\|_{F}^{2}+\lambda_{2}\|\mathbf{B}\|_{F}^{2}+\lambda_{3}\|\mathbf{U}\|_{L^{1}}
$$

subject to $\mathbf{U}>0, \mathbf{Z}>0 ; \mathbf{Z}^{m \times l}$ are the gene loadings with $l$ latent variables, $\mathbf{B}^{l \times c}$ is the latent space for $c$ conditions, $\mathbf{U}^{p \times l}$ specifies which of the $p$ prior-information pathways in $\mathbf{C}$ are represented for each LV, and $\lambda_{i}$ are different regularization parameters used in the training step. $\mathbf{Z}$ is a lowdimensional representation of the gene space where each LV aligns as much as possible to prior knowledge, and it might represent either a known or novel gene module (i.e., a meaningful biological pattern) or noise.

We projected $\mathbf{M}$ (either from S-PrediXcan across each tissue, or S-MultiXcan) into the low-dimensional gene module space learned by MultiPLIER using

$$
\hat{\mathbf{M}}=\left(\mathbf{Z}^{\top} \mathbf{Z}+\lambda_{2} \mathbf{I}\right)^{-1} \mathbf{Z}^{\top} \mathbf{M}
$$

where in $\hat{\mathbf{M}}^{l \times n}$ all traits in PhenomeXcan are now described by gene modules.

\section{LV-trait associations via gene-property analysis}

To compute an association between a gene module and a trait, we used an approach similar to the gene-property analysis in MAGMA [40], which is essentially a competitive test using gene weights from $\mathbf{Z}$ to predict gene $z$-scores from $\mathbf{M}$. Thus, the regression model uses genes as data points by fitting $\mathbf{m}=\beta_{0}+\mathbf{z} \beta_{z}+\epsilon$, where $\epsilon \sim \operatorname{MVN}(0, \hat{\Sigma}), \mathbf{m}$ are gene $p$-values (for a trait) from S-MultiXcan that we transformed to $z$-scores as mentioned before. Since we are only interested in whether genes with a stronger membership to a module (highest weights) are more associated with the phenotype, we performed a one-sided test on the coefficient $\beta_{z}$ with the null hypothesis of $\beta_{z}=0$ against the alternative $\beta_{z}>0$. Since the error terms $\epsilon$ could be correlated due to correlation between predicted expression, we used a generalized least squares approach instead of standard linear regression. To calculate $\hat{\Sigma}$, we first estimated the correlation of predicted expression for each gene pair $\left(\mathbf{t}_{i}, \mathbf{t}_{j}\right)$ in tissue $t$ using equations from $[\underline{19}, \underline{90}]$ : 


$$
\begin{aligned}
& \hat{\Sigma}_{i j}^{t}=\operatorname{Cor}\left(\mathbf{t}_{i}, \mathbf{t}_{j}\right)
\end{aligned}
$$

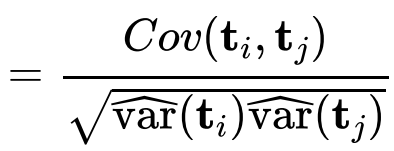

$$
\begin{aligned}
& =\frac{\operatorname{Cov}\left(\sum_{a \in \text { model }_{i}} w_{a}^{i} X_{a}, \sum_{b \in \text { model }_{j}} w_{b}^{j} X_{b}\right)}{\sqrt{\widehat{\widehat{\operatorname{var}}}\left(\mathbf{t}_{i}\right) \widehat{\operatorname{var}}\left(\mathbf{t}_{j}\right)}} \\
& \sum_{a \in \operatorname{model}_{i}} w_{a}^{i} w_{b}^{j} \operatorname{Cov}\left(X_{a}, X_{b}\right) \\
& =\frac{b \in \operatorname{model}_{j}}{\sqrt{\widehat{\operatorname{var}}\left(\mathbf{t}_{i}\right) \widehat{\operatorname{var}}\left(\mathbf{t}_{j}\right)}} \\
& \sum_{a \in \operatorname{model}_{i}} w_{a}^{i} w_{b}^{j} \Gamma_{a b}
\end{aligned}
$$

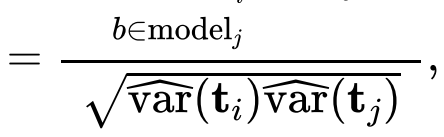

where $\Gamma=\widehat{\operatorname{var}}(\mathbf{X})=(\mathbf{X}-\overline{\mathbf{X}})^{\top}(\mathbf{X}-\overline{\mathbf{X}}) /(m-1)$ is the genotype covariance matrix using 1000 Genomes Project data $[\underline{93}, \underline{94}]$. The variances for predicted gene expression of gene $i$ is estimated as:

$$
\begin{aligned}
\widehat{\operatorname{var}}\left(\mathbf{t}_{i}\right) & =\left(\mathbf{W}^{i}\right)^{\top} \Gamma^{i} \mathbf{W}^{i} \\
& =\sum_{\substack{a \in \operatorname{model}_{i} \\
b \in \operatorname{model}_{i}}} w_{a}^{i} w_{b}^{i} \Gamma_{a b}^{i} .
\end{aligned}
$$

Finally, $\hat{\Sigma}=\sum_{t} \hat{\Sigma}^{t} /|t|$ where $|t|=49$ is the number of tissues.

Because of computational reasons, we did not run the gene-property analysis on all possible LV-trait pairs. In PhenomeXcan, we reduced the number of LV-trait pairs by considering only the top discriminative LVs for each cluster (see "Cluster interpretation" section in Methods) and the traits in that cluster, leading to 5,782 LV-trait tests. For replication in eMERGE, we selected all the 25 LVs analyzed in the main text and ran the gene-property analysis against all 309 traits in this cohort, leading to 7,725 tests. We adjusted the $p$-values using the Benjamini-Hochberg procedure.

\section{Drug-disease prediction}

For the drug-disease prediction, we used a method based on a drug repositioning framework previously used for psychiatry traits [48] where gene-trait associations are anticorrelated with expression profiles for drugs. For the single-gene approach, we computed a drug-disease score by multiplying each S-PrediXcan set of results in tissue $t, \mathbf{M}^{t}$, with the transcriptional responses profiled in LINCS L1000 [33], $\mathbf{L}^{c \times m}$ (for c compounds): $\mathbf{D}^{t, k}=-1 \cdot \mathbf{M}^{t, k} \mathbf{L}^{\top}$, where $k$ refers to the number of most significant gene associations in $\mathbf{M}^{t}$ for each trait. As suggested in [48], $k$ could be either all genes or the top 50,100, 250, and 500; then we average score ranks across all $k$ and obtain $\mathbf{D}^{t}$. Finally, for each drug-disease pair, we took the maximum prediction score across all tissues: $\mathbf{D}_{i j}=\max \left\{\mathbf{D}_{i j}^{t} \mid \forall t\right\}$.

The same procedure was used for the gene module-based approach, where we projected S-PrediXcan results into our latent representation, leading to $\hat{\mathbf{M}}^{t}$; and also $\mathbf{L}$, leading to $\hat{\mathbf{L}}^{l \times c}$. Finally, 
$\mathbf{D}^{t, k}=-1 \cdot \hat{\mathbf{M}}^{t, k} \hat{\mathbf{L}}^{\top}$, where in this case $k$ could be all LVs or the top 5, 10, 25 and 50 (since we have an order of magnitude less LVs than genes).

Since the gold standard of drug-disease medical indications used contained Disease Ontology IDs (DOID) [95], we mapped PhenomeXcan traits to the Experimental Factor Ontology [96] using [97], and then to DOID.

\section{Consensus clustering of traits}

We performed two preprocessing steps on the S-MultiXcan results before the cluster analysis procedure. First, we combined results in $\mathbf{M}$ (S-MultiXcan) for traits that mapped to the same Experimental Factor Ontology (EFO) [6] term using the Stouffer's method: $\sum w_{i} M_{i j} / \sqrt{\sum w_{i}^{2}}$, where $w_{i}$ is a weight based on the GWAS sample size for trait $i$, and $M_{i j}$ is the $z$-score for gene $j$. Second, we standardized all $z$-scores for each trait $i$ by their sum to reduce the effect of highly polygenic traits: $M_{i j} / \sum M_{i j}$. Finally, we projected this data matrix using Equation 2 , obtaining $\hat{\mathbf{M}}$ with $n=3,752$ traits and $l=987 \mathrm{LVs}$ as the input of our clustering pipeline.

A partitioning of $\hat{\mathbf{M}}$ with $n$ traits into $k$ clusters is represented as a label vector $\pi \in \mathbb{N}^{n}$. Consensus clustering approaches consist of two steps: 1) the generation of an ensemble $\Pi$ with $r$ partitions of the dataset: $\Pi=\left\{\pi_{1}, \pi_{2}, \ldots, \pi_{r}\right\}$, and 2 ) the combination of the ensemble into a consolidated solution defined as:

$$
\pi^{*}=\arg \max _{\hat{\pi}} Q\left(\left\{\left|\mathcal{L}^{i}\right| \phi\left(\hat{\pi}_{\mathcal{L}^{i}}, \pi_{i \mathcal{L}^{i}}\right) \mid i \in\{1, \ldots, r\}\right\}\right)
$$

where $\mathcal{L}^{i}$ is a set of data indices with known cluster labels for partition $i, \phi: \mathbb{N}^{n} \times \mathbb{N}^{n} \rightarrow \mathbb{R}$ is a function that measures the similarity between two partitions, and $Q$ is a measure of central tendency, such as the mean or median. We used the adjusted Rand index (ARI) [98] for $\phi$, and the median for $Q$. To obtain $\pi^{*}$, we define a consensus function $\Gamma: \mathbb{N}^{n \times r} \rightarrow \mathbb{N}^{n}$ with $\Pi$ as the input. We used consensus functions based on the evidence accumulation clustering (EAC) paradigm [99], where $\Pi$ is first transformed into a distance matrix $\mathbf{D}_{i j}=d_{i j} / r$, where $d_{i j}$ is the number of times traits $i$ and $j$ were grouped in different clusters across all $r$ partitions in $\Pi$. Then, $\Gamma$ can be any similarity-based clustering algorithm, which is applied on $\mathbf{D}$ to derive the final partition $\pi^{*}$.

For the ensemble generation step, we used different algorithms to create a highly diverse set of partitions (see Figure 5 ) since diversity is an important property for ensembles [100,101,102]. We used three data representations: the raw dataset, its projection into the top 50 principal components, and the embedding learned by UMAP [103] using 50 components. For each of these, we applied five clustering algorithms, covering a wide range of different assumptions on the data structure: $k$-means [104], spectral clustering [105], a Gaussian mixture model (GMM), hierarchical clustering, and DBSCAN [106]. For $k$-means, spectral clustering and GMM, we specified a range of $k$ between 2 and $\sqrt{n} \approx 60$, and for each $k$ we generated five partitions using random seeds. For hierarchical clustering, for each $k$ we generated four partitions using four common linkage criteria: ward, complete, average and single. For DBSCAN, we combined different ranges for parameters $\epsilon$ (the maximum distance between two data points to be considered part of the same neighborhood) and minPts (the minimum number of data points in a neighborhood for a data point to be considered a core point). Specifically, we used minPts values from 2 to 125, and for each data version, we determined a plausible range of $\epsilon$ values by observing the distribution of the mean distance of the minPts-nearest neighbors across all data points. Since some combinations of minPts and $\epsilon$ might not produce a meaningful partition (for instance, when all points are detected as noisy or only one cluster 
is found), we resampled partitions generated by DBSCAN to ensure an equal representation in the ensemble. This procedure generated a final ensemble of 4,428 partitions.

Finally, we used spectral clustering on $\mathbf{D}$ to derive the final consensus partitions. $\mathbf{D}$ was first transformed into a similarity matrix by applying an RBF kernel $\exp \left(-\gamma \mathbf{D}^{2}\right)$ using four different values for $\gamma$ that we empirically determined to work best. Thus for each $k$ between 2 and 60, we derived four consensus partitions and selected the one that maximized Equation $\underline{5}$. We further filtered this set of 59 solutions to keep only those with an ensemble agreement larger than the 75th percentile, leaving a total of 15 final consensus partitions shown in Figure $\underline{6}$.

\section{Cluster interpretation}

We used a supervised learning approach to interpret clustering results by detecting which gene modules are the most important for clusters of traits. For this, we used the highest resolution partition ( $k=29$, although any could be used) to train a decision tree model using each of the clusters as labels and the projected data $\hat{\mathbf{M}}$ as the training samples. For each $k$, we built a set of binary labels with the current cluster's traits as the positive class and the rest of the traits as the negative class. Then, we selected the LV in the root node of the trained model only if its threshold was positive and larger than one standard deviation. Next, we removed this LV from $\hat{\mathbf{M}}$ (regardless of being previously selected or not) and trained the model again. We repeated this procedure 20 times to extract the top 20 LVs that better discriminate traits in a cluster from the rest.

\section{CRISPR-Cas9 screening}

Cell culture. HepG2 cells were obtained from ATCC (ATCC® HB-8065' ${ }^{\text {TM }}$ ), and maintained in Eagle's Minimum Essential Medium with L-Glutamine (EMEM, Cat. 112-018-101, Quality Biology) supplemented with 10\% Fetal Bovine Serum (FBS, Gibco, Cat.16000-044), and 1\% Pen/Strep (Gibco, Cat.15140-122). Cells were kept at $370 \mathrm{C}$ in a humidity-controlled incubator with $5 \% \mathrm{CO}$, and were maintained at a density not exceed more than $80 \%$ confluency.

Genome-wide lentiviral pooled CRISPR-Cas9 library. 3rd lentiviral generation, Broad GPP genomewide Human Brunello CRISPR knockout Pooled library was provided by David Root and John Doench from Addgene (Cat. 73179-LV), and was used for HepG2 cell transduction. It consists of 76,441 sgRNAs, targets 19,114 genes in the human genome with an average of 4 sgRNAs per gene. Each 20 nt sgRNA cassette was inserted into lentiCRIS-PRv2 backbone between U6 promoter and gRNA scaffold. Through cell transduction, the lentiviral vectors which encode Cas9 were used to deliver the sgRNA cassette containing plasmids into cells during cell replication. Unsuccessful transduced cells were excluded through puromycin selection.

Lentiviral titer determination. No-spin lentiviral transduction was utilized for the screen. In a Collagen-I coated 6-wells plate, approximate $2.5 \mathrm{M}$ cells were seeded each well in the presence of $8 \mathrm{ug} / \mathrm{ml}$ polybrene (Millipore Sigma, Cat. TR-1003 G), and a different titrated virus volume (e.g., 0, 50, $100,200,250$, and $400 \mathrm{ul}$ ) was assigned to each well. EMEM complete media was added to make the final volume of $1.24 \mathrm{ml}$. 16-18hrs post transduction, virus/polybrene containing media was removed from each well. Cells were washed twice with $1 \times$ DPBS, and replaced with fresh EMEM. At 24h, cells in each well were trypsinized, diluted (e.g.,1:10), and seeded in pairs of wells of 6-well plates. At 60hr post transduction, cell media in each well was replaced with fresh EMEM. 2ug/ml of puromycin (Gibco, Cat. A1113803) was added to one well out of the pair. 2-5 days after puromycin selection, or the 0 virus well treated with puromycin had no survival of cells, cells in both wells with/without puromycin were collected and counted for viability. Percentage of Infection (PI\%) was obtained by comparing the cell numbers with/without puromycin selection within each pair. By means of Poisson's distribution theory, when transduction efficiency (PI\%) is between 30-50\%, which corresponding to an MOI 

made available under aCC-BY 4.0 International license.

(Multiplicity of Infection) of $\sim 0.35-0.70$. At MOI equal or close to 0.3 , around $95 \%$ of infected cells are predicted to have only one copy of virus. Therefore, a volume of virus (120ul) yielding 30-40\% of transduction efficiency was chosen for further large-scale viral transduction.

Lentiviral Transduction in HepG2 Using Brunello CRISPR Knockout Pooled Library. In order to achieve a coverage (representation) of at least 500 cells per sgRNA, and at an MOI between 0.3-0.4 to ensure $95 \%$ of infected cells get only one viral particle per cell, $200 \mathrm{M}$ cells were initiated for the screen. Transduction was carried out in the similar fashion as described above. Briefly, $2.5 \mathrm{M}$ cells were seeded in each well of 146 -well plates, along with $8 \mathrm{ug} / \mathrm{ml}$ of polybrene. Volume of $120 \mathrm{ul}$ of virus was added to each experimental well. 18hrs post transduction, virus/PB mix medium was removed, and cells in each well were collect-ed, counted, and pooled into T175 flasks. At 60hr post transduction, $2 \mathrm{ug} / \mathrm{ml}$ of puromycin was added to each flask. Mediums were changed every 2 days with fresh EMEM, topped with $2 \mathrm{ug} / \mathrm{ml}$ puromycin. 7 days after puromycin selection, cells were collected, pooled, counted, and replated.

Fluorescent dye staining. 9 days after puromycin selection, cells were assigned to 2 groups. 20-30M cells were collected as Unsorted Control. Cell pellet was spun down at $500 \times \mathrm{g}$ for $5 \mathrm{~min}$ at $40 \mathrm{C}$. Dry pellet was kept at -80 oC for further genomic DNA isolation. The rest of the cells (approximately 200M) were kept in $100 \mathrm{~mm}$ dishes, and stained with fluorescent dye (LipidSpotTM 488, Biotium, Cat. 70065T). In Brief, LipidSpot 488 was diluted to 1:100 with DPBS. $4 \mathrm{ml}$ of staining solution was used for each dish, and incubated at $370 \mathrm{C}$ for $30 \mathrm{~min}$. Cell images were captured through fluorescent microscope EVOS for GFP signal detection (Supplementary Figure $\underline{8}$ ).

Fluorescence-activated cell sorting (FACS). Cells were immediately collected into 50ml tubes (From this point on, keep cells cold), and spin at $500 \times \mathrm{g}$ for $5 \mathrm{~min}$ at $40 \mathrm{C}$. After DPBS wash, cell pellets were resuspended with FACS Sorting Buffer (1x DPBS without Ca2+/Mg2+, 2.5mM EDTA, 25mM HEPES, 1\% BSA. Solution was filter sterilized, and kept at $40 C)$, pi-pet gently to make single cells. Cell solution then filtered through cell strainer (Falcon, Cat. 352235), and were kept on ice protected from light. Collected cells were sorted on FACSJazz. 100um nozzle was used for sorting. $20 \%$ of each GFP-High and GFP-Low (Supplementary Figure 9 ) were collected into $15 \mathrm{ml}$ tubes. After sorting, cells were immediately spun down. Pellets were kept in $-800 \mathrm{C}$ for further genomic DNA isolation.

Genomic DNA isolation and verification. 3 conditions of Genomic DNA (Un-Sorted Control, lentiV2 GFP-High, and lentiV2 GFP-Low) were extracted using QIAamp DNA Blood Mini Kit (Qiagen, Cat.51104), followed by UV Spectroscopy (Nanodrop) to access the quality and quantity of the gDNA. Total 80160ug of gDNA was isolated for each condition. sgRNA cassette and lentiviral specific transgene in isolated gDNA were verified through PCR (Supplementary Figure 10).

Illumina libraries generation and sequencing. Fragment containing sgRNA cassette was amplified using P5 /P7 primers, as indicated in [107] and primer sequences were adapted from Broad Institute protocol (Supplementary Figure 11). Stagger sequence (0-8nt) was included in P5, and 8bp uniquely barcoded sequence in P7. Primers were synthesized through Integrated DNA Technologies (IDT), each primer was PAGE purified. 32 PCR reactions were set up for each condition. Each 100ul PCR reaction consists of roughly 5ug of gDNA, 5ul of each 10uM P5 and P7. ExTaq DNA Polymerase (TaKaRa, Cat. RR001A) was used to amplify the amplicon. PCR Thermal Cycler Parameters set as: Initial at 95oC for $1 \mathrm{~min}$; followed by 24 cycles of Denaturation at $940 \mathrm{C}$ for 30 seconds, Annealing at $52.50 \mathrm{C}$ for 30 seconds, Extension at $720 \mathrm{C}$ for 30 seconds. A final Elongation at $720 \mathrm{C}$ for 10 minutes. 285bp-293bp PCR products were expected (Supplementary Figure $12 \mathrm{~A}$ ). PCR products within the same condition were pooled and purified using SPRIselect beads (Beckman Coulter, Cat. B23318). Purified illumina libraries were quantitated on Qubit, and the quality of the library were analyzed on Bio-analyzer using High Sensitivity DNA Chip. A single approximate 285bp peak was expected. (Supplementary Figure 12 B). Final illumina library samples were sequenced on Nova-seq 6000 . Samples were pooled and loaded on a SP flow cell, along with $20 \%$ PhiX control v3 library spike-in. 
bioRxiv preprint doi: https://doi.org/10.1101/2021.07.05.450786; this version posted August 5, 2021. The copyright holder for this preprint (which was not certified by peer review) is the author/funder, who has granted bioRxiv a license to display the preprint in perpetuity. It is made available under aCC-BY 4.0 International license.

\section{Code and data availability}

The code and data to reproduce all the analyses in this work are available in https://github.com/greenelab/phenoplier. 


\section{References}

1. Relaxed purifying selection and possibly high rate of adaptation in primate lineage-specific genes.

James J Cai, Dmitri A Petrov

Genome biology and evolution (2010-07-12) https://www.ncbi.nlm.nih.gov/pubmed/20624743

DOI: 10.1093/g be/evg $\underline{019}$ · PMID: 20624743 ·PMCID: PMC2997544

2. Elevated rates of protein secretion, evolution, and disease among tissue-specific genes.

Eitan E Winter, Leo Goodstadt, Chris P Ponting

Genome research (2004-01) https://www.ncbi.nlm.nih.gov/pubmed/14707169

DOI: $10.1101 / \mathrm{gr} .1924004 \cdot$ PMID: 14707169 ·PMCID: PMC314278

3. A large-scale analysis of tissue-specific pathology and gene expression of human disease genes and complexes

K. Lage, N. T. Hansen, E. O. Karlberg, A. C. Eklund, F. S. Roque, P. K. Donahoe, Z. Szallasi, T. S. Jensen, S. Brunak

Proceedings of the National Academy of Sciences (2008-12-22) https://doi.org/d5qcv9

DOI: 10.1073/pnas.0810772105 ·PMID: 19104045 ·PMCID: PMC2606902

4. The GTEx Consortium atlas of genetic regulatory effects across human tissues

The GTEx Consortium

Science (2020-09-11) https://doi.org/ghbnhr

DOI: 10.1126/science.aaz1776 · PMID: $\underline{32913098}$ · PMCID: PMC7737656

5. Index and biological spectrum of human DNase I hypersensitive sites

Wouter Meuleman, Alexander Muratov, Eric Rynes, Jessica Halow, Kristen Lee, Daniel Bates,

Morgan Diegel, Douglas Dunn, Fidencio Neri, Athanasios Teodosiadis, ... John Stamatoyannopoulos

Nature (2020-07-29) https://doi.org/gg6dhp

DOI: $10.1038 /$ s41586-020-2559-3 ·PMID: 32728217 ·PMCID: PMC7422677

6. Mechanisms of tissue and cell-type specificity in heritable traits and diseases

Idan Hekselman, Esti Yeger-Lotem

Nature Reviews Genetics (2020-01-08) https://doi.org/ggkx9v

DOI: $\underline{10.1038 / s 41576-019-0200-9} \cdot$ PMID: $\underline{31913361}$

7. The support of human genetic evidence for approved drug indications

Matthew R Nelson, Hannah Tipney, Jeffery L Painter, Judong Shen, Paola Nicoletti, Yufeng Shen,

Aris Floratos, Pak Chung Sham, Mulin Jun Li, Junwen Wang, ... Philippe Sanseau

Nature Genetics (2015-06-29) https://doi.org/f3mn52

DOI: $10.1038 / n g .3314 \cdot P M I D: \underline{26121088}$

8. Are drug targets with genetic support twice as likely to be approved? Revised estimates of the impact of genetic support for drug mechanisms on the probability of drug approval Emily A. King, J. Wade Davis, Jacob F. Degner

PLOS Genetics (2019-12-12) https://doi.org/gg957r

DOI: 10.1371/journal.pgen.1008489 ·PMID: $\underline{31830040}$ ·PMCID: PMC6907751

9. An integrated encyclopedia of DNA elements in the human genome

The ENCODE Project Consortium 
bioRxiv preprint doi: https://doi.org/10.1101/2021.07.05.450786; this version posted August 5, 2021. The copyright holder for this preprint (which was not certified by peer review) is the author/funder, who has granted bioRxiv a license to display the preprint in perpetuity. It is made available under aCC-BY 4.0 International license.

Nature (2012-09-05) https://doi.org/bg9d

DOI: 10.1038/nature11247 · PMID: 22955616 ·PMCID: PMC3439153

10. Integrative analysis of $\mathbf{1 1 1}$ reference human epigenomes

Anshul Kundaje, Wouter Meuleman, Jason Ernst, Misha Bilenky, Angela Yen, Alireza HeraviMoussavi, Pouya Kheradpour, Zhizhuo Zhang, Jianrong Wang, Michael J. Ziller, ... Roadmap Epigenomics Consortium Nature (2015-02-18) https://doi.org/f62jpn

DOI: 10.1038/nature14248 · PMID: 25693563 ·PMCID: PMC4530010

\section{An atlas of active enhancers across human cell types and tissues}

Robin Andersson, Claudia Gebhard, Irene Miguel-Escalada, Ilka Hoof, Jette Bornholdt, Mette Boyd, Yun Chen, Xiaobei Zhao, Christian Schmidl, Takahiro Suzuki, ... The FANTOM Consortium

Nature (2014-03-26) https://doi.org/r35

DOI: 10.1038/nature12787 · PMID: 24670763 ·PMCID: PMC5215096

12. Regulatory genomic circuitry of human disease loci by integrative epigenomics Carles A. Boix, Benjamin T. James, Yongjin P. Park, Wouter Meuleman, Manolis Kellis Nature (2021-02-03) https://doi.org/ghzkhr DOI: 10.1038/s41586-020-03145-Z · PMID: 33536621 · PMCID: PMC7875769

\section{The Post-GWAS Era: From Association to Function}

Michael D. Gallagher, Alice S. Chen-Plotkin

The American Journal of Human Genetics (2018-05) https://doi.org/gdmftd

DOI: 10.1016/j.ajhg.2018.04.002 ·PMID: 29727686 ·PMCID: PMC5986732

\section{Reproducible RNA-seq analysis using recount 2}

Leonardo Collado-Torres, Abhinav Nellore, Kai Kammers, Shannon E Ellis, Margaret A Taub, Kasper D Hansen, Andrew E Jaffe, Ben Langmead, Jeffrey T Leek

Nature Biotechnology (2017-04-11) https://doi.org/gf75hp

DOI: $10.1038 / \mathrm{nbt} .3838$ ·PMID: 28398307 · PMCID: PMC6742427

15. Massive mining of publicly available RNA-seq data from human and mouse

Alexander Lachmann, Denis Torre, Alexandra B. Keenan, Kathleen M. Jagodnik, Hoyjin J. Lee, Lily Wang, Moshe C. Silverstein, Avi Ma'ayan

Nature Communications (2018-04-10) https://doi.org/gc92dr

DOI: 10.1038/s41467-018-03751-6 ·PMID: 29636450 ·PMCID: PMC5893633

16. Identification of therapeutic targets from genetic association studies using hierarchical component analysis

Hao-Chih Lee, Osamu Ichikawa, Benjamin S. Glicksberg, Aparna A. Divaraniya, Christine E. Becker, Pankaj Agarwal, Joel T. Dudley

BioData Mining (2020-06-17) https://doi.org/gjp5pf

DOI: 10.1186/s13040-020-00216-9 ·PMID: 32565911 ·PMCID: PMC7301559

17. Novel Variance-Component TWAS method for studying complex human diseases with applications to Alzheimer's dementia

Shizhen Tang, Aron S. Buchman, Philip L. De Jager, David A. Bennett, Michael P. Epstein, Jingjing Yang

PLOS Genetics (2021-04-02) https://doi.org/gjpr3j

DOI: 10.1371/journal.pgen.1009482 · PMID: 33798195 ·PMCID: PMC8046351 
bioRxiv preprint doi: https://doi.org/10.1101/2021.07.05.450786; this version posted August 5, 2021. The copyright holder for this preprint (which was not certified by peer review) is the author/funder, who has granted bioRxiv a license to display the preprint in perpetuity. It is made available under aCC-BY 4.0 International license.

18. Integrative approaches for large-scale transcriptome-wide association studies

Alexander Gusev, Arthur Ko, Huwenbo Shi, Gaurav Bhatia, Wonil Chung, Brenda WJH Penninx, Rick Jansen, Eco JC de Geus, Dorret I Boomsma, Fred A Wright, ... Bogdan Pasaniuc

Nature Genetics (2016-02-08) https://doi.org/f3vf4p

DOI: $10.1038 / n g .3506$ · PMID: 26854917 PMCID: PMC4767558

19. Integrating predicted transcriptome from multiple tissues improves association detection Alvaro N. Barbeira, Milton Pividori, Jiamao Zheng, Heather E. Wheeler, Dan L. Nicolae, Hae Kyung Im

PLOS Genetics (2019-01-22) https://doi.org/ghs8vx

DOI: $10.1371 /$ journal.pgen.1007889 ·PMID: $\underline{30668570}$ ·PMCID: PMC6358100

20. A gene-based association method for mapping traits using reference transcriptome data Eric R Gamazon, Heather E Wheeler, Kaanan P Shah, Sahar V Mozaffari, Keston Aquino-Michaels, Robert J Carroll, Anne E Eyler, Joshua C Denny, Dan L Nicolae, Nancy J Cox, ... GTEx Consortium Nature Genetics (2015-08-10) https://doi.org/f7p9zv

DOI: $\underline{10.1038 / n g}$.3367 · PMID: 26258848 · PMCID: PMC4552594

21. Integrating Gene Expression with Summary Association Statistics to Identify Genes Associated with 30 Complex Traits

Nicholas Mancuso, Huwenbo Shi, Pagé Goddard, Gleb Kichaev, Alexander Gusev, Bogdan Pasaniuc The American Journal of Human Genetics (2017-03) https://doi.org/f9wvsg

DOI: 10.1016/j.ajhg.2017.01.031 · PMID: 28238358 · PMCID: PMC5339290

22. Heritability enrichment of specifically expressed genes identifies disease-relevant tissues and cell types

Hilary K. Finucane, Yakir A. Reshef, Verneri Anttila, Kamil Slowikowski, Alexander Gusev, Andrea Byrnes, Steven Gazal, Po-Ru Loh, Caleb Lareau, Noam Shoresh, ... The Brainstorm Consortium Nature Genetics (2018-04-09) https://doi.org/gdfjgt

DOI: 10.1038/s41588-018-0081-4 ·PMID: 29632380 ·PMCID: PMC5896795

23. Integrating Autoimmune Risk Loci with Gene-Expression Data Identifies Specific Pathogenic Immune Cell Subsets

Xinli Hu, Hyun Kim, Eli Stahl, Robert Plenge, Mark Daly, Soumya Raychaudhuri

The American Journal of Human Genetics (2011-10) https://doi.org/fpghp4

DOI: 10.1016/j.ajhg.2011.09.002 ·PMID: 21963258 ·PMCID: PMC3188838

24. SNPsea: an algorithm to identify cell types, tissues and pathways affected by risk loci Kamil Slowikowski, Xinli Hu, Soumya Raychaudhuri

Bioinformatics (2014-09-01) https://doi.org/f6j6v3

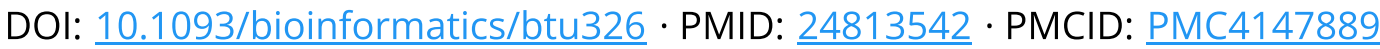

25. Meta-analysis of $\mathbf{3 7 5 , 0 0 0}$ individuals identifies 38 susceptibility loci for migraine

Padhraig Gormley, Verneri Anttila, Bendik S Winsvold, Priit Palta, Tonu Esko, Tune H Pers, Kai-How Farh, Ester Cuenca-Leon, Mikko Muona, Nicholas A Furlotte, ... International Headache Genetics Consortium

Nature Genetics (2016-06-20) https://doi.org/bmzx

DOI: $10.1038 / n g .3598 \cdot P M I D: ~ 27322543$ · PMCID: PMC5331903

26. Biological interpretation of genome-wide association studies using predicted gene functions

Tune H. Pers, Juha M. Karjalainen, Yingleong Chan, Harm-Jan Westra, Andrew R. Wood, Jian Yang, Julian C. Lui, Sailaja Vedantam, Stefan Gustafsson, Tonu Esko, ... Genetic Investigation of 
bioRxiv preprint doi: https://doi.org/10.1101/2021.07.05.450786; this version posted August 5, 2021. The copyright holder for this preprint (which was not certified by peer review) is the author/funder, who has granted bioRxiv a license to display the preprint in perpetuity. It is made available under aCC-BY 4.0 International license.

ANthropometric Traits (GIANT) Consortium

Nature Communications (2015-01-19) https://doi.org/f3mwhd

DOI: $10.1038 /$ ncomms6890 ·PMID: 25597830 ·PMCID: PMC4420238

27. Estimating the causal tissues for complex traits and diseases

Halit Ongen, Andrew A Brown, Olivier Delaneau, Nikolaos I Panousis, Alexandra C Nica, Emmanouil T Dermitzakis, GTEx Consortium

Nature Genetics (2017-10-23) https://doi.org/ggrr72

DOI: $\underline{10.1038 / n g .3981} \cdot$ PMID: 29058715

28. A global overview of pleiotropy and genetic architecture in complex traits

Kyoko Watanabe, Sven Stringer, Oleksandr Frei, Maša Umićević Mirkov, Christiaan de Leeuw, Tinca J. C. Polderman, Sophie van der Sluis, Ole A. Andreassen, Benjamin M. Neale, Danielle Posthuma Nature Genetics (2019-08-19) https://doi.org/ggr84r

DOI: $10.1038 /$ s41588-019-0481-0 · PMID: $\underline{31427789}$

29. Detection and interpretation of shared genetic influences on $\mathbf{4 2}$ human traits

Joseph K Pickrell, Tomaz Berisa, Jimmy Z Liu, Laure Ségurel, Joyce Y Tung, David A Hinds

Nature Genetics (2016-05-16) https://doi.org/f8ssw4

DOI: 10.1038/ng. $\underline{3570}$ · PMID: 27182965 ·PMCID: PMC5207801

30. An Expanded View of Complex Traits: From Polygenic to Omnigenic

Evan A. Boyle, Yang I. Li, Jonathan K. Pritchard

Cell (2017-06) https://doi.org/gçpgdz

DOI: 10.1016/j.cell.2017.05.038 · PMID: 28622505 · PMCID: PMC5536862

31. Trans Effects on Gene Expression Can Drive Omnigenic Inheritance

Xuanyao Liu, Yang I. Li, Jonathan K. Pritchard

Cell(2019-05) https://doi.org/gtz8bj

DOI: $10.1016 / j$. .cell.2019.04.014 ·PMID: 31051098 ·PMCID: PMC6553491

32. PhenomeXcan: Mapping the genome to the phenome through the transcriptome

Milton Pividori, Padma S. Rajagopal, Alvaro Barbeira, Yanyu Liang, Owen Melia, Lisa Bastarache, YoSon Park, GTEx Consortium, Xiaoquan Wen, Hae K. Im

Science Advances (2020-09) https://doi.org/ghbvbf

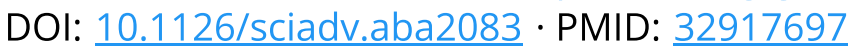

33. A Next Generation Connectivity Map: L1000 Platform and the First 1,000,000 Profiles

Aravind Subramanian, Rajiv Narayan, Steven M. Corsello, David D. Peck, Ted E. Natoli, Xiaodong Lu, Joshua Gould, John F. Davis, Andrew A. Tubelli, Jacob K. Asiedu, ... Todd R. Golub

Cell(2017-11) https://doi.org/cgwt

DOI: 10.1016/j.cell.2017.10.049 ·PMID: 29195078 · PMCID: PMC5990023

34. MultiPLIER: A Transfer Learning Framework for Transcriptomics Reveals Systemic Features of Rare Disease

Jaclyn N. Taroni, Peter C. Grayson, Qiwen Hu, Sean Eddy, Matthias Kretzler, Peter A. Merkel, Casey

S. Greene

Cell Systems (2019-05) https://doi.org/gf75g $\underline{5}$

DOI: 10.1016/j.cels.2019.04.003 · PMID: $\underline{31121115}$ · PMCID: PMC6538307

35. Pathway-level information extractor (PLIER) for gene expression data

Weiguang Mao, Elena Zaslavsky, Boris M. Hartmann, Stuart C. Sealfon, Maria Chikina 
bioRxiv preprint doi: https://doi.org/10.1101/2021.07.05.450786; this version posted August 5, 2021. The copyright holder for this preprint (which was not certified by peer review) is the author/funder, who has granted bioRxiv a license to display the preprint in perpetuity. It is made available under aCC-BY 4.0 International license.

Nature Methods (2019-06-27) https://doi.org/g775g

DOI: 10.1038/s41592-019-0456-1 · PMID: 31249421 ·PMCID: PMC7262669

36. The Electronic Medical Records and Genomics (eMERGE) Network: past, present, and future Omri Gottesman, Helena Kuivaniemi, Gerard Tromp, W. Andrew Faucett, Rongling Li, Teri A. Manolio, Saskia C. Sanderson, Joseph Kannry, Randi Zinberg, Melissa A. Basford, ... and The eMERGE Network Genetics in Medicine (2013-06-06) https://doi.org/f5dwbt DOI: 10.1038/gim.2013.72 · PMID: 23743551 · PMCID: PMC3795928

37. The UK Biobank resource with deep phenotyping and genomic data Clare Bycroft, Colin Freeman, Desislava Petkova, Gavin Band, Lloyd T. Elliott, Kevin Sharp, Allan Motyer, Damjan Vukcevic, Olivier Delaneau, Jared O'Connell, ... Jonathan Marchini Nature (2018-10-10) https://doi.org/gfb7h2 DOI: $10.1038 /$ s41586-018-0579-z · PMID: 30305743 ·PMCID: PMC6786975

38. Finding function: evaluation methods for functional genomic data Chad L Myers, Daniel R Barrett, Matthew A Hibbs, Curtis Huttenhower, Olga G Troyanskaya BMC Genomics (2006-07-25) https://doi.org/fg6wnk

DOI: $10.1186 / 1471-2164-7-187$ ·PMID: 16869964 ·PMCID: PMC1560386

39. The CAFA challenge reports improved protein function prediction and new functional annotations for hundreds of genes through experimental screens

Naihui Zhou, Yuxiang Jiang, Timothy R. Bergquist, Alexandra J. Lee, Balint Z. Kacsoh, Alex W. Crocker, Kimberley A. Lewis, George Georghiou, Huy N. Nguyen, Md Nafiz Hamid, ... Iddo Friedberg Genome Biology (2019-11-19) https://doi.org/ggnxpz

DOI: 10.1186/s13059-019-1835-8 · PMID: 31744546 · PMCID: PMC6864930

40. MAGMA: Generalized Gene-Set Analysis of GWAS Data

Christiaan A. de Leeuw, Joris M. Mooij, Tom Heskes, Danielle Posthuma

PLOS Computational Biology (2015-04-17) https://doi.org/gf92gp

DOI: 10.1371/journal.pcbi.1004219 · PMID: 25885710 · PMCID: PMC4401657

41. Estimating the population abundance of tissue-infiltrating immune and stromal cell populations using gene expression

Etienne Becht, Nicolas A. Giraldo, Laetitia Lacroix, Bénédicte Buttard, Nabila Elarouci, Florent Petitprez, Janick Selves, Pierre Laurent-Puig, Catherine Sautès-Fridman, Wolf H. Fridman, Aurélien de Reyniès

Genome Biology (2016-10-20) https://doi.org/f87sgf

DOI: 10.1186/s13059-016-1070-5 ·PMID: 27765066 · PMCID: PMC5073889

42. Fast gene set enrichment analysis

Gennady Korotkevich, Vladimir Sukhov, Nikolay Budin, Boris Shpak, Maxim N. Artyomov, Alexey

Sergushichev

Cold Spring Harbor Laboratory (2021-02-01) https://doi.org/gfpg $\underline{\text { hm }}$

DOI: $10.1101 / 060012$

43. DrugBank 4.0: shedding new light on drug metabolism

Vivian Law, Craig Knox, Yannick Djoumbou, Tim Jewison, An Chi Guo, Yifeng Liu, Adam Maciejewski, David Arndt, Michael Wilson, Vanessa Neveu, ... David S. Wishart

Nucleic Acids Research (2014-01) https://doi.org/£3mn6d

DOI: 10.1093/nar/gkt1068 · PMID: 24203711 · PMCID: PMC3965102 
bioRxiv preprint doi: https://doi.org/10.1101/2021.07.05.450786; this version posted August 5, 2021. The copyright holder for this preprint (which was not certified by peer review) is the author/funder, who has granted bioRxiv a license to display the preprint in perpetuity. It is made available under aCC-BY 4.0 International license.

44. Systematic integration of biomedical knowledge prioritizes drugs for repurposing

Daniel Scott Himmelstein, Antoine Lizee, Christine Hessler, Leo Brueggeman, Sabrina L Chen,

Dexter Hadley, Ari Green, Pouya Khankhanian, Sergio E Baranzini

eLife (2017-09-22) https://doi.org/cdfk

DOI: 10.7554/elife.26726 · PMID: 28936969 ·PMCID: PMC5640425

45. Dhimmel/Lincs V2.0: Refined Consensus Signatures From Lincs L1000

Daniel Himmelstein, Leo Brueggeman, Sergio Baranzini

Zenodo (2016-03-08) https://doi.org/f3mqvr

DOI: $10.5281 /$ zenodo.47223

46. Computational Repositioning of the Anticonvulsant Topiramate for Inflammatory Bowel Disease

J. T. Dudley, M. Sirota, M. Shenoy, R. K. Pai, S. Roedder, A. P. Chiang, A. A. Morgan, M. M. Sarwal, P. J. Pasricha, A. J. Butte

Science Translational Medicine (2011-08-17) https://doi.org/bmh5ts

DOI: $10.1126 /$ scitransImed.3002648 · PMID: 21849664 ·PMCID: PMC3479650

47. Discovery and Preclinical Validation of Drug Indications Using Compendia of Public Gene Expression Data

M. Sirota, J. T. Dudley, J. Kim, A. P. Chiang, A. A. Morgan, A. Sweet-Cordero, J. Sage, A. J. Butte

Science Translational Medicine (2011-08-17) https://doi.org/c3fwxv

DOI: 10.1126/scitransImed.3001318 · PMID: 21849665 · PMCID: PMC3502016

48. Analysis of genome-wide association data highlights candidates for drug repositioning in psychiatry

Hon-Cheong So, Carlos Kwan-Long Chau, Wan-To Chiu, Kin-Sang Ho, Cho-Pong Lo, Stephanie HoYue Yim, Pak-Chung Sham

Nature Neuroscience (2017-08-14) https://doi.org/gbrssh

DOI: $10.1038 / \mathrm{nn} \cdot 4618 \cdot P M I D: \underline{28805813}$

49. Dhimmel/Indications V1.0. Pharmacotherapydb: The Open Catalog Of Drug Therapies For Disease

Daniel S. Himmelstein, Pouya Khankhanian, Christine S. Hessler, Ari J. Green, Sergio E. Baranzini Zenodo (2016-03-15) https://doi.org/f3mqwb

DOI: $10.5281 /$ zenodo.47664

50. Niacin in patients with low HDL cholesterol levels receiving intensive statin therapy.

William E Boden, Jeffrey L Probstfield, Todd Anderson, Bernard R Chaitman, Patrice Desvignes-

Nickens, Kent Koprowicz, Ruth McBride, Koon Teo, William Weintraub

The New England journal of medicine (2011-11-15)

https://www.ncbi.nlm.nih.gov/pubmed/22085343

DOI: $10.1056 /$ nejmoa1107579 ·PMID: 22085343

51. Effects of extended-release niacin with laropiprant in high-risk patients.

Martin J Landray, Richard Haynes, Jemma C Hopewell, Sarah Parish, Theingi Aung, Joseph Tomson, Karl Wallendszus, Martin Craig, Lixin Jiang, ... Jane Armitage

The New England journal of medicine (2014-07-17)

https://www.ncbi.nlm.nih.gov/pubmed/25014686

DOI: 10.1056/nejmoa1300955 ·PMID: 25014686

52. Assessment of the Role of Niacin in Managing Cardiovascular Disease Outcomes: A Systematic Review and Meta-analysis. 
bioRxiv preprint doi: https://doi.org/10.1101/2021.07.05.450786; this version posted August 5, 2021. The copyright holder for this preprint (which was not certified by peer review) is the author/funder, who has granted bioRxiv a license to display the preprint in perpetuity. It is made available under aCC-BY 4.0 International license.

Elvira D'Andrea, Spencer P Hey, Cherie L Ramirez, Aaron S Kesselheim

JAMA network open (2019-04-05) https://www.ncbi.nlm.nih.gov/pubmed/30977858

DOI: 10.1001/jamanetworkopen.2019.2224 · PMID: 30977858 · PMCID: PMC6481429

\section{Mechanism of Action of Niacin}

Vaijinath S. Kamanna, Moti L. Kashyap

The American Journal of Cardiology (2008-04) https://doi.org/c8zwdt

DOI: 10.1016/j.amjcard.2008.02.029 · PMID: 18375237

54. Niacin: an old lipid drug in a new NAD+ dress

Mario Romani, Dina Carina Hofer, Elena Katsyuba, Johan Auwerx

Journal of Lipid Research (2019-04) https://doi.org/gjpjet

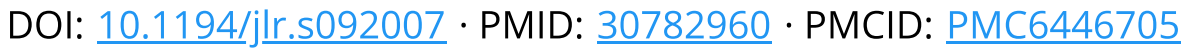

55. The therapeutic role of niacin in dyslipidemia management.

William E Boden, Mandeep S Sidhu, Peter P Toth

Journal of cardiovascular pharmacology and therapeutics (2013-12-20)

https://www.ncbi.nlm.nih.gov/pubmed/24363242

DOI: $10.1177 / 1074248413514481$ PMID: 24363242

56. High-density lipoproteins in the prevention of cardiovascular disease: changing the paradigm.

S Tuteja, DJ Rader

Clinical pharmacology and therapeutics (2014-04-08)

https://www.ncbi.nlm.nih.gov/pubmed/24713591

DOI: $10.1038 /$ clpt.2014.79 $\cdot$ PMID: 24713591

57. The nicotinic acid receptor GPR109A (HM74A or PUMA-G) as a new therapeutic target S OFFERMANNS

Trends in Pharmacological Sciences (2006-07) https://doi.org/fgb4tr

DOI: $10.1016 / j$. tips.2006.05.008 · PMID: 16766048

\section{Langerhans Cells Release Prostaglandin D2 in Response to Nicotinic Acid}

Dominique Maciejewski-Lenoir, Jeremy G. Richman, Yaron Hakak, Ibragim Gaidarov, Dominic P. Behan, Daniel T. Connolly

Journal of Investigative Dermatology (2006-12) https://doi.org/dgxg $\underline{75}$

DOI: $\underline{10.1038 / \text { sj:jid.5700586 · PMID: } 17008871}$

59. Nicotinic acid inhibits progression of atherosclerosis in mice through its receptor GPR109A expressed by immune cells

Martina Lukasova, Camille Malaval, Andreas Gille, Jukka Kero, Stefan Offermanns

Journal of Clinical Investigation (2011-03-01) https://doi.org/cgftcq

DOI: 10.1172/jci41651 · PMID: 21317532 · PMCID: $\underline{\text { PMC3048854 }}$

60. Role of HDL, ABCA1, and ABCG1 Transporters in Cholesterol Efflux and Immune Responses Laurent Yvan-Charvet, Nan Wang, Alan R. Tall

Arteriosclerosis, Thrombosis, and Vascular Biology (2010-02) https://doi.org/ds23w6

DOI: $\underline{10.1161 / a t v b a h a .108 .179283}$ ·PMID: 19797709 ·PMCID: PMC2812788

61. Shared and organism-specific host responses to childhood diarrheal diseases revealed by whole blood transcript profiling

Hannah A. DeBerg, Mussaret B. Zaidi, Matthew C. Altman, Prasong Khaenam, Vivian H. Gersuk, Freddy D. Campos, Iza Perez-Martinez, Mario Meza-Segura, Damien Chaussabel, Jacques 
bioRxiv preprint doi: https://doi.org/10.1101/2021.07.05.450786; this version posted August 5, 2021. The copyright holder for this preprint (which was not certified by peer review) is the author/funder, who has granted bioRxiv a license to display the preprint in perpetuity. It is made available under aCC-BY 4.0 International license.

Banchereau, ... Peter S. Linsley

PLOS ONE (2018-01-29) https://doi.org/gcwgcr

DOI: 10.1371/journal.pone.0192082 · PMID: 29377961 · PMCID: PMC5788382

62. Copy Number Loss of the Interferon Gene Cluster in Melanomas Is Linked to Reduced T Cell Infiltrate and Poor Patient Prognosis

Peter S. Linsley, Cate Speake, Elizabeth Whalen, Damien Chaussabel

PLOS ONE (2014-10-14) https://doi.org/gk9k8s

DOI: 10.1371/journal.pone.0109760 ·PMID: 25314013 ·PMCID: PMC4196925

63. The Ro60 autoantigen binds endogenous retroelements and regulates inflammatory gene expression

T. Hung, G. A. Pratt, B. Sundararaman, M. J. Townsend, C. Chaivorapol, T. Bhangale, R. R. Graham, W. Ortmann, L. A. Criswell, G. W. Yeo, T. W. Behrens

Science (2015-09-17) https://doi.org/f7vs67

DOI: 10.1126/science.aac7442 · PMID: 26382853 ·PMCID: PMC4691329

64. Homo sapiens (ID 258384) - BioProject - NCBI

https://www.ncbi.nlm.nih.gov/bioproject/PRJNA258384

65. Identification of Genes Critical for Resistance to Infection by West Nile Virus Using RNA-Seq Analysis

Feng Qian, Lisa Chung, Wei Zheng, Vincent Bruno, Roger Alexander, Zhong Wang, Xiaomei Wang, Sebastian Kurscheid, Hongyu Zhao, Erol Fikrig, ... Ruth Montgomery

Viruses (2013-07-08) https://doi.org/f49d7g

DOI: $10.3390 / v 5071664$ ·PMID: 23881275 ·PMCID: PMC3738954

66. Mycobacterial infection induces a specific human innate immune response

John D. Blischak, Ludovic Tailleux, Amy Mitrano, Luis B. Barreiro, Yoav Gilad

Scientific Reports (2015-11-20) https://doi.org/f7zk5c

DOI: 10.1038/srep16882 · PMID: 26586179 ·PMCID: PMC4653619

67. Niacin Inhibits Apoptosis and Rescues Premature Ovarian Failure

Shufang Wang, Min Sun, Ling Yu, Yixuan Wang, Yuanqing Yao, Deqing Wang

Cellular Physiology and Biochemistry (2018) https://doi.org/gfqucq

DOI: $10.1159 / 000495051$ · PMID: $\underline{30415247}$

68. Chronic niacin administration ameliorates ovulation, histological changes in the ovary and adiponectin concentrations in a rat model of polycystic ovary syndrome

Negin Asadi, Mahin Izadi, Ali Aflatounian, Mansour Esmaeili-Dehaj, Mohammad Ebrahim Rezvani, Zeinab Hafizi

Reproduction, Fertility and Development (2021) https://doi.org/gjpjkt

DOI: $\underline{10.1071 / \mathrm{rd} 20306} \cdot$ PMID: 33751926

69. Clustering trees: a visualization for evaluating clusterings at multiple resolutions

Luke Zappia, Alicia Oshlack

GigaScience (2018-07) https://doi.org/gfzqf드

DOI: 10.1093/gigascience/giy $\underline{083}$ ·PMID: 30010766 · PMCID: PMC6057528

70. Prognostic value of grip strength: findings from the Prospective Urban Rural Epidemiology (PURE) study.

Darryl P Leong, Koon K Teo, Sumathy Rangarajan, Patricio Lopez-Jaramillo, Alvaro Avezum, Andres Orlandini, Pamela Seron, Suad H Ahmed, Annika Rosengren, Roya Kelishadi, ... 
bioRxiv preprint doi: https://doi.org/10.1101/2021.07.05.450786; this version posted August 5, 2021. The copyright holder for this preprint (which was not certified by peer review) is the author/funder, who has granted bioRxiv a license to display the preprint in perpetuity. It is made available under aCC-BY 4.0 International license.

Lancet (London, England) (2015-05-13) https://www.ncbi.nlm.nih.gov/pubmed/25982160

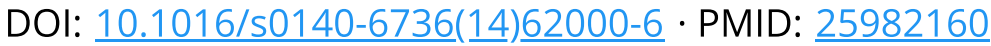

71. Densely Interconnected Transcriptional Circuits Control Cell States in Human Hematopoiesis

Noa Novershtern, Aravind Subramanian, Lee N. Lawton, Raymond H. Mak, W. Nicholas Haining, Marie E. McConkey, Naomi Habib, Nir Yosef, Cindy Y. Chang, Tal Shay, ... Benjamin L. Ebert Cell(2011-01) https://doi.org/cf5k92

DOI: 10.1016/j.cell.2011.01.004 · PMID: 21241896 ·PMCID: PMC3049864

72. CD19 ${ }^{+} \mathrm{CD}^{+}$Cells as Indicators of Preeclampsia

Federico Jensen, Gerd Wallukat, Florian Herse, Oliver Budner, Tarek El-Mousleh, Serban-Dan Costa, Ralf Dechend, Ana Claudia Zenclussen

Hypertension (2012-04) https://doi.org/gj36rs

DOI: 10.1161/hypertensionaha.111.188276 · PMID: 22353610

73. Conditional and interaction gene-set analysis reveals novel functional pathways for blood pressure

Christiaan A. de Leeuw, Sven Stringer, llona A. Dekkers, Tom Heskes, Danielle Posthuma

Nature Communications (2018-09-14) https://doi.org/gd6d85

DOI: $10.1038 /$ s41467-018-06022-6 ·PMID: $\underline{30218068} \cdot$ PMCID: PMC6138636

\section{Estrogen and hypertension}

Muhammad S. Ashraf, Wanpen Vongpatanasin

Current Hypertension Reports (2006-09) https://doi.org/d638rf

DOI: $10.1007 / \mathrm{s} 11906-006-0080-1 \cdot P M I D: 16965722$

75. Depression as a predictor for coronary heart disease. a review and meta-analysis.

Reiner Rugulies

American journal of preventive medicine (2002-07)

https://www.ncbi.nlm.nih.gov/pubmed/12093424

DOI: 10.1016/s0749-3797(02)00439-7 · PMID: 12093424

76. Mental Disorders Across the Adult Life Course and Future Coronary Heart Disease

Catharine R. Gale, G. David Batty, David P. J. Osborn, Per Tynelius, Finn Rasmussen

Circulation (2014-01-14) https://doi.org/qm4

DOI: 10.1161/circulationaha.113.002065 ·PMID: 24190959 · PMCID: PMC4107269

77. Mortality gap for people with bipolar disorder and schizophrenia: UK-based cohort study 2000-2014

Joseph F. Hayes, Louise Marston, Kate Walters, Michael B. King, David P. J. Osborn

British Journal of Psychiatry (2018-01-02) https://doi.org/gbwcj $\underline{x}$

DOI: 10.1192/bjp.bp.117.202606 · PMID: 28684403 · PMCID: PMC5579328

78. Getting to the Heart of Alzheimer Disease

Joshua M. Tublin, Jeremy M. Adelstein, Federica del Monte, Colin K. Combs, Loren E. Wold

Circulation Research (2019-01-04) https://doi.org/gjzjgg

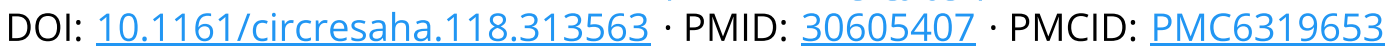

79. The overlap between vascular disease and Alzheimer's disease - lessons from pathology Johannes Attems, Kurt A Jellinger

BMC Medicine (2014-11-11) https://doi.org/f6pjol4

DOI: 10.1186/s12916-014-0206-2 ·PMID: 25385447 ·PMCID: PMC4226890 
bioRxiv preprint doi: https://doi.org/10.1101/2021.07.05.450786; this version posted August 5, 2021. The copyright holder for this preprint (which was not certified by peer review) is the author/funder, who has granted bioRxiv a license to display the preprint in perpetuity. It is made available under aCC-BY 4.0 International license.

80. Cardiovascular Risk Factors for Alzheimer's Disease

Clive Rosendorff, Michal S. Beeri, Jeremy M. Silverman

The American Journal of Geriatric Cardiology (2007-03) https://doi.org/bpfw5d

DOI: $10.1111 / \mathrm{j} .1076-7460.2007 .06696 . x \cdot P M I D: \underline{17483665}$

81. Reverse cholesterol transport and cholesterol efflux in atherosclerosis

R. Ohashi, H. Mu, X. Wang, Q. Yao, C. Chen

QJM: An International Journal of Medicine (2005-12) https://doi.org/dn2fgt

DOI: $10.1093 /$ gjmed/hci136 · PMID: 16258026

82. Lipid and Lipoprotein Metabolism in Microglia

Bailey A. Loving, Kimberley D. Bruce

Frontiers in Physiology (2020-04-28) https://doi.org/gk92xd

DOI: $10.3389 / f p h y s .2020 .00393$ · PMID: $\underline{32411016}$ · PMCID: PMC7198855

83. recount3: summaries and queries for large-scale RNA-seq expression and splicing

Christopher Wilks, Shijie C. Zheng, Feng Yong Chen, Rone Charles, Brad Solomon, Jonathan P. Ling, Eddie Luidy Imada, David Zhang, Lance Joseph, Jeffrey T. Leek, ... Ben Langmead

Cold Spring Harbor Laboratory (2021-05-25) https://doi.org/gj7cmg

DOI: $10.1101 / 2021.05 .21 .445138$

84. Opportunities and challenges for transcriptome-wide association studies

Michael Wainberg, Nasa Sinnott-Armstrong, Nicholas Mancuso, Alvaro N. Barbeira, David A.

Knowles, David Golan, Raili Ermel, Arno Ruusalepp, Thomas Quertermous, Ke Hao, ... Anshul

Kundaje

Nature Genetics (2019-03-29) https://doi.org/gf3hmr

DOI: 10.1038/s41588-019-0385-z ·PMID: 30926968 · PMCID: PMC6777347

85. Probabilistic colocalization of genetic variants from complex and molecular traits: promise and limitations

Abhay Hukku, Milton Pividori, Francesca Luca, Roger Pique-Regi, Hae Kyung Im, Xiaoquan Wen

The American Journal of Human Genetics (2021-01) https://doi.org/gj

DOI: 10.1016/j.ajhg.2020.11.012 ·PMID: $\underline{33308443}$ ·PMCID: PMC7820626

86. Transcriptome-wide association study of schizophrenia and chromatin activity yields mechanistic disease insights

Alexander Gusev, Nicholas Mancuso, Hyejung Won, Maria Kousi, Hilary K. Finucane, Yakir Reshef, Lingyun Song, Alexias Safi, Steven McCarroll, Benjamin M. Neale, ... Schizophrenia Working Group of the Psychiatric Genomics Consortium

Nature Genetics (2018-04-09) https://doi.org/gdfdf2

DOI: 10.1038/s41588-018-0092-1 ·PMID: 29632383 ·PMCID: PMC5942893

87. Shared genetic origin of asthma, hay fever and eczema elucidates allergic disease biology

Manuel A Ferreira, Judith M Vonk, Hansjörg Baurecht, Ingo Marenholz, Chao Tian, Joshua D Hoffman, Quinta Helmer, Annika Tillander, Vilhelmina Ullemar, Jenny van Dongen, ... LifeLines

Cohort Study

Nature Genetics (2017-10-30) https://doi.org/gchg $\underline{\underline{62}}$

DOI: 10.1038/ng. 3985 · PMID: 29083406 · PMCID: PMC5989923

88. A genome-wide cross-trait analysis from UK Biobank highlights the shared genetic architecture of asthma and allergic diseases

Zhaozhong Zhu, Phil H. Lee, Mark D. Chaffin, Wonil Chung, Po-Ru Loh, Quan Lu, David C. Christiani, Liming Liang 
bioRxiv preprint doi: https://doi.org/10.1101/2021.07.05.450786; this version posted August 5, 2021. The copyright holder for this preprint (which was not certified by peer review) is the author/funder, who has granted bioRxiv a license to display the preprint in perpetuity. It is made available under aCC-BY 4.0 International license.

Nature Genetics (2018-05-21) https://doi.org/gdpmtn

DOI: 10.1038/s41588-018-0121-0 ·PMID: 29785011 ·PMCID: PMC5980765

89. Systematic tissue annotations of -omics samples by modeling unstructured metadata Nathaniel T. Hawkins, Marc Maldaver, Anna Yannakopoulos, Lindsay A. Guare, Arjun Krishnan Cold Spring Harbor Laboratory (2021-05-20) https://doi.org/gj2pkc

DOI: $10.1101 / 2021.05 .10 .443525$

90. Exploring the phenotypic consequences of tissue specific gene expression variation inferred from GWAS summary statistics

Alvaro N. Barbeira, Scott P. Dickinson, Rodrigo Bonazzola, Jiamao Zheng, Heather E. Wheeler, Jason M. Torres, Eric S. Torstenson, Kaanan P. Shah, Tzintzuni Garcia, Todd L. Edwards, ... GTEx Consortium

Nature Communications (2018-05-08) https://doi.org/gdjppㅗㅡ

DOI: 10.1038/s41467-018-03621-1 ·PMID: 29739930 ·PMCID: PMC5940825

91. Probabilistic Colocalization of Genetic Variants from Complex and Molecular Traits: Promise and Limitations

Abhay Hukku, Milton Pividori, Francesca Luca, Roger Pique-Regi, Hae Kyung Im, Xiaoquan Wen Cold Spring Harbor Laboratory (2020-07-01) https://doi.org/gjwh3p

DOI: $10.1101 / 2020.07 .01 .182097$

92. The Molecular Signatures Database Hallmark Gene Set Collection

Arthur Liberzon, Chet Birger, Helga Thorvaldsdóttir, Mahmoud Ghandi, Jill P. Mesirov, Pablo

Tamayo

Cell Systems (2015-12) https://doi.org/gf78hq

DOI: $10.1016 / j$. cels.2015.12.004 ·PMID: 26771021 · PMCID: PMC4707969

93. A global reference for human genetic variation

The 1000 Genomes Project Consortium

Nature (2015-09-30) https://doi.org/73d

DOI: 10.1038/nature15393 · PMID: 26432245 ·PMCID: PMC4750478

94. GWAS summary statistics imputation support data and integration with PrediXcan MASHR Alvaro Numa Barbeira, Hae Kyung Im

Zenodo (2019-12-10) https://doi.org/gjojww

DOI: $10.5281 /$ zenodo.3657902

95. Human Disease Ontology 2018 update: classification, content and workflow expansion

Lynn M Schriml, Elvira Mitraka, James Munro, Becky Tauber, Mike Schor, Lance Nickle, Victor Felix, Linda Jeng, Cynthia Bearer, Richard Lichenstein, ... Carol Greene

Nucleic Acids Research (2019-01-08) https://doi.org/ggx9wp

DOI: 10.1093/nar/gky1032 · PMID: 30407550 · PMCID: PMC6323977

96. Modeling sample variables with an Experimental Factor Ontology

James Malone, Ele Holloway, Tomasz Adamusiak, Misha Kapushesky, Jie Zheng, Nikolay Kolesnikov, Anna Zhukova, Alvis Brazma, Helen Parkinson

Bioinformatics (2010-04-15) https://doi.org/dsb6vt

DOI: 10.1093/bioinformatics/btq099 ·PMID: 20200009 ·PMCID: PMC2853691

97. GitHub - EBISPOT/EFO-UKB-mappings

GitHub

https://github.com/EBISPOT/EFO-UKB-mappings 
bioRxiv preprint doi: https://doi.org/10.1101/2021.07.05.450786; this version posted August 5, 2021. The copyright holder for this preprint (which was not certified by peer review) is the author/funder, who has granted bioRxiv a license to display the preprint in perpetuity. It is made available under aCC-BY 4.0 International license.

98. Comparing partitions

Lawrence Hubert, Phipps Arabie

Journal of Classification (1985-12) https://doi.org/lbphmzh

DOI: $10.1007 / \mathrm{bf01908075}$

99. Combining multiple clusterings using evidence accumulation

Ana L. N. Fred, Anil K. Jain

IEEE Transactions on Pattern Analysis and Machine Intelligence (2005-06) https://doi.org/bsknv6 DOI: $\underline{10.1109 / \text { tpami.2005.113 · PMID: } 15943417}$

100. Diversity control for improving the analysis of consensus clustering

Milton Pividori, Georgina Stegmayer, Diego H. Milone

Information Sciences (2016-09) https://doi.org/ghtgbk

DOI: $10.1016 / j$. ins.2016.04.027

101. A Link-Based Approach to the Cluster Ensemble Problem

Natthakan Iam-On, Tossapon Boongoen, Simon Garrett, Chris Price

IEEE Transactions on Pattern Analysis and Machine Intelligence (2011-12) https://doi.org/cqgkh3 DOI: 10.1109/tpami.2011.84 ·PMID: 21576752

102. Hybrid clustering solution selection strategy

Zhiwen Yu, Le Li, Yunjun Gao, Jane You, Jiming Liu, Hau-San Wong, Guoqiang Han

Pattern Recognition (2014-10) https://doi.org/ghtzwt

DOI: 10.1016/j.patcog.2014.04.005

103. UMAP: Uniform Manifold Approximation and Projection for Dimension Reduction

Leland McInnes, John Healy, James Melville

$\operatorname{arXiv}(2020-09-21)$ https://arxiv.org/abs/1802.03426

104. k-means++: the advantages of careful seeding

David Arthur, Sergei Vassilvitskii

Proceedings of the Eighteenth Annual ACM-SIAM Symposium on Discrete Algorithms (2007)

http://ilpubs.stanford.edu:8090/778/1/2006-13.pdf

105. On Spectral Clustering: Analysis and an algorithm

Andrew Ng, Michael Jordan, Yair Weiss

Advances in Neural Information Processing Systems (2001)

https://ai.stanford.edu/ ang/papers/nips01-spectral.pdf

106. A Density-Based Algorithm for Discovering Clusters in Large Spatial Databases with Noise Martin Ester, Hans-Peter Kriegel, Jörg Sander, Xiaowei Xu

Proceedings of the Second International Conference on Knowledge Discovery and Data Mining (1996) https://www.aaai.org/Papers/KDD/1996/KDD96-037.pdf

107. Optimized sgRNA design to maximize activity and minimize off-target effects of CRISPRCas9.

John G Doench, Nicolo Fusi, Meagan Sullender, Mudra Hegde, Emma W Vaimberg, Katherine F Donovan, Ian Smith, Zuzana Tothova, Craig Wilen, Robert Orchard, ... David E Root Nature biotechnology (2016-01-18) https://www.ncbi.nlm.nih.gov/pubmed/26780180 DOI: $10.1038 / \mathrm{nbt} .3437$ ·PMID: 26780180 ·PMCID: PMC4744125 


\section{Acknowledgements}

Figure 1 was created with BioRender.com.

\section{Supplementary material}

\section{CRISPR-screen}
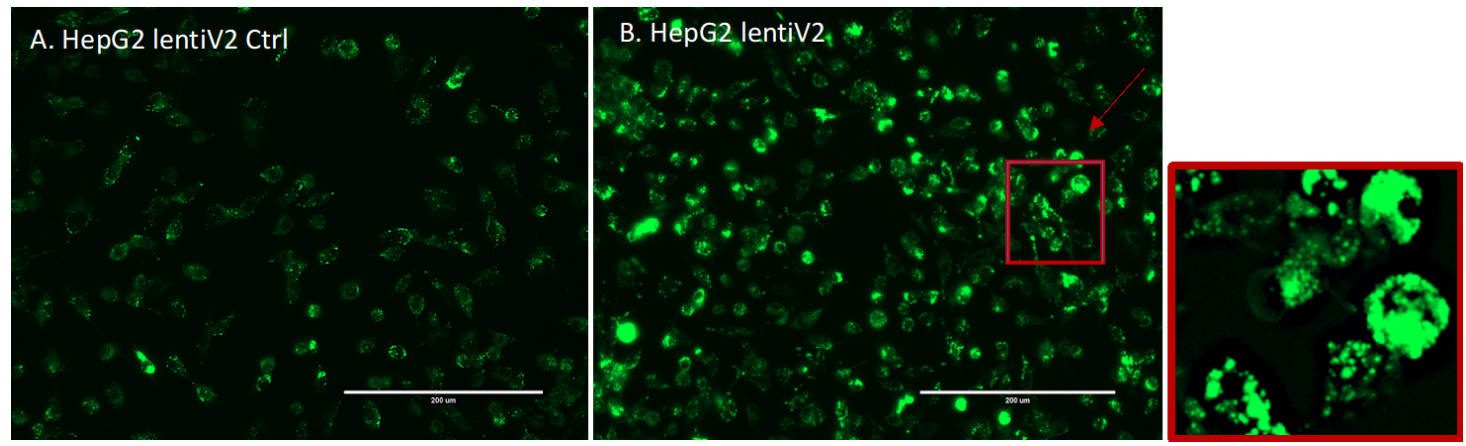

Figure 8: EVOS Fluorescent Microscope Image Capture. A. HepG2_lentiV2_Ctrl with no-viral transduction. B. HepG2_lentiV2 with viral transduction.

A
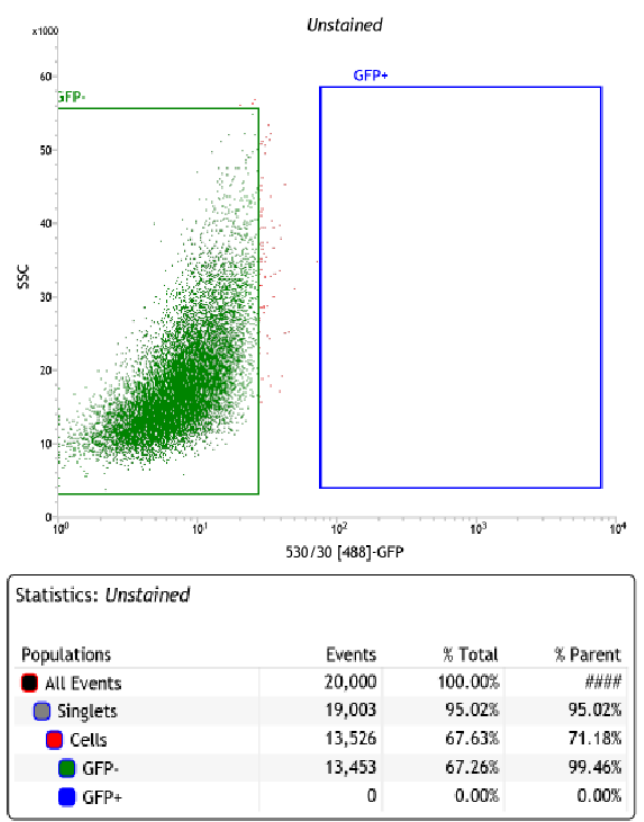

B
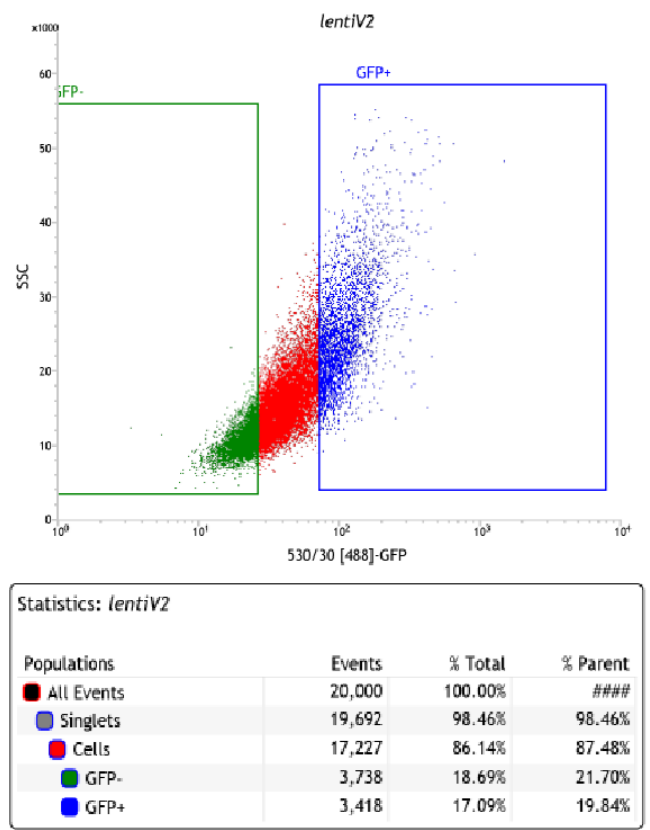

Figure 9: Fluorescence-Activated Cell Sorting Gate Setting. A. HepG2_UnStained WT. B. HepG2_lentiV2 with viral transduction. 
bioRxiv preprint doi: https://doi.org/10.1101/2021.07.05.450786; this version posted August 5, 2021. The copyright holder for this preprint (which was not certified by peer review) is the author/funder, who has granted bioRxiv a license to display the preprint in perpetuity. It is made available under aCC-BY 4.0 International license.

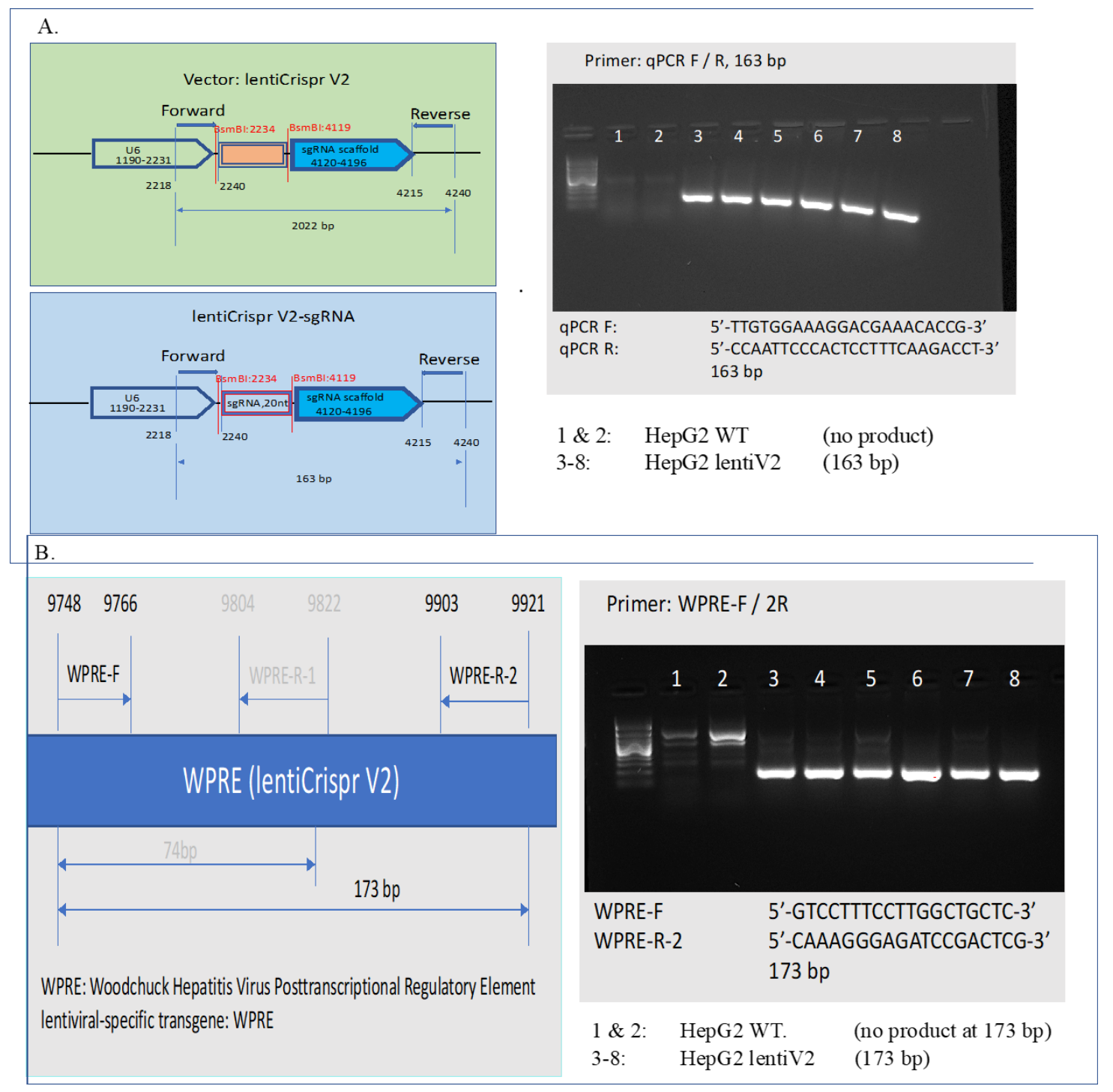

Figure 10: Verification of sgRNA cassette and lentiV2 transgene. A. 20nt sgRNA cassette was verified in lentiV2 transduced genomic DNA population, 163 bp PCR product obtained, while WT HepG2 didn't possess the cassette, thus, no PCR product. B. lentiviral-specific transgene WPRE was verified in lentiV2 transduced genomic DNA population, while no transduced WT didn't have the transgene, therefore, no 173 bp PCR product observed.

\section{Table 1. Primers for Generating Illumina Libraries}

P5/P7 flowcell attachment sequence

Illumina sequencing primer

Vector primer binding sequence

Stagger region / Barcode region

P5 primer :

5'AATGATACGGCGACCACCGAGATCTACACTCTTTCCCTACACGACGCTCTTCCGATCT[s]TTGTGGAAAGGACGAAACACCG

P7 primer:

5'CAAGCAGAAGACGGCATACGAGATNNNNNNNNGTGACTGGAGTTCAGACGTGTGCTCTTCCGATCTCCAATTCCCACTCCTTTCAAGACCT

\begin{tabular}{|l|c|}
\hline \multicolumn{2}{|c|}{ P5 Stagger Region sequences ([s]) } \\
\hline & $\begin{array}{c}\text { Stagger Sequence to include in P5 } \\
\text { primer, 5'-3' }\end{array}$ \\
\hline P5 0 nt & C \\
\hline P5 $\mathrm{nt}$ & $\mathrm{GC}$ \\
\hline P5 2 nt & AGC \\
\hline P5 3 nt & CAAC \\
\hline P5 4 nt & TGCACC \\
\hline P5 6 nt & ACGCAAC \\
\hline P5 7nt & GAAGACCC \\
\hline P5 8nt & \\
\hline
\end{tabular}

\begin{tabular}{|l|c|}
\hline \multicolumn{2}{|c|}{ P7 barcode (index) sequences (NNNNNNNN) } \\
\hline & Sequence to include in P7 primer, 5'-3' $^{\prime}$ \\
\hline P7-001 & CGGTTCAA \\
\hline P7-002 & GCTGGATT \\
\hline P7-003 & TAACTCGG \\
\hline P7-004 & TAACAGTT \\
\hline P7-005 & ATACTCAA \\
\hline P7-006 & GCTGAGAA \\
\hline P7-007 & ATTGGAGG \\
\hline P7-008 & TAGTCTAA \\
\hline P7-009 & CGGTGACC \\
\hline
\end{tabular}

Figure 11: 
bioRxiv preprint doi: https://doi.org/10.1101/2021.07.05.450786; this version posted August 5, 2021. The copyright holder for this preprint (which was not certified by peer review) is the author/funder, who has granted bioRxiv a license to display the preprint in perpetuity. It is made available under aCC-BY 4.0 International license.

\section{A. Construct For Illumina Library Generation}

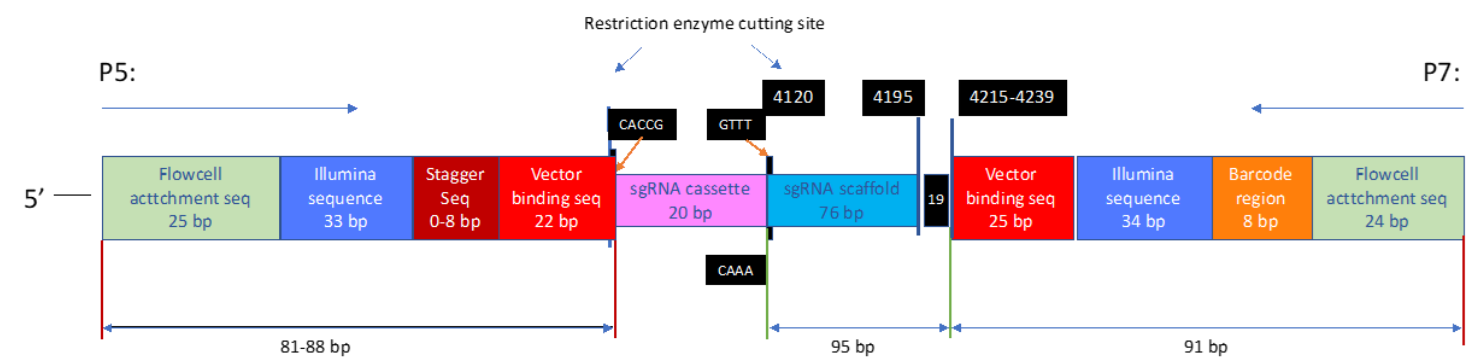

B. 2100 expert_High Sensitivity DNA Assay

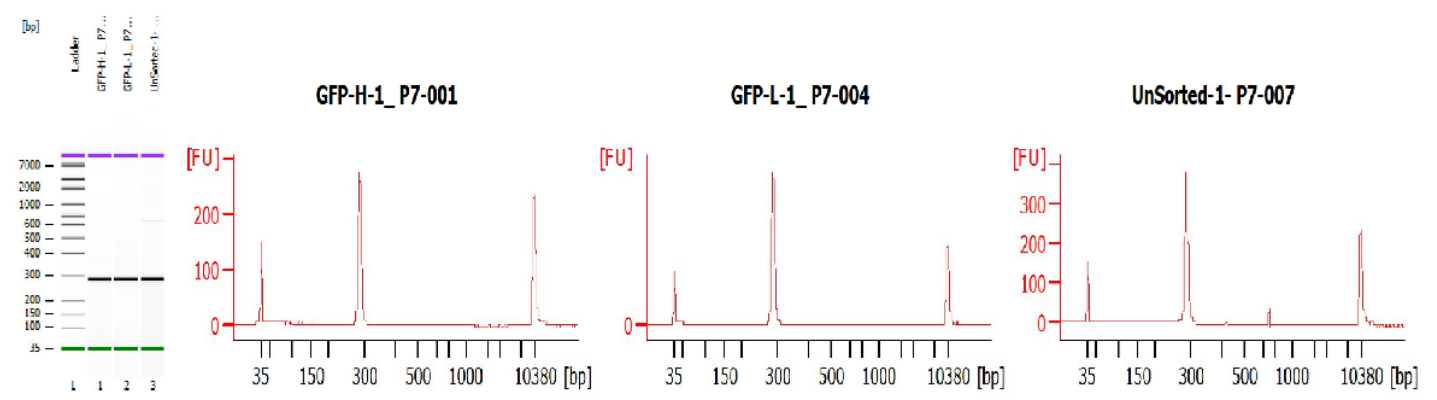

Figure 12: Illumina library generation. A. Construct for generating illumina libraries. B. Final illumina library from HS DNA — showed a single 285 bp peak was generated.

\section{LV603}

Table 2: Pathways aligned to LV603 from the MultiPLIER models.

\begin{tabular}{|l|l|l|}
\hline Pathway & AUC & FDR \\
\hline IRIS Neutrophil-Resting & 0.91 & $4.51 \mathrm{e}-35$ \\
\hline SVM Neutrophils & 0.98 & $1.43 \mathrm{e}-09$ \\
\hline PID IL8CXCR2 PATHWAY & 0.81 & $7.04 \mathrm{e}-03$ \\
\hline SIG PIP3 SIGNALING IN B LYMPHOCYTES & 0.77 & $1.95 \mathrm{e}-02$ \\
\hline
\end{tabular}

Table 3: Significant trait associations of LV603 in PhenomeXcan.

\begin{tabular}{|c|c|c|c|}
\hline Trait description & Sample size & Cases & FDR \\
\hline Myeloid White Cell Count & 173,480 & & $3.63 e-07$ \\
\hline Sum Basophil Neutrophil Count & 173,480 & & $4.07 e-07$ \\
\hline Neutrophil Count & 173,480 & & 4.17e-07 \\
\hline Sum Neutrophil Eosinophil Count & 173,480 & & $4.72 \mathrm{e}-07$ \\
\hline Granulocyte Count & 173,480 & & $5.16 \mathrm{e}-07$ \\
\hline White Blood Cell Count & 173,480 & & $2.67 e-06$ \\
\hline Neutrophill count & 349,856 & & $1.58 \mathrm{e}-05$ \\
\hline White blood cell (leukocyte) count & 350,470 & & $2.06 \mathrm{e}-05$ \\
\hline
\end{tabular}

Table 4: Significant trait associations of LV603 in eMERGE.

\begin{tabular}{|l|l|l|l|l|}
\hline Phecode & Trait description & Sample size & Cases & FDR \\
\hline
\end{tabular}


bioRxiv preprint doi: https://doi.org/10.1101/2021.07.05.450786; this version posted August 5, 2021. The copyright holder for this preprint (which was not certified by peer review) is the author/funder, who has granted bioRxiv a license to display the preprint in perpetuity. It is made available under aCC-BY 4.0 International license.

\begin{tabular}{|c|c|c|c|c|}
\hline Phecode & Trait description & Sample size & Cases & FDR \\
\hline No significant associations & & & & \\
\hline
\end{tabular}

\section{Gene modules enrichment for lipids gene-sets}

Table 5: Gene modules (LVs) nominally enriched for the lipids-increasing gene-set from the CRISPR-SCreen $(P<0.01)$. LVs significantly aligned with pathways (FDR < 0.05) from the MultiPLIER models are shown in boldface.

\begin{tabular}{|l|l|l|l|}
\hline Gene module & Lipids gene-set & Leading edge & p-value \\
\hline LV246 & increase & DGAT2, ACACA & 0.0035 \\
\hline LV702 & increase & ACACA, DGAT2 & 0.0046 \\
\hline LV607 & increase & ACACA, DGAT2 & 0.0058 \\
\hline LV890 & increase & ACACA, DGAT2 & 0.0067 \\
\hline LV74 & increase & MBTPS1, DGAT2 & 0.0078 \\
\hline LV865 & increase & ACACA, DGAT2 & 0.0092 \\
\hline LV841 & increase & ACACA, DGAT2 & 0.0096 \\
\hline
\end{tabular}

Table 6: Gene modules (LVs) nominally enriched for the lipids-decreasing gene-set from the CRISPR-screen $(P<0.01)$. LVs significantly aligned with pathways (FDR < 0.05) from the MultiPLIER models are shown in boldface.

\begin{tabular}{|l|l|l|l|}
\hline Gene module & Lipids gene-set & Leading edge & p-value \\
\hline LV520 & decrease & FBXW7, TCF7L2 & 0.0006 \\
\hline LV801 & decrease & UBE2J2, TCF7L2 & 0.0022 \\
\hline LV512 & decrease & FBXW7, TCF7L2 & 0.0025 \\
\hline LV612 & decrease & PTEN, FBXW7 & 0.0036 \\
\hline LV41 & decrease & PCYT2, TCF7L2 & 0.0041 \\
\hline LV838 & decrease & UBE2J2, TCF7L2 & 0.0070 \\
\hline LV302 & decrease & TCF7L2, PTEN & 0.0083 \\
\hline LV959 & decrease & TCF7L2, PTEN & 0.0092 \\
\hline
\end{tabular}

\section{LV246}

Table 7: Pathways aligned to LV246 from the MultiPLIER models.

\begin{tabular}{|l|l|l|}
\hline Pathway & AUC & FDR \\
\hline REACTOME FATTY ACID TRIACYLGLYCEROL AND KETONE BODY METABOLISM & 0.89 & $3.97 \mathrm{e}-16$ \\
\hline REACTOME METABOLISM OF LIPIDS AND LIPOPROTEINS & 0.67 & $1.14 \mathrm{e}-08$ \\
\hline REACTOME TRIGLYCERIDE BIOSYNTHESIS & 0.86 & $6.52 \mathrm{e}-04$ \\
\hline KEGG PYRUVATE METABOLISM & 0.82 & $2.66 \mathrm{e}-03$ \\
\hline KEGG PROPANOATE METABOLISM & 0.83 & $4.27 \mathrm{e}-03$ \\
\hline
\end{tabular}

Table 8: Significant trait associations of LV246 in PhenomeXcan. 
bioRxiv preprint doi: https://doi.org/10.1101/2021.07.05.450786; this version posted August 5, 2021. The copyright holder for this preprint (which was not certified by peer review) is the author/funder, who has granted bioRxiv a license to display the preprint in perpetuity. It is made available under aCC-BY 4.0 International license.

\begin{tabular}{|c|c|c|c|}
\hline Trait description & Sample size & Cases & FDR \\
\hline CH2DB NMR & 24,154 & & $1.05 \mathrm{e}-12$ \\
\hline High cholesterol (self-reported) & 361,141 & 43,957 & $7.78 \mathrm{e}-07$ \\
\hline Ankle spacing width & 206,589 & & $2.06 \mathrm{e}-05$ \\
\hline Ankle spacing width (right) & 114,614 & & $9.03 e-05$ \\
\hline HDL Cholesterol NMR & 19,270 & & $2.46 \mathrm{e}-04$ \\
\hline Cholesterol lowering medication & 193,148 & 24,247 & $2.54 \mathrm{e}-04$ \\
\hline Ankle spacing width (left) & 114,630 & & $5.39 e-04$ \\
\hline Fasting Glucose & 46,186 & & $1.90 \mathrm{e}-03$ \\
\hline Cholesterol lowering medication & 165,340 & 38,057 & $6.74 \mathrm{e}-03$ \\
\hline Pulse rate, automated reading & 340,162 & & $8.61 \mathrm{e}-03$ \\
\hline Recent easy annoyance or irritability & 117,483 & & $1.04 \mathrm{e}-02$ \\
\hline Treatment/medication code: simvastatin & 361,141 & 40,921 & $1.11 \mathrm{e}-02$ \\
\hline Pulse rate & 118,850 & & $1.19 \mathrm{e}-02$ \\
\hline Mean platelet (thrombocyte) volume & 350,470 & & $1.37 e-02$ \\
\hline Duration of moderate activity & 268,826 & & $1.69 \mathrm{e}-02$ \\
\hline LDL Cholesterol NMR & 13,527 & & $1.94 \mathrm{e}-02$ \\
\hline Red blood cell (erythrocyte) distribution width & 350,473 & & $1.99 \mathrm{e}-02$ \\
\hline Intra-ocular pressure, corneal-compensated (right) & 76,630 & & $2.63 e-02$ \\
\hline Heel bone mineral density (BMD) (right) & 114,552 & & $2.74 \mathrm{e}-02$ \\
\hline Triglycerides NMR & 21,559 & & $3.47 e-02$ \\
\hline Heel bone mineral density T-score, automated (right) & 114,614 & & $3.75 e-02$ \\
\hline Heel quantitative ultrasound index, direct entry (right) & 114,614 & & $3.75 e-02$ \\
\hline Days/week of moderate physical activity $10+$ minutes & 343,943 & & $4.85 \mathrm{e}-02$ \\
\hline Ischaemic heart disease (wide definition) & 361,194 & 20,857 & $4.97 e-02$ \\
\hline
\end{tabular}

Table 9: Significant trait associations of LV246 in eMERGE.

\begin{tabular}{|l|l|l|l|l|}
\hline Phecode & Trait description & Sample size & Cases & FDR \\
\hline 276.41 & Acidosis & 41,838 & 1,526 & $2.40 \mathrm{e}-03$ \\
\hline 276.4 & Acid-base balance disorder & 42,005 & 1,693 & $2.97 \mathrm{e}-03$ \\
\hline
\end{tabular}

\section{LV116}

Table 10: Pathways aligned to LV116 from the MultiPLIER models.

\begin{tabular}{|l|l|l|}
\hline Pathway & AUC & FDR \\
\hline REACTOME INTERFERON SIGNALING & 0.84 & $3.48 \mathrm{e}-09$ \\
\hline SVM Macrophages M1 & 0.92 & $2.09 \mathrm{e}-05$ \\
\hline REACTOME INTERFERON ALPHA BETA SIGNALING & 0.94 & $3.36 \mathrm{e}-05$ \\
\hline
\end{tabular}


bioRxiv preprint doi: https://doi.org/10.1101/2021.07.05.450786; this version posted August 5, 2021. The copyright holder for this preprint (which was not certified by peer review) is the author/funder, who has granted bioRxiv a license to display the preprint in perpetuity. It is made available under aCC-BY 4.0 International license.

\begin{tabular}{|l|l|l|}
\hline Pathway & AUC & FDR \\
\hline REACTOME CYTOKINE SIGNALING IN IMMUNE SYSTEM & 0.67 & $1.53 \mathrm{e}-04$ \\
\hline IRIS DendriticCelI-LPSstimulated & 0.65 & $1.09 \mathrm{e}-03$ \\
\hline KEGG CYTOSOLIC DNA SENSING PATHWAY & 0.84 & $3.22 \mathrm{e}-03$ \\
\hline REACTOME NEGATIVE REGULATORS OF RIG I MDA5 SIGNALING & 0.81 & $1.61 \mathrm{e}-02$ \\
\hline
\end{tabular}

\section{LV931}

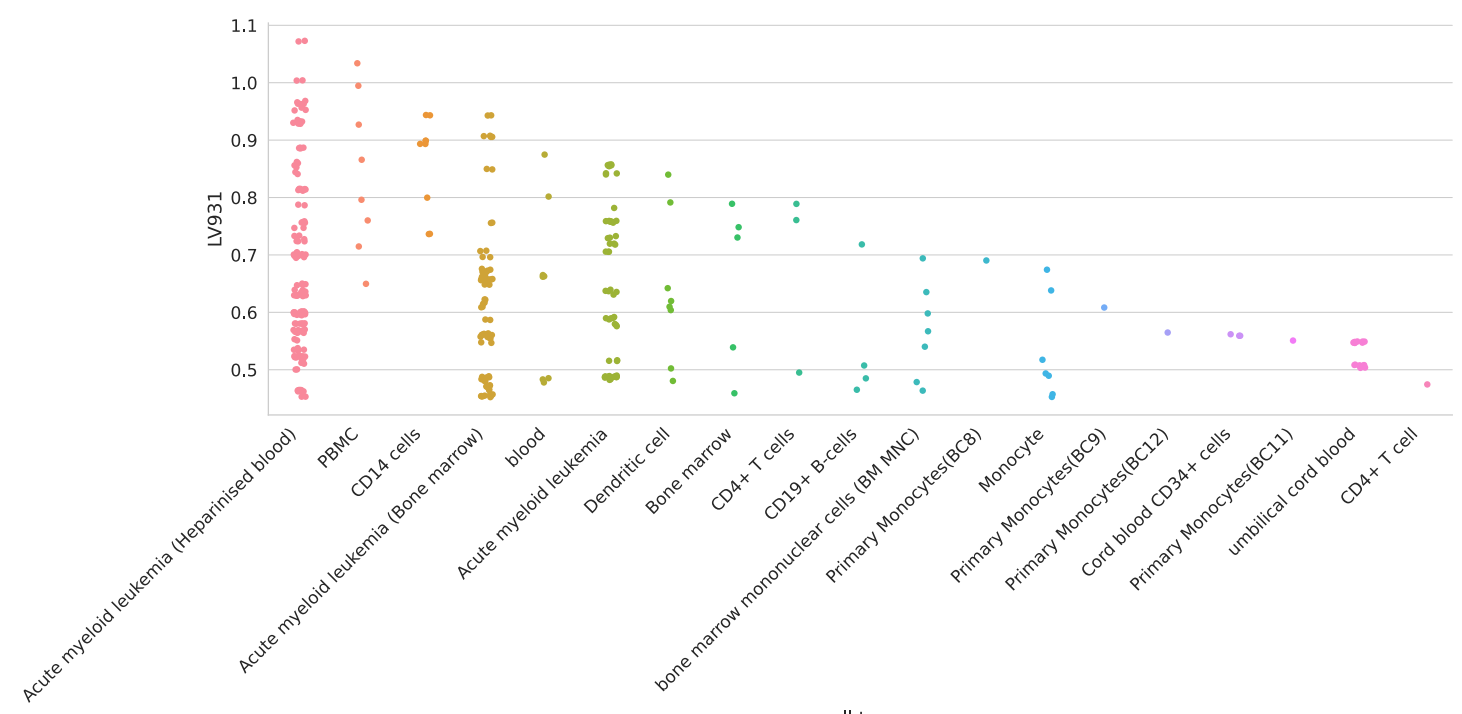

cell type

Figure 13: Cell types for LV931.

Table 11: Pathways aligned to LV931 from the MultiPLIER models.

\begin{tabular}{|l|l|l|}
\hline Pathway & AUC & FDR \\
\hline MIPS SPLICEOSOME & 0.63 & $3.13 \mathrm{e}-02$ \\
\hline PID TGFBRPATHWAY & 0.71 & $3.99 \mathrm{e}-02$ \\
\hline
\end{tabular}

\section{LV66}

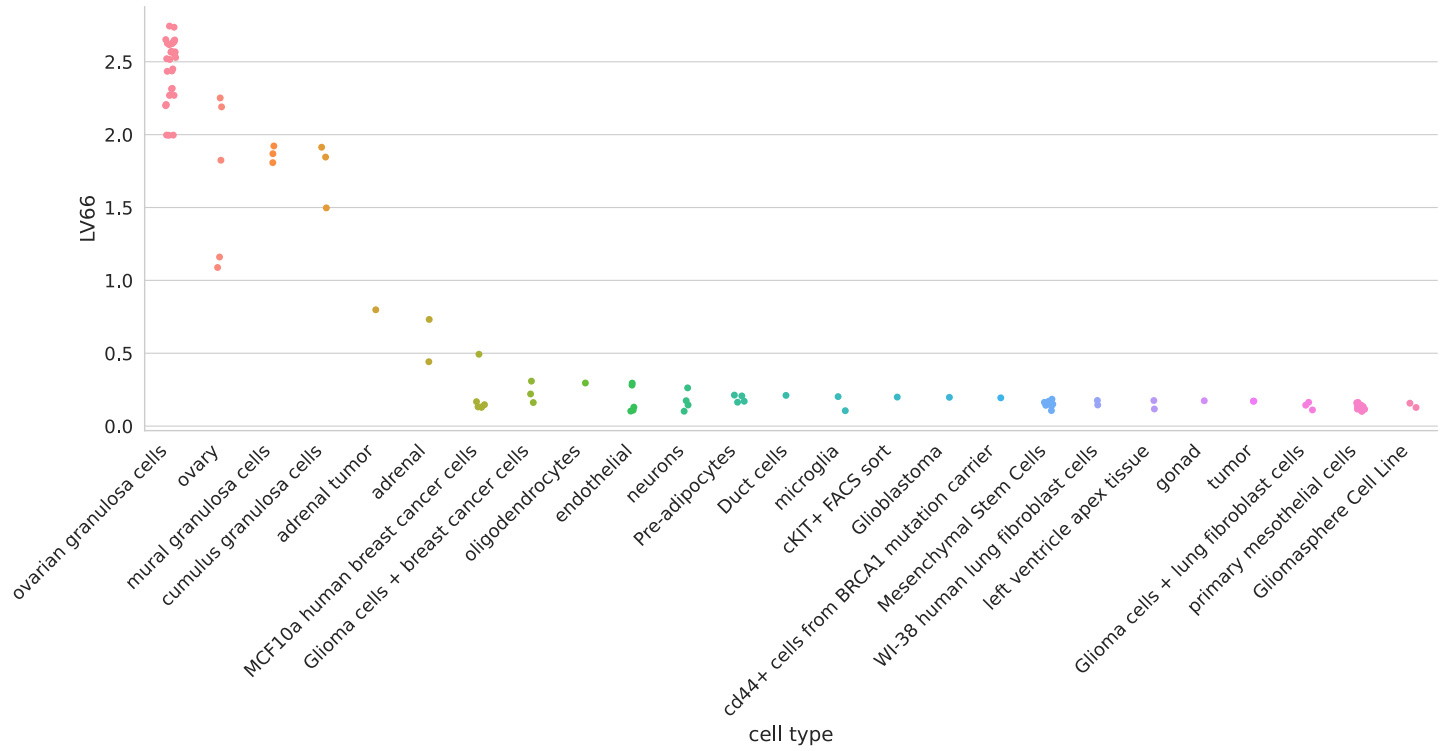

Figure 14: Cell types for LV66. 
bioRxiv preprint doi: https://doi.org/10.1101/2021.07.05.450786; this version posted August 5 , 2021. The copyright holder for this preprint (which was not certified by peer review) is the author/funder, who has granted bioRxiv a license to display the preprint in perpetuity. It is made available under aCC-BY 4.0 International license.

Table 12: Pathways aligned to LV66 from the MultiPLIER models.

\begin{tabular}{|l|l|l|}
\hline Pathway & AUC & FDR \\
\hline REACTOME METABOLISM OF LIPIDS AND LIPOPROTEINS & 0.62 & $3.12 \mathrm{e}-04$ \\
\hline
\end{tabular}

\section{Agreement of consensus clustering partitions with the ensemble by number of clusters}

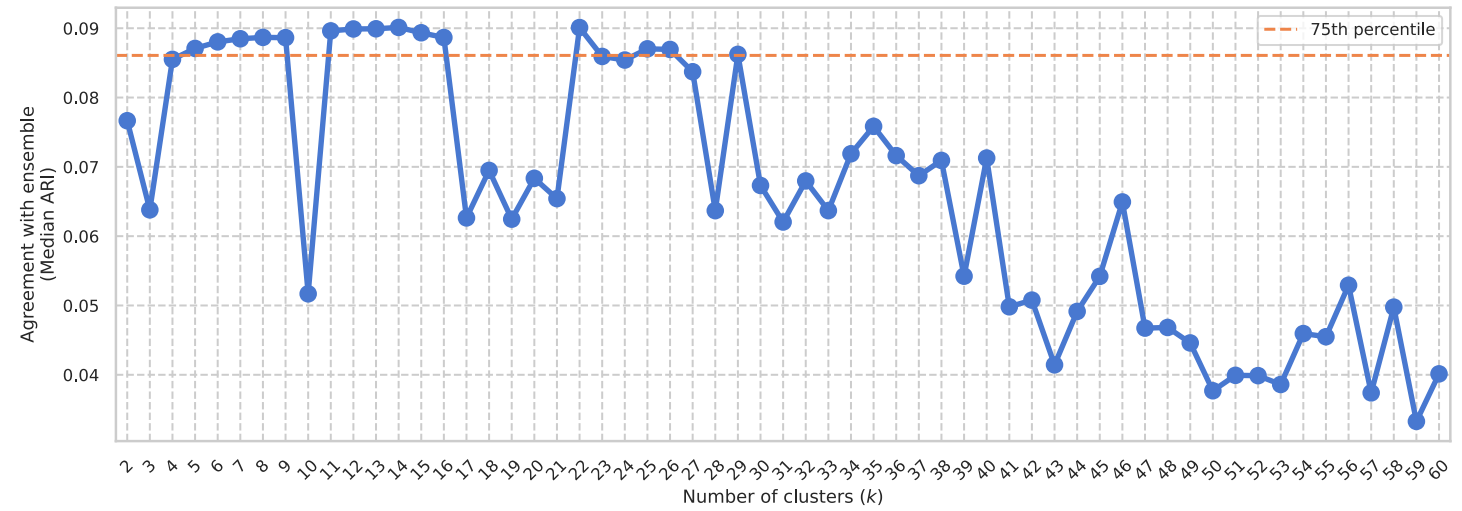

Figure 15: Final selected partitions for follow-up analysis. From all consensus clustering partitions generated with $k$ from 2 to 60, we selected those with a median adjusted Rand index (ARI) with the ensemble members greater the 75th percentile.

\section{Cluster-specific and general transcriptional processes associated with disease}


bioRxiv preprint doi: https://doi.org/10.1101/2021.07.05.450786; this version posted August 5, 2021. The copyright holder for this preprint

(which was not certified by peer review) is the author/funder, who has granted bioRxiv a license to display the preprint in perpetuity. It is made available under aCC-BY 4.0 International license.

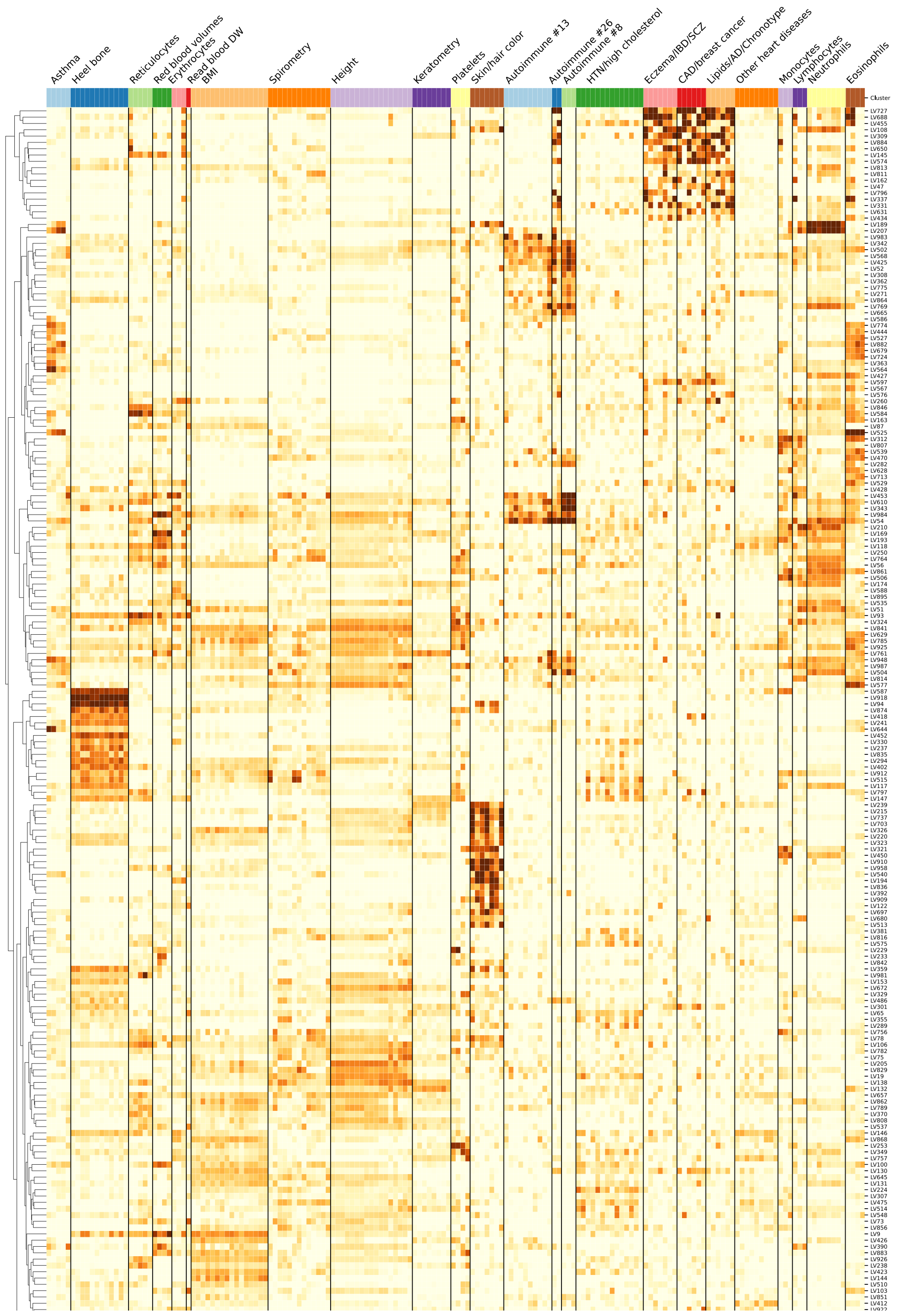


bioRxiv preprint doi: https://doi.org/10.1101/2021.07.05.450786; this version posted August 5, 2021. The copyright holder for this preprint (which was not certified by peer review) is the author/funder, who has granted bioRxiv a license to display the preprint in perpetuity. It is made available under aCC-BY 4.0 International license.

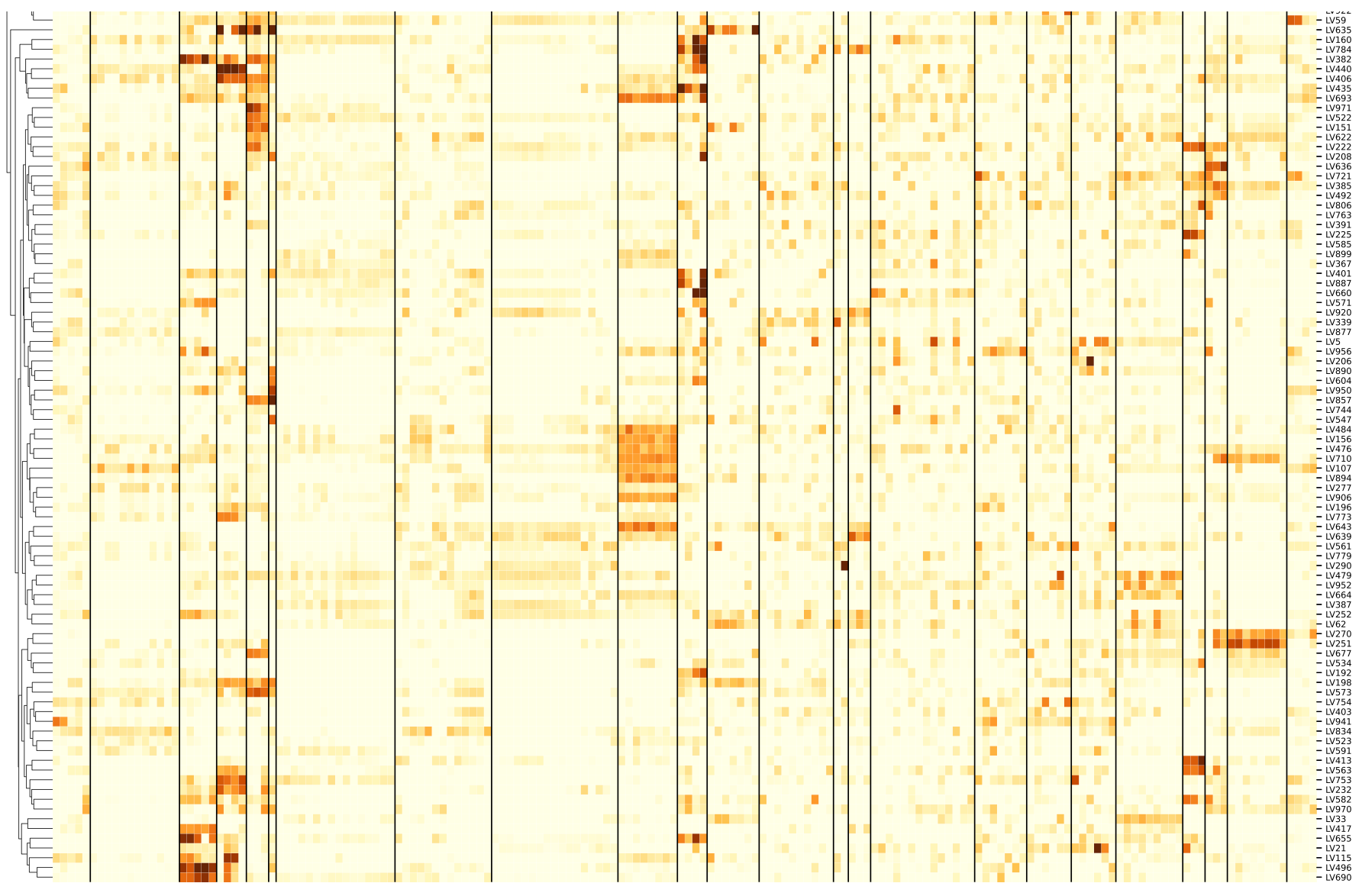

Figure 16: Cluster-specific and general transcriptional processes associated with disease using novel LVs. The plot shows a submatrix of $\hat{\mathbf{M}}$ for the main trait clusters at $k=29$, considering only LVs (rows) that are not aligned with any pathway. Standardized values from -6 (lighter color) to 21 (darker color).

\section{LV928}
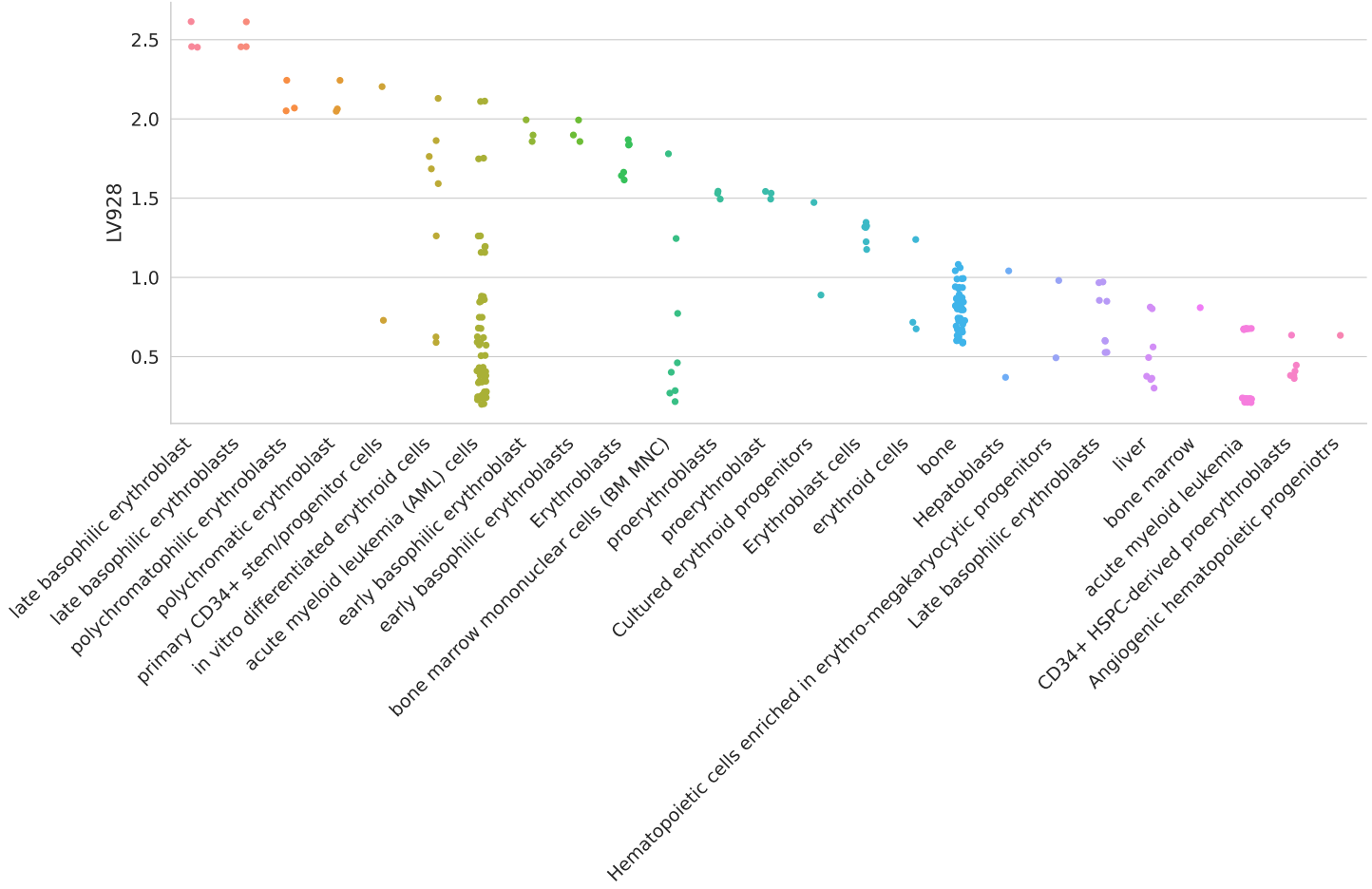

cell type

Figure 17: Cell types for LV928.

Table 13: Pathways aligned to LV928 from the MultiPLIER models. 
bioRxiv preprint doi: https://doi.org/10.1101/2021.07.05.450786; this version posted August 5, 2021. The copyright holder for this preprint (which was not certified by peer review) is the author/funder, who has granted bioRxiv a license to display the preprint in perpetuity. It is made available under aCC-BY 4.0 International license.

\begin{tabular}{|l|l|l|}
\hline Pathway & AUC & FDR \\
\hline DMAP ERY3 & 0.81 & $1.16 \mathrm{e}-24$ \\
\hline DMAP ERY4 & 0.78 & $2.49 \mathrm{e}-17$ \\
\hline
\end{tabular}

Table 14: Significant trait associations of LV928 in PhenomeXcan.

\begin{tabular}{|c|c|c|c|c|}
\hline Trait description & Sample size & Cases & Partition / cluster & FDR \\
\hline Mean sphered cell volume & 344,729 & & $29 / 2$ & $2.18 e-46$ \\
\hline Mean reticulocyte volume & 344,728 & & $29 / 2$ & $4.08 e-44$ \\
\hline Mean corpuscular volume & 350,473 & & $29 / 2$ & $5.57 e-33$ \\
\hline Red blood cell (erythrocyte) distribution width & 350,473 & & $29 / 23$ & $7.62 \mathrm{e}-31$ \\
\hline Reticulocyte percentage & 344,728 & & $29 / 4$ & $2.12 \mathrm{e}-29$ \\
\hline Reticulocyte count & 344,729 & & $29 / 4$ & $6.88 \mathrm{e}-28$ \\
\hline Reticulocyte Count & 173,480 & & $29 / 4$ & $1.06 \mathrm{e}-23$ \\
\hline Mean corpuscular haemoglobin & 350,472 & & $29 / 2$ & $7.89 \mathrm{e}-23$ \\
\hline High light scatter reticulocyte count & 344,729 & & $29 / 4$ & $3.05 e-21$ \\
\hline Immature reticulocyte fraction & 344,728 & & $29 / 4$ & $5.04 \mathrm{e}-21$ \\
\hline High light scatter reticulocyte percentage & 344,729 & & $29 / 4$ & $1.57 e-16$ \\
\hline Red blood cell (erythrocyte) count & 350,475 & & $29 / 5$ & $2.53 e-16$ \\
\hline Red Blood Cell Count & 173,480 & & $29 / 5$ & $2.62 \mathrm{e}-09$ \\
\hline Haemoglobin concentration & 350,474 & & $29 / 5$ & $1.25 \mathrm{e}-03$ \\
\hline Haematocrit percentage & 350,475 & & $29 / 5$ & $3.77 e-03$ \\
\hline
\end{tabular}

Table 15: Significant trait associations of LV928 in eMERGE.

\begin{tabular}{|l|l|l|l|l|}
\hline Phecode & Trait description & Sample size & Cases & FDR \\
\hline 250.24 & Type 2 diabetes with neurological manifestations & 43,236 & 2,963 & $1.44 \mathrm{e}-02$ \\
\hline 195 & Cancer, suspected or other & 50,040 & 2,250 & $2.42 \mathrm{e}-02$ \\
\hline 514.2 & Solitary pulmonary nodule & 50,389 & 2,270 & $4.65 \mathrm{e}-02$ \\
\hline
\end{tabular}


bioRxiv preprint doi: https://doi.org/10.1101/2021.07.05.450786; this version posted August 5, 2021. The copyright holder for this preprint (which was not certified by peer review) is the author/funder, who has granted bioRxiv a license to display the preprint in perpetuity. It is made available under aCC-BY 4.0 International license.

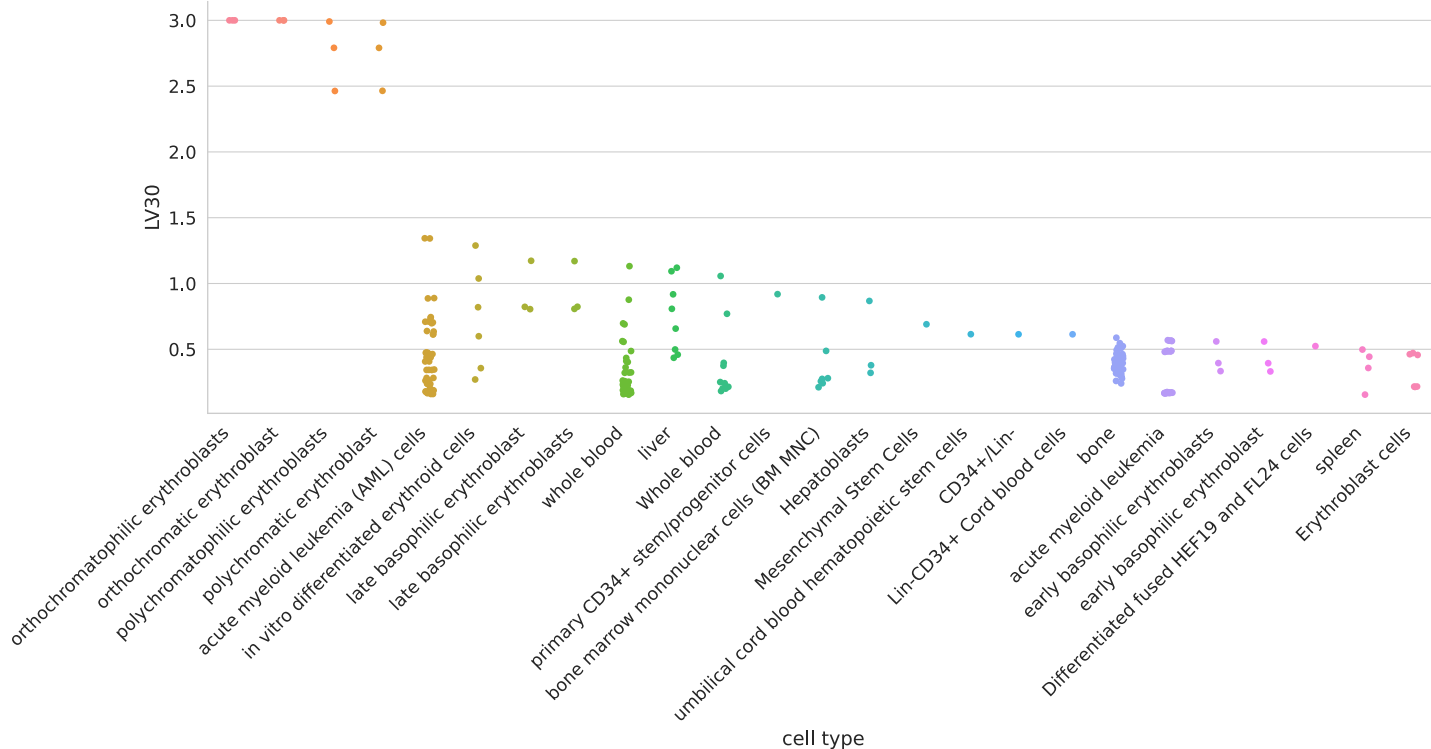

Figure 18: Cell types for LV30.

Table 16: Pathways aligned to LV30 from the MultiPLIER models.

\begin{tabular}{|l|l|l|}
\hline Pathway & AUC & FDR \\
\hline DMAP ERY3 & 0.95 & $5.62 \mathrm{e}-52$ \\
\hline DMAP ERY4 & 0.98 & $5.28 \mathrm{e}-51$ \\
\hline DMAP ERY5 & 0.98 & $1.96 \mathrm{e}-49$ \\
\hline
\end{tabular}

Table 17: Significant trait associations of LV30 in PhenomeXcan.

\begin{tabular}{|c|c|c|c|c|}
\hline Trait description & Sample size & Cases & Partition / cluster & FDR \\
\hline Mean reticulocyte volume & 344,728 & & $29 / 2$ & $1.41 e-51$ \\
\hline Immature reticulocyte fraction & 344,728 & & $29 / 4$ & $5.79 e-40$ \\
\hline Mean sphered cell volume & 344,729 & & $29 / 2$ & $3.26 \mathrm{e}-36$ \\
\hline Mean corpuscular volume & 350,473 & & $29 / 2$ & $3.18 \mathrm{e}-35$ \\
\hline Reticulocyte percentage & 344,728 & & $29 / 4$ & $1.41 \mathrm{e}-28$ \\
\hline Mean corpuscular haemoglobin & 350,472 & & $29 / 2$ & $3.72 \mathrm{e}-28$ \\
\hline High light scatter reticulocyte count & 344,729 & & $29 / 4$ & $8.20 \mathrm{e}-28$ \\
\hline Reticulocyte count & 344,729 & & $29 / 4$ & $2.13 e-26$ \\
\hline Reticulocyte Count & 173,480 & & $29 / 4$ & $1.11 \mathrm{e}-24$ \\
\hline High light scatter reticulocyte percentage & 344,729 & & $29 / 4$ & $4.05 e-22$ \\
\hline
\end{tabular}

Table 18: Significant trait associations of LV30 in eMERGE.

\begin{tabular}{|l|l|l|l|l|}
\hline Phecode & Trait description & Sample size & Cases & FDR \\
\hline No significant associations & & & & \\
\hline
\end{tabular}


bioRxiv preprint doi: https://doi.org/10.1101/2021.07.05.450786; this version posted August 5, 2021. The copyright holder for this preprint (which was not certified by peer review) is the author/funder, who has granted bioRxiv a license to display the preprint in perpetuity. It is made available under aCC-BY 4.0 International license.

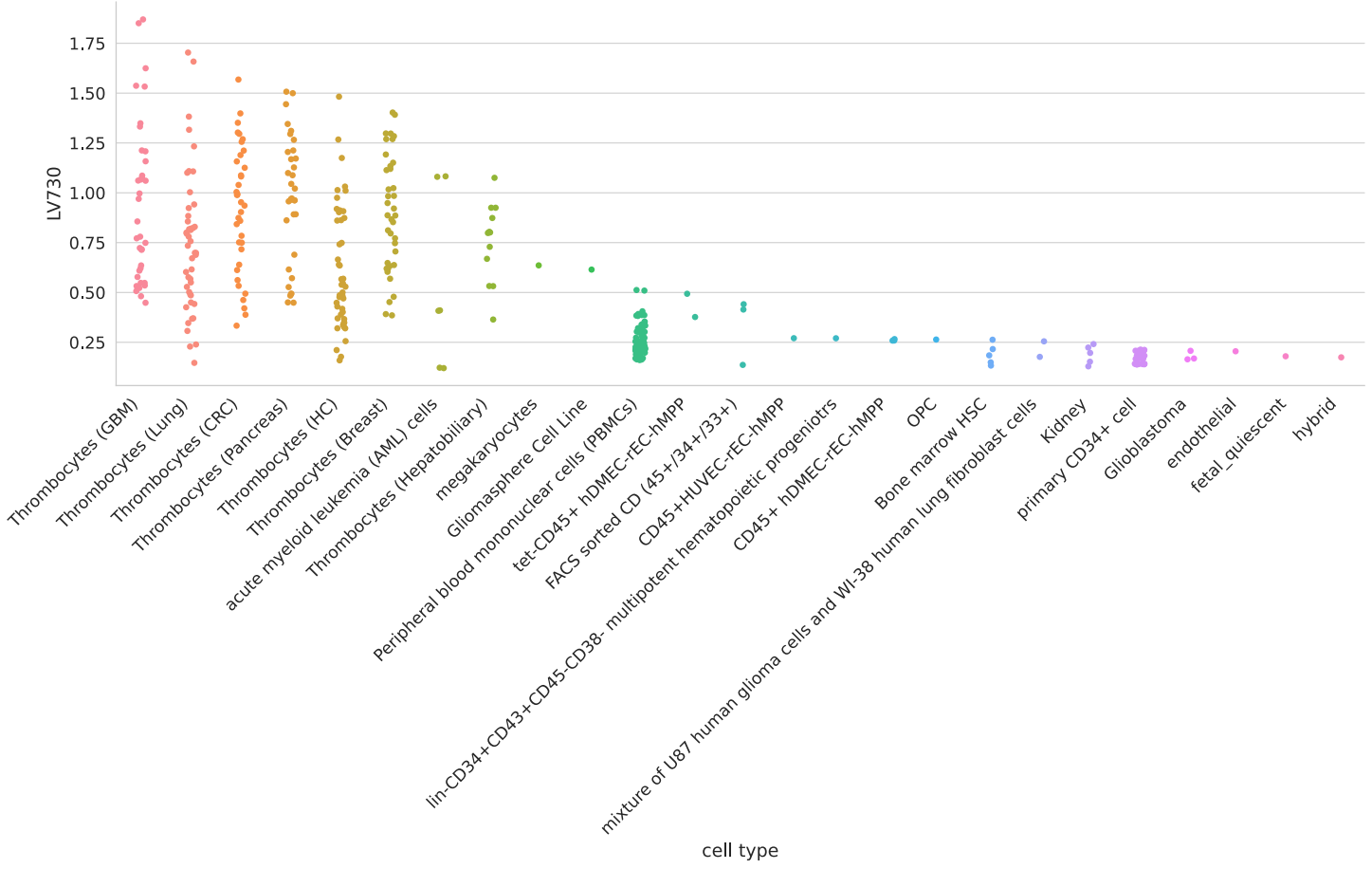

Figure 19: Cell types for LV730.

Table 19: Pathways aligned to LV730 from the MultiPLIER models.

\begin{tabular}{|l|l|l|}
\hline Pathway & AUC & FDR \\
\hline DMAP MEGA2 & 0.82 & $2.64 \mathrm{e}-05$ \\
\hline
\end{tabular}

Table 20: Significant trait associations of LV730 in PhenomeXcan.

\begin{tabular}{|l|l|l|l|l|}
\hline Trait description & Sample size & Cases & Partition / cluster & FDR \\
\hline Platelet distribution width & 350,470 & & $29 / 1$ & $2.88 \mathrm{e}-13$ \\
\hline Mean platelet (thrombocyte) volume & 350,470 & & $29 / 1$ & $7.26 \mathrm{e}-13$ \\
\hline Platelet count & 350,474 & $29 / 1$ & $1.24 \mathrm{e}-07$ \\
\hline Platelet Count & 173,480 & & $29 / 1$ & $1.21 \mathrm{e}-06$ \\
\hline Platelet crit & 350,471 & & $29 / 1$ & $1.38 \mathrm{e}-04$ \\
\hline
\end{tabular}

Table 21: Significant trait associations of LV730 in eMERGE.

\begin{tabular}{|l|l|l|l|l|}
\hline Phecode & Trait description & Sample size & Cases & FDR \\
\hline No significant associations & & & & \\
\hline
\end{tabular}

\section{LV598}


bioRxiv preprint doi: https://doi.org/10.1101/2021.07.05.450786; this version posted August 5, 2021. The copyright holder for this preprint (which was not certified by peer review) is the author/funder, who has granted bioRxiv a license to display the preprint in perpetuity. It is made available under aCC-BY 4.0 International license.

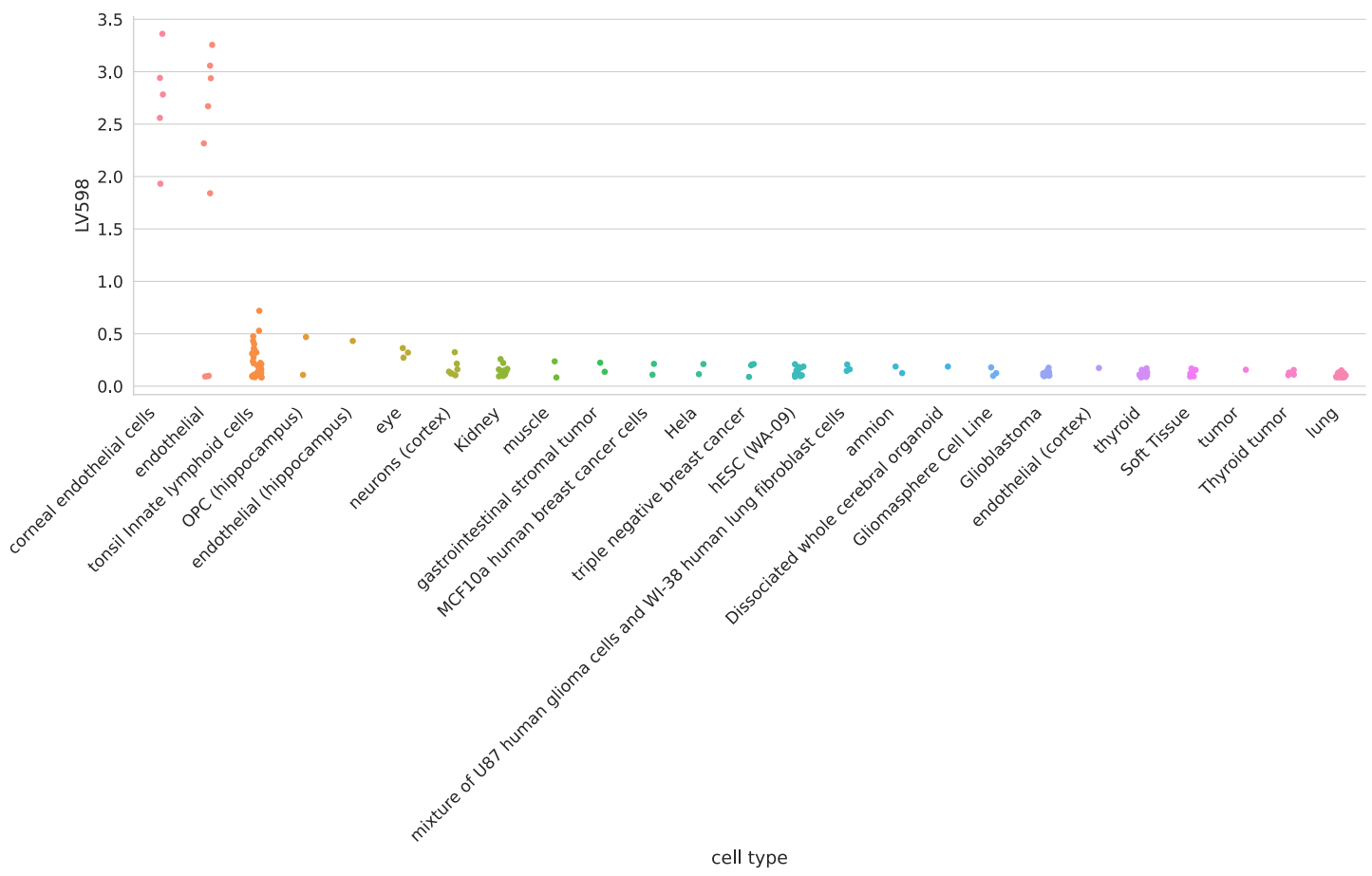

Figure 20: Cell types for LV598.

Table 22: Pathways aligned to LV598 from the MultiPLIER models.

\begin{tabular}{|l|l|l|}
\hline Pathway & AUC & FDR \\
\hline PID SYNDECAN 1 PATHWAY & 0.81 & $1.20 \mathrm{e}-02$ \\
\hline REACTOME COLLAGEN FORMATION & 0.77 & $1.89 \mathrm{e}-02$ \\
\hline
\end{tabular}

Table 23: Significant trait associations of LV598 in PhenomeXcan.

\begin{tabular}{|c|c|c|c|c|}
\hline Trait description & Sample size & Cases & Partition / cluster & FDR \\
\hline 6mm strong meridian (right) & 66,256 & & $29 / 10$ & $3.21 \mathrm{e}-07$ \\
\hline 6mm weak meridian (right) & 66,256 & & $29 / 10$ & $2.04 \mathrm{e}-06$ \\
\hline $6 \mathrm{~mm}$ strong meridian (left) & 65,551 & & $29 / 10$ & $2.44 \mathrm{e}-06$ \\
\hline 3mm strong meridian (left) & 75,398 & & $29 / 10$ & $2.53 e-06$ \\
\hline $6 \mathrm{~mm}$ weak meridian (left) & 65,551 & & $29 / 10$ & $1.20 \mathrm{e}-05$ \\
\hline $3 \mathrm{~mm}$ weak meridian (left) & 75,398 & & $29 / 10$ & $1.58 \mathrm{e}-05$ \\
\hline $3 \mathrm{~mm}$ strong meridian (right) & 75,410 & & $29 / 10$ & $2.95 e-05$ \\
\hline $3 \mathrm{~mm}$ weak meridian (right) & 75,410 & & $29 / 10$ & $3.86 \mathrm{e}-05$ \\
\hline
\end{tabular}

Table 24: Significant trait associations of LV598 in eMERGE.

\begin{tabular}{|c|c|c|c|c|}
\hline Phecode & Trait description & Sample size & Cases & FDR \\
\hline No significant associations & & & & \\
\hline
\end{tabular}

\section{LV844}


bioRxiv preprint doi: https://doi.org/10.1101/2021.07.05.450786; this version posted August 5, 2021. The copyright holder for this preprint (which was not certified by peer review) is the author/funder, who has granted bioRxiv a license to display the preprint in perpetuity. It is made available under aCC-BY 4.0 International license.

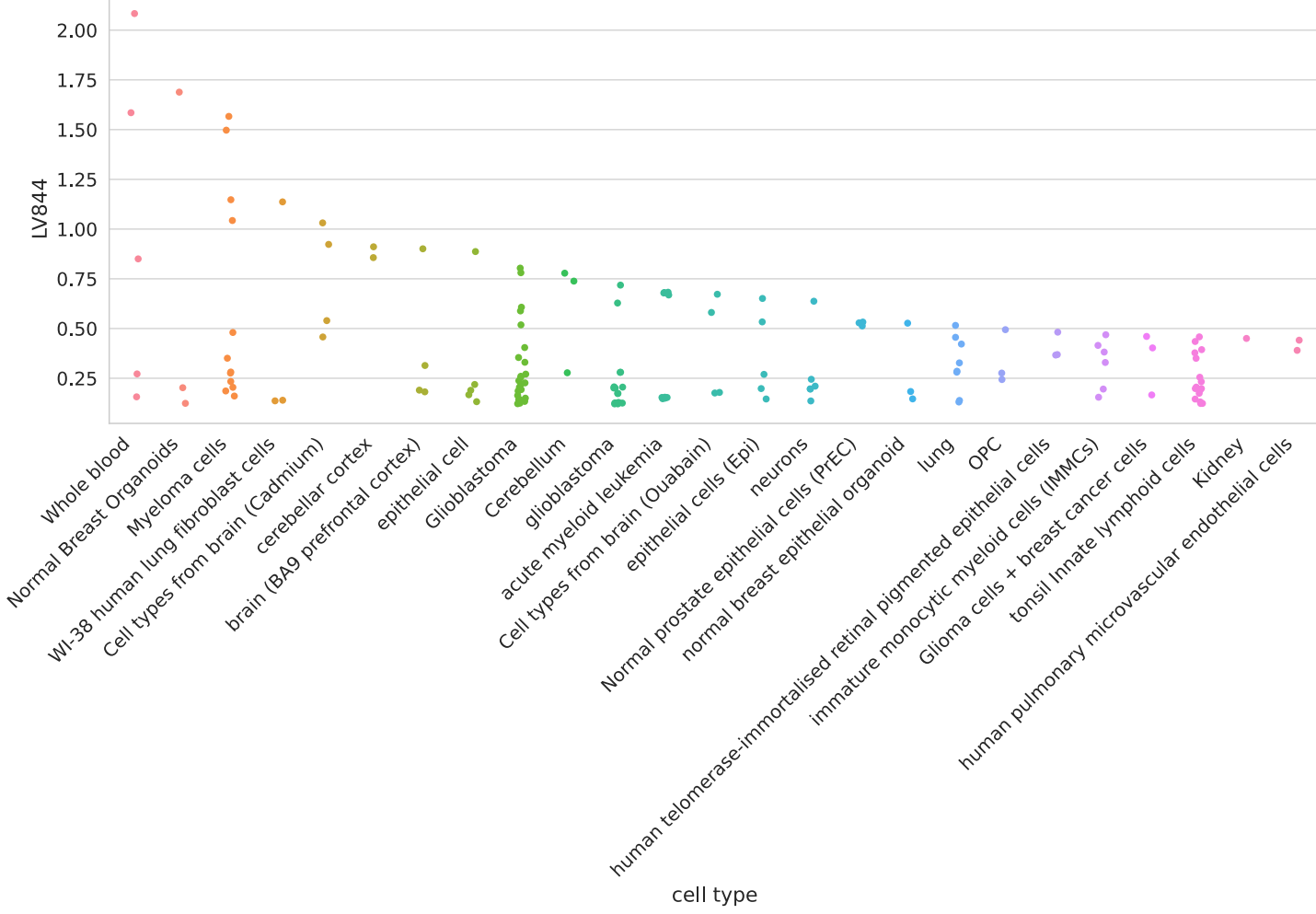

Figure 21: Cell types for LV844.

Table 25: Pathways aligned to LV844 from the MultiPLIER models.

\begin{tabular}{|l|l|l|}
\hline Pathway & AUC & FDR \\
\hline KEGG ANTIGEN PROCESSING AND PRESENTATION & 0.80 & $1.35 \mathrm{e}-03$ \\
\hline
\end{tabular}

Table 26: Significant trait associations of LV844 in PhenomeXcan.

\begin{tabular}{|l|l|l|l|l|}
\hline Trait description & Sample size & Cases & Partition / cluster & FDR \\
\hline Rheumatoid Arthritis & 80,799 & $\begin{array}{l}19,23 \\
4\end{array}$ & $29 / 26$ & $1.20 \mathrm{e}-57$ \\
\hline malabsorption/coeliac disease (self-reported) & 361,141 & 1,587 & $29 / 8$ & $1.25 \mathrm{e}-43$ \\
\hline Coeliac disease & 361,194 & 842 & $29 / 8$ & $1.52 \mathrm{e}-41$ \\
\hline Intestinal malabsorption (ICD10 K90) & 361,194 & 922 & $29 / 8$ & $5.28 \mathrm{e}-40$ \\
\hline Started insulin within one year diagnosis of diabetes & 16,415 & 1,999 & $29 / 13$ & $7.77 \mathrm{e}-38$ \\
\hline Systemic Lupus Erythematosus & 23,210 & 7,219 & $29 / 26$ & $6.45 \mathrm{e}-35$ \\
\hline Age diabetes diagnosed & 16,166 & & $29 / 13$ & $1.92 \mathrm{e}-34$ \\
\hline Never eat: Wheat products & 359,777 & 9,573 & $29 / 13$ & $1.37 \mathrm{e}-31$ \\
\hline hyperthyroidism (self-reported) & 361,141 & 2,730 & $29 / 13$ & $3.41 \mathrm{e}-30$ \\
\hline Medication: insulin product & 361,141 & 3,545 & $29 / 13$ & $1.78 \mathrm{e}-25$ \\
\hline Insulin medication (females) & 193,148 & 1,476 & $29 / 13$ & $2.79 \mathrm{e}-23$ \\
\hline Insulin medication (males) & 165,340 & 2,248 & $29 / 13$ & $1.27 \mathrm{e}-20$ \\
\hline hypothyroidism (self-reported) & 361,141 & 17,57 & $29 / 13$ & $3.35 \mathrm{e}-20$ \\
\hline Medication: levothyroxine sodium & 361,141 & 14,68 & $29 / 13$ & $2.76 \mathrm{e}-19$ \\
\hline
\end{tabular}


bioRxiv preprint doi: https://doi.org/10.1101/2021.07.05.450786; this version posted August 5, 2021. The copyright holder for this preprint (which was not certified by peer review) is the author/funder, who has granted bioRxiv a license to display the preprint in perpetuity. It is made available under aCC-BY 4.0 International license.

\begin{tabular}{|l|l|l|l|l|}
\hline Trait description & Sample size & Cases & Partition / cluster & FDR \\
\hline psoriasis (self-reported) & 361,141 & 4,192 & $29 / 13$ & $6.74 \mathrm{e}-16$ \\
\hline
\end{tabular}

Table 27: Significant trait associations of LV844 in eMERGE.

\begin{tabular}{|c|c|c|c|c|}
\hline $\begin{array}{l}\text { Pheco } \\
\text { de }\end{array}$ & Trait description & $\begin{array}{l}\text { Sample } \\
\text { size }\end{array}$ & $\begin{array}{l}\text { Case } \\
\text { s }\end{array}$ & FDR \\
\hline 714.1 & Rheumatoid arthritis & 49,453 & $\begin{array}{l}2,54 \\
1\end{array}$ & $1.53 e-08$ \\
\hline 250.1 & Type 1 diabetes & 42,723 & $\begin{array}{l}2,45 \\
0\end{array}$ & $3.85 e-08$ \\
\hline 714 & Rheumatoid arthritis and other inflammatory polyarthropathies & 50,215 & $\begin{array}{l}3,30 \\
3\end{array}$ & $1.02 \mathrm{e}-06$ \\
\hline 440 & Atherosclerosis & 47,471 & $\begin{array}{l}4,99 \\
3\end{array}$ & $6.73 e-03$ \\
\hline 578.8 & Hemorrhage of rectum and anus & 47,545 & $\begin{array}{l}1,99 \\
1\end{array}$ & $6.73 e-03$ \\
\hline 585.32 & End stage renal disease & 43,309 & $\begin{array}{l}1,84 \\
2\end{array}$ & $9.01 e-03$ \\
\hline 440.2 & Atherosclerosis of the extremities & 45,524 & $\begin{array}{l}3,04 \\
6\end{array}$ & $1.09 \mathrm{e}-02$ \\
\hline 514.2 & Solitary pulmonary nodule & 50,389 & $\begin{array}{l}2,27 \\
0\end{array}$ & $1.39 \mathrm{e}-02$ \\
\hline 444 & Arterial embolism and thrombosis & 43,378 & 900 & $2.97 e-02$ \\
\hline 440.22 & $\begin{array}{l}\text { Atherosclerosis of native arteries of the extremities with intermittent } \\
\text { claudication }\end{array}$ & 44,639 & $\begin{array}{l}2,16 \\
1\end{array}$ & $3.61 \mathrm{e}-02$ \\
\hline
\end{tabular}

\section{LV155}

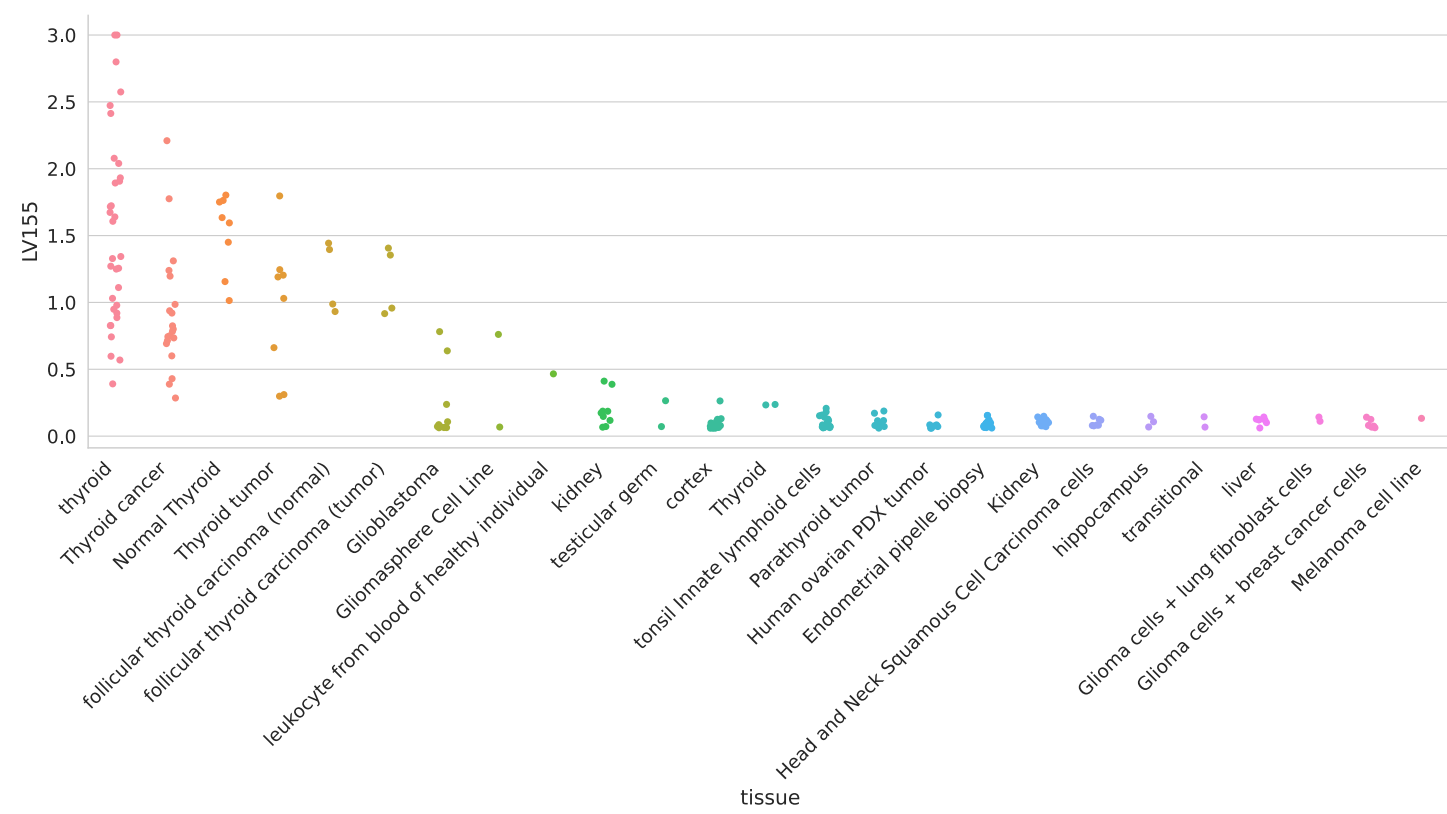

Figure 22: Cell types for LV155.

Table 28: Pathways aligned to LV155 from the MultiPLIER models. 
bioRxiv preprint doi: https://doi.org/10.1101/2021.07.05.450786; this version posted August 5, 2021. The copyright holder for this preprint (which was not certified by peer review) is the author/funder, who has granted bioRxiv a license to display the preprint in perpetuity. It is made available under aCC-BY 4.0 International license.

\begin{tabular}{|l|l|l|}
\hline Pathway & AUC & FDR \\
\hline No pathways significantly enriched & \\
\hline
\end{tabular}

Table 29: Significant trait associations of LV155 in PhenomeXcan.

\begin{tabular}{|l|l|l|l|l|}
\hline Trait description & Sample size & Cases & Partition / cluster & FDR \\
\hline hypothyroidism (self-reported) & 361,141 & 17,574 & $29 / 13$ & $1.65 e-03$ \\
\hline hyperthyroidism (self-reported) & 361,141 & 2,730 & $29 / 13$ & $1.03 e-02$ \\
\hline Medication: levothyroxine sodium & 361,141 & 14,689 & $29 / 13$ & $1.12 e-02$ \\
\hline
\end{tabular}

Table 30: Trait associations of LV155 in eMERGE.

\begin{tabular}{|l|l|l|l|l|}
\hline Phecode & Trait description & Sample size & Cases & FDR \\
\hline 244.2 & Acquired hypothyroidism & 45,839 & 1,155 & $5.66 \mathrm{e}-02$ \\
\hline
\end{tabular}

\section{LV57}

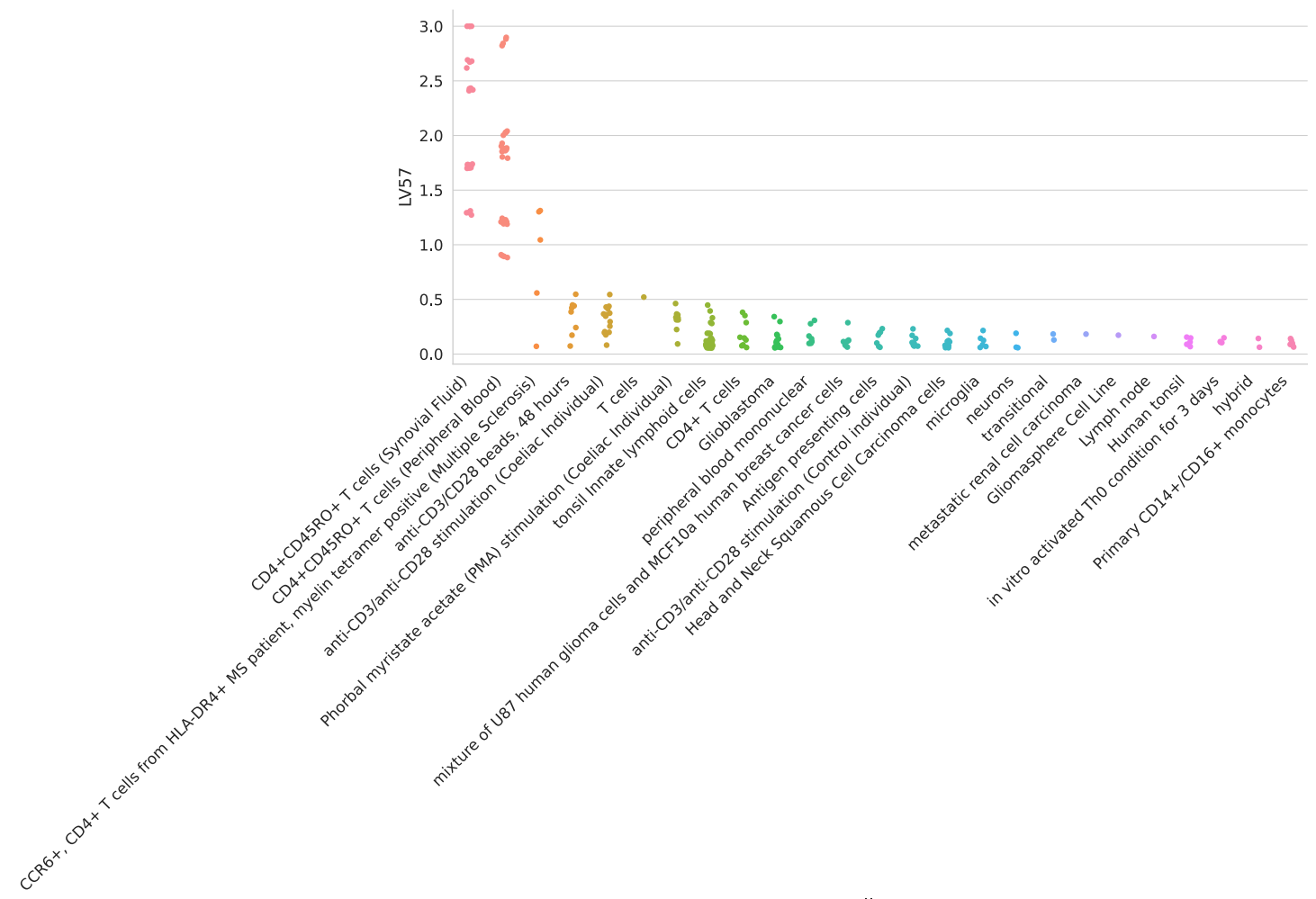

Figure 23: Cell types for LV57.

Table 31: Pathways aligned to LV57 from the MultiPLIER models.

\begin{tabular}{|l|l|l|}
\hline Pathway & AUC & FDR \\
\hline KEGG T CELL RECEPTOR SIGNALING PATHWAY & 0.70 & $1.26 \mathrm{e}-03$ \\
\hline SVM T cells CD4 memory activated & 0.79 & $2.59 \mathrm{e}-03$ \\
\hline IRIS CD4Tcell-Th2-restimulated12hour & 0.78 & $7.57 \mathrm{e}-03$ \\
\hline KEGG ALLOGRAFT REJECTION & 1.00 & $1.09 \mathrm{e}-02$ \\
\hline Custom Treg & 0.98 & $1.37 \mathrm{e}-02$ \\
\hline
\end{tabular}


bioRxiv preprint doi: https://doi.org/10.1101/2021.07.05.450786; this version posted August 5, 2021. The copyright holder for this preprint (which was not certified by peer review) is the author/funder, who has granted bioRxiv a license to display the preprint in perpetuity. It is made available under aCC-BY 4.0 International license.

\begin{tabular}{|l|l|l|}
\hline Pathway & AUC & FDR \\
\hline PID NFAT TFPATHWAY & 0.74 & $1.52 \mathrm{e}-02$ \\
\hline IRIS MemoryTcell-RO-activated & 0.70 & $2.87 \mathrm{e}-02$ \\
\hline
\end{tabular}

Table 32: Significant trait associations of LV57 in PhenomeXcan.

\begin{tabular}{|l|l|l|l|l|}
\hline Trait description & Sample size & Cases & Partition / cluster & FDR \\
\hline hypothyroidism (self-reported) & 361,141 & $\begin{array}{l}17,57 \\
4\end{array}$ & $29 / 13$ & $7.21 \mathrm{e}-25$ \\
\hline Medication: levothyroxine sodium & 361,141 & $\begin{array}{l}14,68 \\
9\end{array}$ & $29 / 13$ & $3.71 \mathrm{e}-23$ \\
\hline hyperthyroidism (self-reported) & 361,141 & 2,730 & $29 / 13$ & $8.93 e-07$ \\
\hline Started insulin within one year diagnosis of diabetes & 16,415 & 1,999 & $29 / 13$ & $6.60 \mathrm{e}-05$ \\
\hline Medication: insulin product & 361,141 & 3,545 & $29 / 13$ & $5.20 \mathrm{e}-04$ \\
\hline Insulin medication (females) & 193,148 & 1,476 & $29 / 13$ & $9.40 \mathrm{e}-04$ \\
\hline Insulin medication (males) & 165,340 & 2,248 & $29 / 13$ & $3.63 e-03$ \\
\hline
\end{tabular}

Table 33: Significant trait associations of LV57 in eMERGE.

\begin{tabular}{|l|l|l|l|l|}
\hline $\begin{array}{l}\text { Phecod } \\
\text { e }\end{array}$ & Trait description & Sample size & Cases & FDR \\
\hline 244 & Hypothyroidism & 54,404 & 9,720 & $7.66 e-09$ \\
\hline 244.4 & Hypothyroidism NOS & 53,968 & 9,284 & $7.66 e-09$ \\
\hline 279 & Disorders involving the immune mechanism & 56,771 & 3,309 & $1.07 e-02$ \\
\hline 514.2 & Solitary pulmonary nodule & 50,389 & 2,270 & $2.62 e-02$ \\
\hline 714 & Rheumatoid arthritis and other inflammatory polyarthropathies & 50,215 & 3,303 & $3.77 e-02$ \\
\hline
\end{tabular}

\section{LV54}

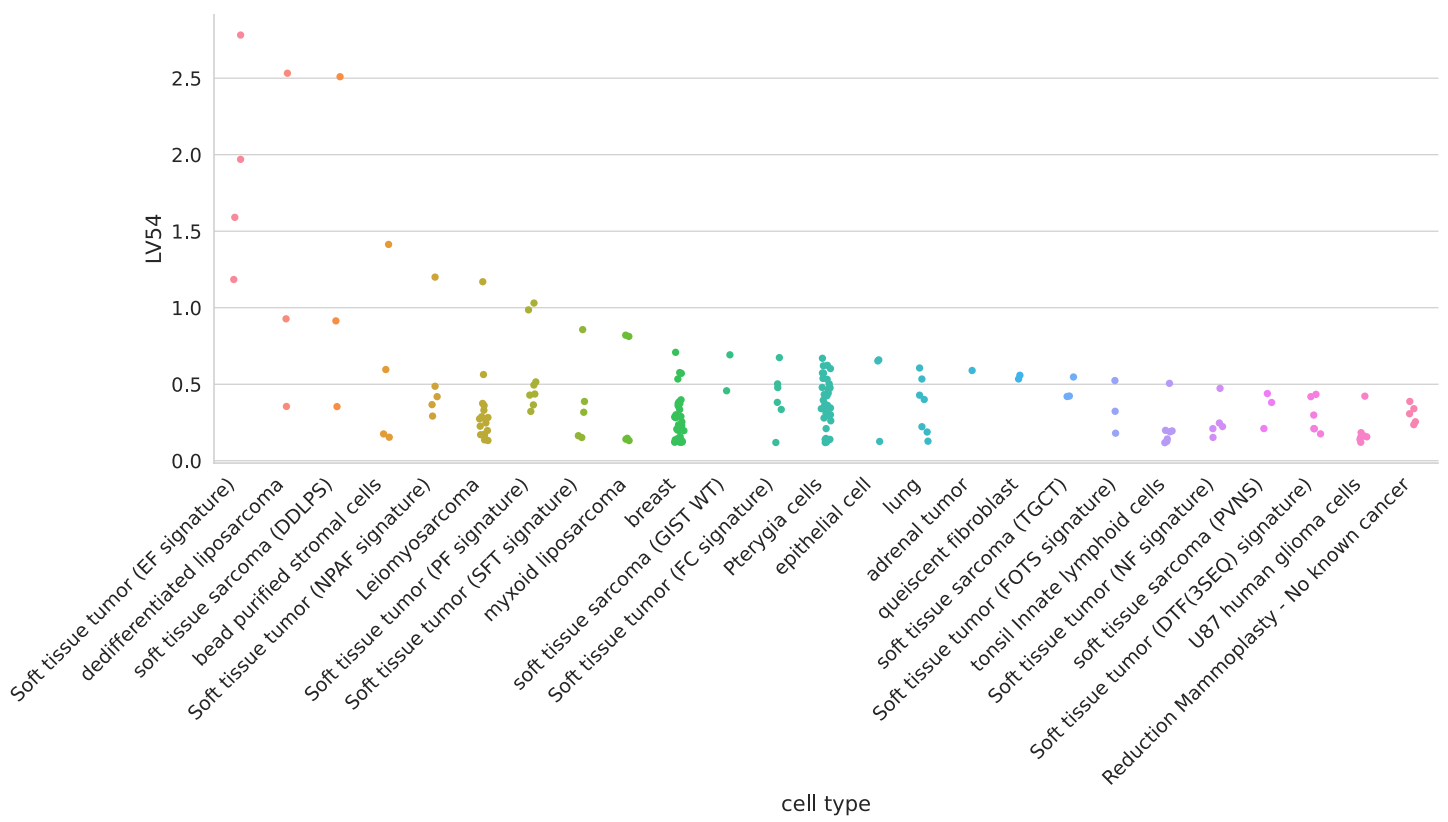

Figure 24: Cell types for LV54. 
bioRxiv preprint doi: https://doi.org/10.1101/2021.07.05.450786; this version posted August 5, 2021. The copyright holder for this preprint (which was not certified by peer review) is the author/funder, who has granted bioRxiv a license to display the preprint in perpetuity. It is made available under aCC-BY 4.0 International license.

Table 34: Pathways aligned to LV54 from the MultiPLIER models.

Pathway

AUC

FDR

No pathways significantly enriched

Table 35: Significant trait associations of LV54 in PhenomeXcan.

\begin{tabular}{|c|c|c|c|c|}
\hline Trait description & Sample size & Cases & Partition / cluster & FDR \\
\hline Intestinal malabsorption (ICD10 K90) & 361,194 & 922 & $29 / 8$ & $3.10 e-25$ \\
\hline Coeliac disease & 361,194 & 842 & $29 / 8$ & $4.78 \mathrm{e}-25$ \\
\hline Never eat: Wheat products & 359,777 & 9,573 & $29 / 13$ & $3.93 e-23$ \\
\hline Systemic Lupus Erythematosus & 23,210 & 7,219 & $29 / 26$ & $8.16 e-23$ \\
\hline Started insulin within one year diagnosis of diabetes & 16,415 & 1,999 & $29 / 13$ & $2.57 e-20$ \\
\hline hyperthyroidism (self-reported) & 361,141 & 2,730 & $29 / 13$ & $6.70 \mathrm{e}-19$ \\
\hline Medication: insulin product & 361,141 & 3,545 & $29 / 13$ & $3.62 \mathrm{e}-18$ \\
\hline Age diabetes diagnosed & 16,166 & & $29 / 13$ & $9.20 \mathrm{e}-18$ \\
\hline malabsorption/coeliac disease (self-reported) & 361,141 & 1,587 & $29 / 8$ & $9.63 e-15$ \\
\hline Insulin medication (males) & 165,340 & 2,248 & $29 / 13$ & $6.01 e-14$ \\
\hline psoriasis (self-reported) & 361,141 & 4,192 & $29 / 13$ & $1.81 \mathrm{e}-13$ \\
\hline Rheumatoid Arthritis & 80,799 & $\begin{array}{l}19,23 \\
4\end{array}$ & $29 / 26$ & $2.17 e-13$ \\
\hline Insulin medication (females) & 193,148 & 1,476 & $29 / 13$ & $2.61 \mathrm{e}-12$ \\
\hline Medication: levothyroxine sodium & 361,141 & $\begin{array}{l}14,68 \\
9\end{array}$ & $29 / 13$ & $4.25 e-10$ \\
\hline hypothyroidism (self-reported) & 361,141 & $\begin{array}{l}17,57 \\
4\end{array}$ & $29 / 13$ & $2.49 \mathrm{e}-08$ \\
\hline
\end{tabular}

Table 36: Significant trait associations of LV54 in eMERGE.

\begin{tabular}{|l|l|l|l|l|}
\hline $\begin{array}{l}\text { Phecod } \\
\text { e }\end{array}$ & Trait description & Sample size & Cases & FDR \\
\hline 250.1 & Type 1 diabetes & 42,723 & 2,450 & $1.69 \mathrm{e}-13$ \\
\hline 244 & Hypothyroidism & 54,404 & 9,720 & $1.01 \mathrm{e}-05$ \\
\hline 244.4 & Hypothyroidism NOS & 53,968 & 9,284 & $1.01 \mathrm{e}-05$ \\
\hline 695 & Erythematous conditions & 48,347 & 4,210 & $8.54 \mathrm{e}-05$ \\
\hline 714 & Rheumatoid arthritis and other inflammatory polyarthropathies & 50,215 & 3,303 & $6.58 \mathrm{e}-04$ \\
\hline 440 & Atherosclerosis & 47,471 & 4,993 & $1.90 \mathrm{e}-03$ \\
\hline 585 & Renal failure & 51,437 & 9,970 & $7.10 \mathrm{e}-03$ \\
\hline 585.33 & Chronic Kidney Disease, Stage III & 46,279 & 4,812 & $7.49 \mathrm{e}-03$ \\
\hline 585.32 & End stage renal disease & 43,309 & 1,842 & $7.49 \mathrm{e}-03$ \\
\hline 250.6 & Polyneuropathy in diabetes & 41,948 & 1,675 & $8.55 \mathrm{e}-03$ \\
\hline 250 & Diabetes mellitus & 52,531 & 12,25 & $1.02 \mathrm{e}-02$ \\
\hline
\end{tabular}


bioRxiv preprint doi: https://doi.org/10.1101/2021.07.05.450786; this version posted August 5, 2021. The copyright holder for this preprint (which was not certified by peer review) is the author/funder, who has granted bioRxiv a license to display the preprint in perpetuity. It is made available under aCC-BY 4.0 International license.

\begin{tabular}{|l|l|l|l|l|}
\hline $\begin{array}{l}\text { Phecod } \\
\text { e }\end{array}$ & Trait description & Sample size & Cases & FDR \\
\hline 285.2 & Anemia of chronic disease & 39,673 & 2,606 & $1.64 \mathrm{e}-02$ \\
\hline 502 & Postinflammatory pulmonary fibrosis & 42,396 & 1,723 & $1.77 \mathrm{e}-02$ \\
\hline 415.1 & Acute pulmonary heart disease & 49,887 & 1,857 & $1.88 \mathrm{e}-02$ \\
\hline 285.21 & Anemia in chronic kidney disease & 38,616 & 1,549 & $2.53 \mathrm{e}-02$ \\
\hline 585.3 & Chronic renal failure [CKD] & 49,204 & 7,737 & $2.62 \mathrm{e}-02$ \\
\hline 743 & Osteoporosis, osteopenia and pathological fracture & 55,165 & 11,99 & $2.87 \mathrm{e}-02$ \\
\hline 415.11 & Pulmonary embolism and infarction, acute & 49,867 & 1,837 & $3.04 \mathrm{e}-02$ \\
\hline 577 & Diseases of pancreas & 60,538 & 1,795 & $3.06 \mathrm{e}-02$ \\
\hline 585.1 & Acute renal failure & 46,803 & 5,336 & $3.23 \mathrm{e}-02$ \\
\hline 195 & Cancer, suspected or other & 50,040 & 2,250 & $3.27 \mathrm{e}-02$ \\
\hline 289.4 & Lymphadenitis & 47,564 & 3,078 & $3.67 \mathrm{e}-02$ \\
\hline 440.2 & Atherosclerosis of the extremities & 45,524 & 3,046 & $4.52 \mathrm{e}-02$ \\
\hline
\end{tabular}

\section{LV847}

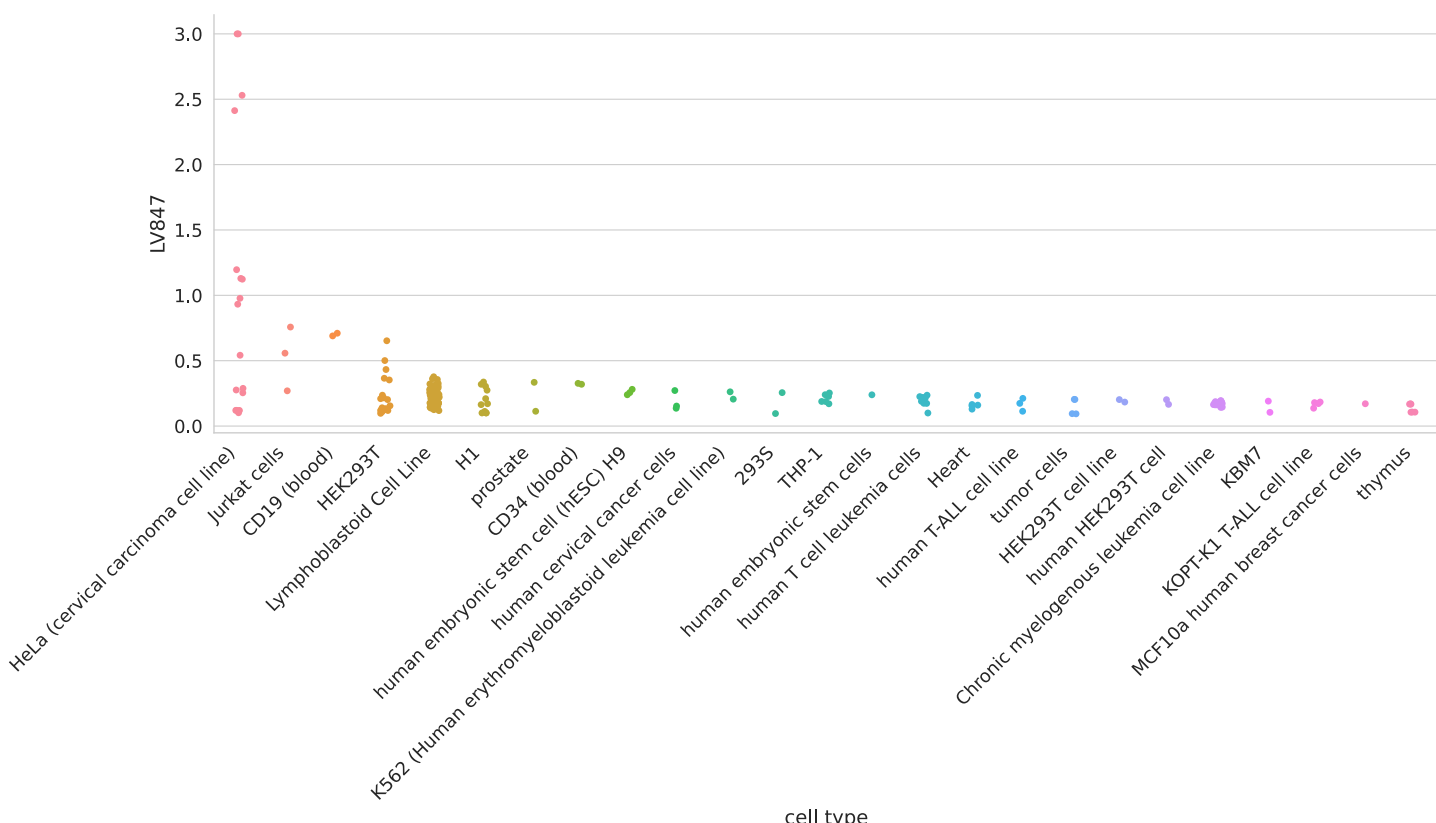

Figure 25: Cell types for LV847.

Table 37: Pathways aligned to LV847 from the MultiPLIER models.

\begin{tabular}{|l|l|l|}
\hline Pathway & AUC & FDR \\
\hline KEGG SYSTEMIC LUPUS ERYTHEMATOSUS & 0.74 & $1.86 \mathrm{e}-04$ \\
\hline REACTOME MEIOTIC RECOMBINATION & 0.78 & $3.60 \mathrm{e}-04$ \\
\hline REACTOME RNA POL I TRANSCRIPTION & 0.75 & $5.56 \mathrm{e}-04$ \\
\hline REACTOME AMYLOIDS & 0.76 & $2.17 \mathrm{e}-03$ \\
\hline
\end{tabular}

Table 38: Significant trait associations of LV847 in PhenomeXcan. 
bioRxiv preprint doi: https://doi.org/10.1101/2021.07.05.450786; this version posted August 5, 2021. The copyright holder for this preprint (which was not certified by peer review) is the author/funder, who has granted bioRxiv a license to display the preprint in perpetuity. It is made available under aCC-BY 4.0 International license.

\begin{tabular}{|c|c|c|c|c|}
\hline Trait description & $\begin{array}{l}\text { Sample } \\
\text { size }\end{array}$ & $\begin{array}{l}\text { Cas } \\
\text { es }\end{array}$ & $\begin{array}{l}\text { Partition / } \\
\text { cluster }\end{array}$ & FDR \\
\hline Mean corpuscular haemoglobin & 350,472 & & $29 / 2$ & $7.34 \mathrm{e}-73$ \\
\hline Mean corpuscular volume & 350,473 & & $29 / 2$ & $1.43 e-50$ \\
\hline Blood pressure medication (females) & 193,148 & $\begin{array}{l}33 \\
519\end{array}$ & $29 / 17$ & $1.38 \mathrm{e}-18$ \\
\hline Heart attack, angina, stroke or hypertension & 360,420 & $\begin{array}{l}253 \\
, 56 \\
5\end{array}$ & $29 / 17$ & $2.92 \mathrm{e}-15$ \\
\hline hypertension & 360,420 & $\begin{array}{l}97, \\
139\end{array}$ & $29 / 17$ & $4.82 \mathrm{e}-14$ \\
\hline hypertension (self-reported) & 361,141 & $\begin{array}{l}93 \\
560\end{array}$ & $29 / 17$ & $1.02 \mathrm{e}-13$ \\
\hline Medication: bendroflumethiazide & 361,141 & $\begin{array}{l}20 \\
196\end{array}$ & $29 / 17$ & $1.06 \mathrm{e}-08$ \\
\hline Mean sphered cell volume & 344,729 & & $29 / 2$ & $2.16 \mathrm{e}-08$ \\
\hline Blood pressure medication (males) & 165,340 & $\begin{array}{l}40, \\
987\end{array}$ & $29 / 17$ & $1.14 \mathrm{e}-07$ \\
\hline $\begin{array}{l}\text { Medication for cholesterol, blood pressure, diabetes, or take } \\
\text { exogenous hormones (females) }\end{array}$ & 193,148 & $\begin{array}{l}133 \\
, 33 \\
8\end{array}$ & $29 / 17$ & $1.21 \mathrm{e}-06$ \\
\hline Diastolic blood pressure, automated reading & 340,162 & & $29 / 17$ & $2.93 e-06$ \\
\hline Medication for cholesterol, blood pressure or diabetes (males) & 165,340 & $\begin{array}{l}110 \\
37 \\
2\end{array}$ & $29 / 17$ & $5.01 \mathrm{e}-06$ \\
\hline Mean reticulocyte volume & 344,728 & & $29 / 2$ & $8.38 \mathrm{e}-03$ \\
\hline
\end{tabular}

Table 39: Significant trait associations of LV847 in eMERGE.

\begin{tabular}{|c|c|c|c|c|}
\hline $\begin{array}{l}\text { Pheco } \\
\text { de }\end{array}$ & Trait description & $\begin{array}{l}\text { Sample } \\
\text { size }\end{array}$ & $\begin{array}{l}\text { Case } \\
\text { s }\end{array}$ & FDR \\
\hline 585.32 & End stage renal disease & 43,309 & $\begin{array}{l}1,84 \\
2\end{array}$ & $3.11 e-08$ \\
\hline 443 & Peripheral vascular disease & 47,867 & $\begin{array}{l}5,38 \\
9\end{array}$ & $4.13 e-06$ \\
\hline 442.1 & Aortic aneurysm & 45,589 & $\begin{array}{l}3,11 \\
1\end{array}$ & $1.01 \mathrm{e}-05$ \\
\hline 411.3 & Angina pectoris & 43,503 & $\begin{array}{l}4,38 \\
2\end{array}$ & $4.28 \mathrm{e}-05$ \\
\hline 440.2 & Atherosclerosis of the extremities & 45,524 & $\begin{array}{l}3,04 \\
6\end{array}$ & $6.57 e-05$ \\
\hline 415.11 & Pulmonary embolism and infarction, acute & 49,867 & $\begin{array}{l}1,83 \\
7\end{array}$ & $9.90 \mathrm{e}-05$ \\
\hline 416 & Cardiomegaly & 53,289 & $\begin{array}{l}5,25 \\
9\end{array}$ & $1.34 \mathrm{e}-04$ \\
\hline 415.1 & Acute pulmonary heart disease & 49,887 & $\begin{array}{l}1,85 \\
7\end{array}$ & $1.49 \mathrm{e}-04$ \\
\hline
\end{tabular}


bioRxiv preprint doi: https://doi.org/10.1101/2021.07.05.450786; this version posted August 5, 2021. The copyright holder for this preprint (which was not certified by peer review) is the author/funder, who has granted bioRxiv a license to display the preprint in perpetuity. It is made available under aCC-BY 4.0 International license.

\begin{tabular}{|c|c|c|c|c|}
\hline $\begin{array}{l}\text { Pheco } \\
\text { de }\end{array}$ & Trait description & $\begin{array}{l}\text { Sample } \\
\text { size }\end{array}$ & $\begin{array}{l}\text { Case } \\
\text { s }\end{array}$ & FDR \\
\hline 599.3 & Dysuria & 42,858 & $\begin{array}{l}3,58 \\
1\end{array}$ & $1.74 \mathrm{e}-04$ \\
\hline 585 & Renal failure & 51,437 & $\begin{array}{l}9,97 \\
0\end{array}$ & $3.90 \mathrm{e}-04$ \\
\hline 411 & Ischemic Heart Disease & 54,275 & $\begin{array}{l}15,1 \\
54\end{array}$ & $1.19 \mathrm{e}-03$ \\
\hline 531 & Peptic ulcer (excl. esophageal) & 59,472 & $\begin{array}{l}1,56 \\
1\end{array}$ & $2.26 \mathrm{e}-03$ \\
\hline 250.6 & Polyneuropathy in diabetes & 41,948 & $\begin{array}{l}1,67 \\
5\end{array}$ & $2.32 \mathrm{e}-03$ \\
\hline 443.9 & Peripheral vascular disease, unspecified & 46,926 & $\begin{array}{l}4,44 \\
8\end{array}$ & $2.40 \mathrm{e}-03$ \\
\hline 519 & Other diseases of respiratory system, not elsewhere classified & 56,909 & $\begin{array}{l}2,05 \\
6\end{array}$ & $2.43 e-03$ \\
\hline 401.2 & Hypertensive heart and/or renal disease & 30,405 & $\begin{array}{l}6,25 \\
3\end{array}$ & $2.43 e-03$ \\
\hline 411.8 & Other chronic ischemic heart disease, unspecified & 44,123 & $\begin{array}{l}5,00 \\
2\end{array}$ & $2.71 \mathrm{e}-03$ \\
\hline 440.22 & $\begin{array}{l}\text { Atherosclerosis of native arteries of the extremities with intermittent } \\
\text { claudication }\end{array}$ & 44,639 & $\begin{array}{l}2,16 \\
1\end{array}$ & $2.97 \mathrm{e}-03$ \\
\hline 401.22 & Hypertensive chronic kidney disease & 28,944 & $\begin{array}{l}4,79 \\
2\end{array}$ & $5.61 \mathrm{e}-03$ \\
\hline 514 & Abnormal findings examination of lungs & 54,668 & $\begin{array}{l}6,54 \\
9\end{array}$ & $6.96 e-03$ \\
\hline 427.6 & Premature beats & 31,575 & $\begin{array}{l}2,45 \\
3\end{array}$ & $1.27 e-02$ \\
\hline 585.1 & Acute renal failure & 46,803 & $\begin{array}{l}5,33 \\
6\end{array}$ & $1.39 \mathrm{e}-02$ \\
\hline 418 & Nonspecific chest pain & 51,082 & $\begin{array}{l}17,7 \\
65\end{array}$ & $1.39 \mathrm{e}-02$ \\
\hline 250.1 & Type 1 diabetes & 42,723 & $\begin{array}{l}2,45 \\
0\end{array}$ & $1.44 \mathrm{e}-02$ \\
\hline 285.21 & Anemia in chronic kidney disease & 38,616 & $\begin{array}{l}1,54 \\
9\end{array}$ & $1.82 \mathrm{e}-02$ \\
\hline 368 & Visual disturbances & 56,141 & $\begin{array}{l}2,69 \\
4\end{array}$ & $1.88 \mathrm{e}-02$ \\
\hline 427.5 & Arrhythmia (cardiac) NOS & 36,861 & $\begin{array}{l}7,73 \\
9\end{array}$ & $2.01 \mathrm{e}-02$ \\
\hline 687.1 & Rash and other nonspecific skin eruption & 47,039 & $\begin{array}{l}4,96 \\
4\end{array}$ & $2.15 e-02$ \\
\hline 185 & Cancer of prostate & 52,630 & $\begin{array}{l}2,81 \\
5\end{array}$ & $2.31 \mathrm{e}-02$ \\
\hline 747 & Cardiac and circulatory congenital anomalies & 59,494 & $\begin{array}{l}2,16 \\
7\end{array}$ & $2.47 \mathrm{e}-02$ \\
\hline 444 & Arterial embolism and thrombosis & 43,378 & 900 & $2.53 e-02$ \\
\hline
\end{tabular}


bioRxiv preprint doi: https://doi.org/10.1101/2021.07.05.450786; this version posted August 5, 2021. The copyright holder for this preprint (which was not certified by peer review) is the author/funder, who has granted bioRxiv a license to display the preprint in perpetuity. It is made available under aCC-BY 4.0 International license.

\begin{tabular}{|c|c|c|c|c|}
\hline $\begin{array}{l}\text { Pheco } \\
\text { de }\end{array}$ & Trait description & $\begin{array}{l}\text { Sample } \\
\text { size }\end{array}$ & $\begin{array}{l}\text { Case } \\
\mathbf{S}\end{array}$ & FDR \\
\hline 585.3 & Chronic renal failure [CKD] & 49,204 & $\begin{array}{l}7,73 \\
7\end{array}$ & $2.53 e-02$ \\
\hline 440 & Atherosclerosis & 47,471 & $\begin{array}{l}4,99 \\
3\end{array}$ & $2.62 \mathrm{e}-02$ \\
\hline 591 & Urinary tract infection & 49,727 & $\begin{array}{l}10,0 \\
16\end{array}$ & $2.94 \mathrm{e}-02$ \\
\hline 411.1 & Unstable angina (intermediate coronary syndrome) & 41,763 & $\begin{array}{l}2,64 \\
2\end{array}$ & $3.06 \mathrm{e}-02$ \\
\hline 285.2 & Anemia of chronic disease & 39,673 & $\begin{array}{l}2,60 \\
6\end{array}$ & $3.06 \mathrm{e}-02$ \\
\hline 274.1 & Gout & 59,252 & $\begin{array}{l}3,39 \\
4\end{array}$ & $3.23 e-02$ \\
\hline 585.34 & Chronic Kidney Disease, Stage IV & 43,322 & $\begin{array}{l}1,85 \\
5\end{array}$ & $3.84 \mathrm{e}-02$ \\
\hline 452 & Other venous embolism and thrombosis & 40,476 & $\begin{array}{l}3,81 \\
6\end{array}$ & $4.49 \mathrm{e}-02$ \\
\hline 427.12 & Paroxysmal ventricular tachycardia & 31,154 & $\begin{array}{l}2,03 \\
2\end{array}$ & $4.52 \mathrm{e}-02$ \\
\hline
\end{tabular}

\section{LV136}

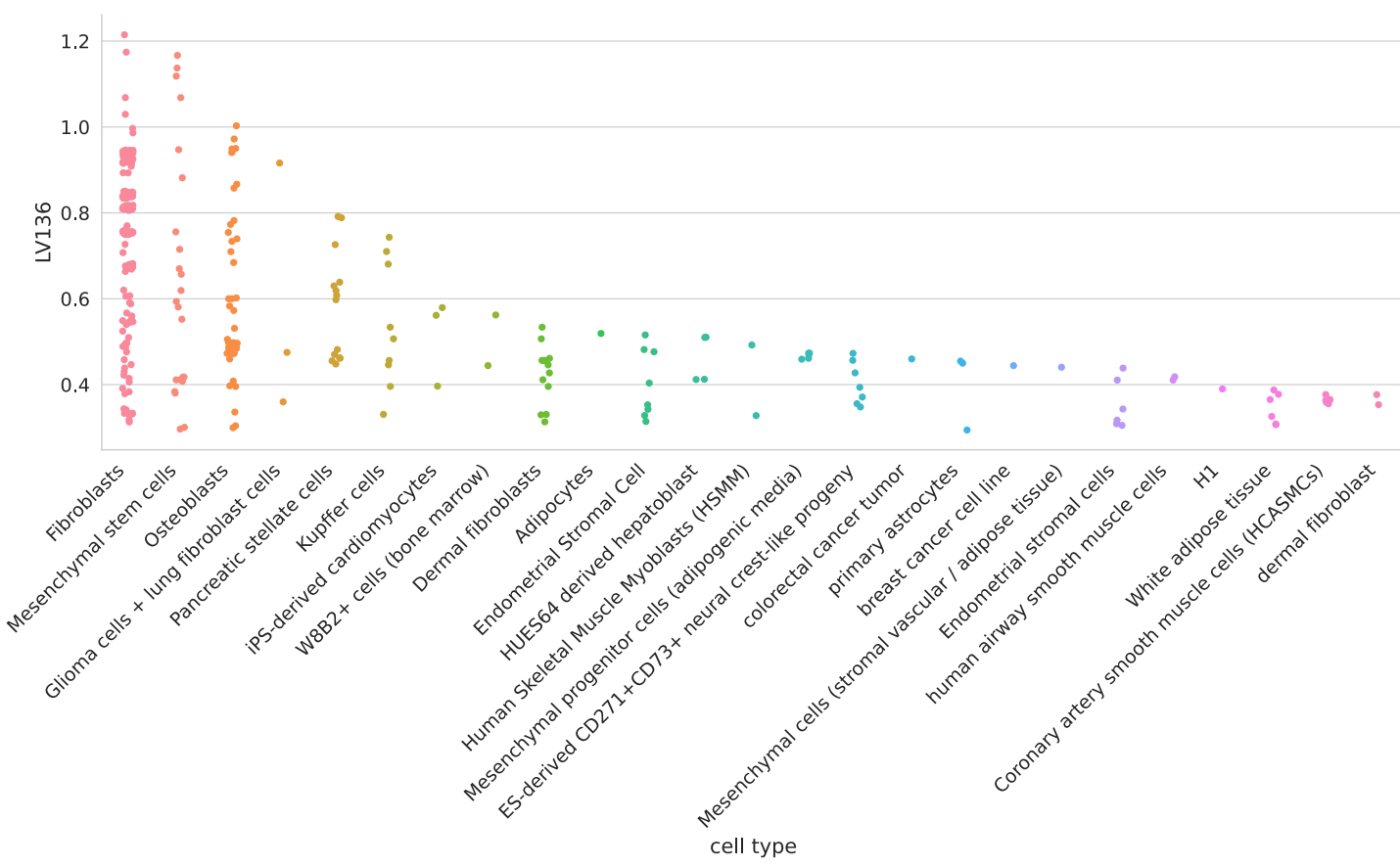

Figure 26: Cell types for LV136. Pulmonary microvascular endothelial cells were exposed to hypoxia for 24 hours or more [108];

Table 40: Pathways aligned to LV136 from the MultiPLIER models.

\begin{tabular}{|l|l|l|}
\hline Pathway & AUC & FDR \\
\hline PID INTEGRIN1 PATHWAY & 0.88 & $9.35 \mathrm{e}-06$ \\
\hline KEGG ECM RECEPTOR INTERACTION & 0.80 & $7.29 \mathrm{e}-05$ \\
\hline
\end{tabular}


bioRxiv preprint doi: https://doi.org/10.1101/2021.07.05.450786; this version posted August 5, 2021. The copyright holder for this preprint (which was not certified by peer review) is the author/funder, who has granted bioRxiv a license to display the preprint in perpetuity. It is made available under aCC-BY 4.0 International license.

\begin{tabular}{|l|l|l|}
\hline Pathway & AUC & FDR \\
\hline REACTOME COLLAGEN FORMATION & 0.87 & $2.00 \mathrm{e}-04$ \\
\hline REACTOME MUSCLE CONTRACTION & 0.75 & $1.49 \mathrm{e}-02$ \\
\hline
\end{tabular}

Table 41: Significant trait associations of LV136 in PhenomeXcan.

\begin{tabular}{|c|c|c|c|c|}
\hline Trait description & Sample size & Cases & Partition / cluster & FDR \\
\hline $3 \mathrm{~mm}$ strong meridian (right) & 75,410 & & $29 / 10$ & $6.37 e-11$ \\
\hline $6 \mathrm{~mm}$ strong meridian (left) & 65,551 & & $29 / 10$ & $1.53 e-09$ \\
\hline $6 \mathrm{~mm}$ strong meridian (right) & 66,256 & & $29 / 10$ & $1.78 \mathrm{e}-09$ \\
\hline 3mm strong meridian (left) & 75,398 & & $29 / 10$ & $9.90 e-09$ \\
\hline Coronary Artery Disease & 184,305 & $\begin{array}{l}60,80 \\
1\end{array}$ & $29 / 11$ & $1.26 \mathrm{e}-08$ \\
\hline $3 \mathrm{~mm}$ weak meridian (right) & 75,410 & & $29 / 10$ & $1.26 \mathrm{e}-08$ \\
\hline $6 \mathrm{~mm}$ weak meridian (right) & 66,256 & & $29 / 10$ & $2.41 \mathrm{e}-08$ \\
\hline $3 \mathrm{~mm}$ weak meridian (left) & 75,398 & & $29 / 10$ & $3.96 \mathrm{e}-08$ \\
\hline $6 \mathrm{~mm}$ weak meridian (left) & 65,551 & & $29 / 10$ & $9.31 \mathrm{e}-08$ \\
\hline Coronary atherosclerosis & 361,194 & $\begin{array}{l}14,33 \\
4\end{array}$ & $29 / 14$ & $3.04 \mathrm{e}-06$ \\
\hline Ischaemic heart disease (wide definition) & 361,194 & $\begin{array}{l}20,85 \\
7\end{array}$ & $29 / 14$ & $5.71 e-06$ \\
\hline Heart attack & 360,420 & 8,288 & $29 / 14$ & $2.36 \mathrm{e}-04$ \\
\hline Myocardial infarction & 361,194 & 7,018 & $29 / 14$ & $5.20 \mathrm{e}-04$ \\
\hline Acute myocardial infarction (ICD10 I21) & 361,194 & 5,948 & $29 / 14$ & $8.14 \mathrm{e}-04$ \\
\hline heart attack/myocardial infarction (self-reported) & 361,141 & 8,239 & $29 / 14$ & $1.16 \mathrm{e}-03$ \\
\hline Major coronary heart disease event & 361,194 & $\begin{array}{l}10,15 \\
7\end{array}$ & $29 / 14$ & $1.47 e-02$ \\
\hline
\end{tabular}

Table 42: Trait associations of LV136 in eMERGE.

\begin{tabular}{|l|l|l|l|l|}
\hline Phecode & Trait description & Sample size & Cases & FDR \\
\hline 747.1 & Cardiac congenital anomalies & 59,198 & 1,871 & $1.57 \mathrm{e}-01$ \\
\hline 411.4 & Coronary atherosclerosis & 52,836 & 13,715 & $1.60 \mathrm{e}-01$ \\
\hline
\end{tabular}

\section{LV93}


bioRxiv preprint doi: https://doi.org/10.1101/2021.07.05.450786; this version posted August 5, 2021. The copyright holder for this preprint (which was not certified by peer review) is the author/funder, who has granted bioRxiv a license to display the preprint in perpetuity. It is made available under aCC-BY 4.0 International license.

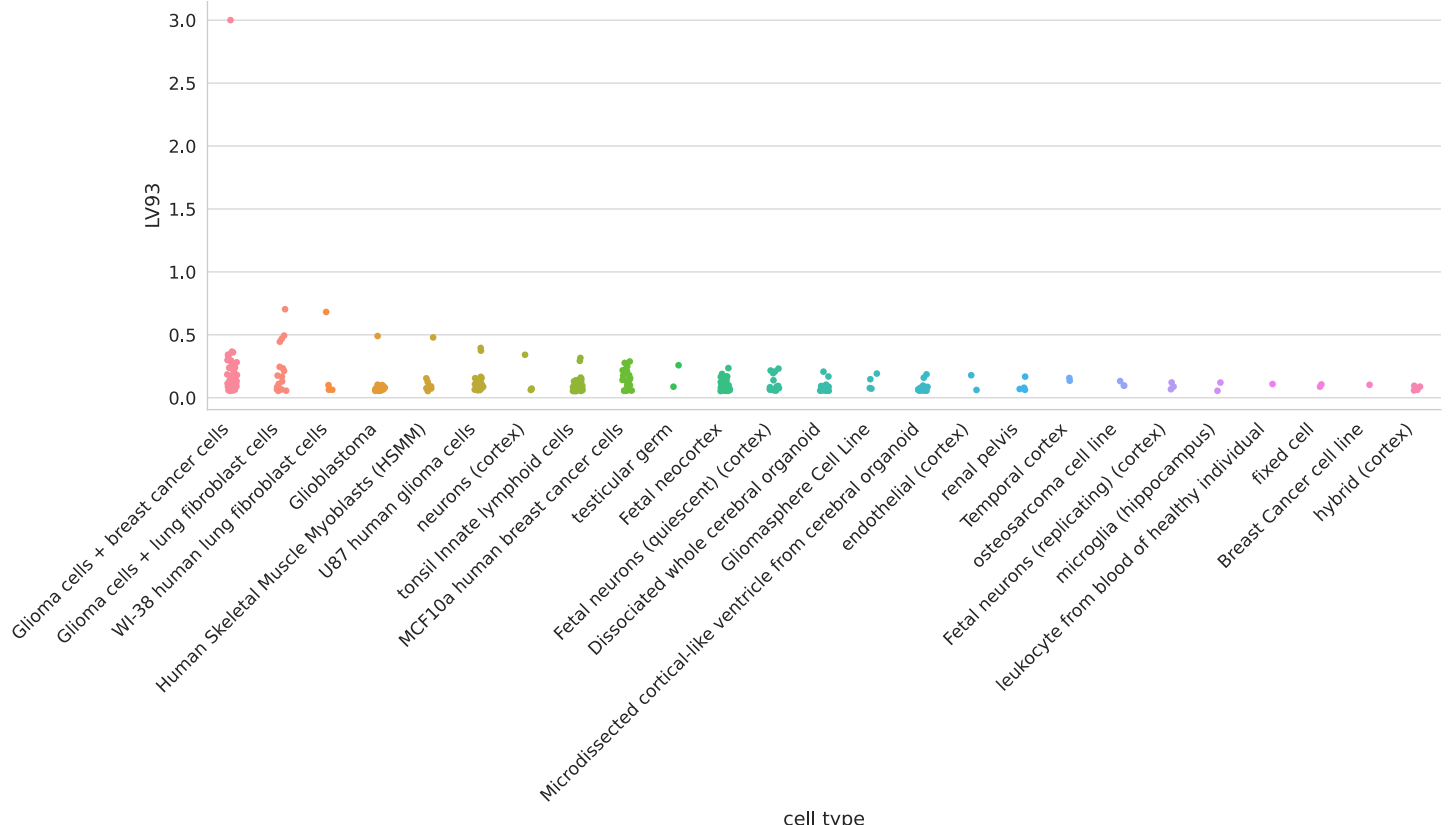

Figure 27: Cell types for LV93.

Table 43: Pathways aligned to LV93 from the MultiPLIER models.

\begin{tabular}{|l|l|l|}
\hline Pathway & AUC & FDR \\
\hline No pathways significantly enriched & \\
\hline
\end{tabular}

Table 44: Significant trait associations of LV93 in PhenomeXcan.

\begin{tabular}{|c|c|c|c|c|}
\hline Trait description & Sample size & Cases & Partition / cluster & FDR \\
\hline $\mathrm{CH} 2 \mathrm{DB}$ NMR & 24,154 & & $29 / 16$ & $5.91 \mathrm{e}-24$ \\
\hline Reticulocyte Count & 173,480 & & $29 / 4$ & $1.33 e-14$ \\
\hline High light scatter reticulocyte count & 344,729 & & $29 / 4$ & $2.52 \mathrm{e}-13$ \\
\hline Reticulocyte count & 344,729 & & $29 / 4$ & $1.35 e-12$ \\
\hline Reticulocyte percentage & 344,728 & & $29 / 4$ & $4.93 e-11$ \\
\hline High light scatter reticulocyte percentage & 344,729 & & $29 / 4$ & $2.18 \mathrm{e}-10$ \\
\hline Immature reticulocyte fraction & 344,728 & & $29 / 4$ & $2.31 \mathrm{e}-08$ \\
\hline Chronotype & 128,266 & & $29 / 16$ & $9.73 e-04$ \\
\hline HDL Cholesterol NMR & 19,270 & & $29 / 16$ & $2.41 \mathrm{e}-03$ \\
\hline
\end{tabular}

Table 45: Significant trait associations of LV93 in eMERGE.

\begin{tabular}{|l|l|l|l|l|}
\hline Phecode & Trait description & Sample size & Cases & FDR \\
\hline 208 & Benign neoplasm of colon & 55,694 & 8,597 & $1.39 \mathrm{e}-02$ \\
\hline 440.2 & Atherosclerosis of the extremities & 45,524 & 3,046 & $2.87 \mathrm{e}-02$ \\
\hline
\end{tabular}

\section{LV206}


bioRxiv preprint doi: https://doi.org/10.1101/2021.07.05.450786; this version posted August 5, 2021. The copyright holder for this preprint (which was not certified by peer review) is the author/funder, who has granted bioRxiv a license to display the preprint in perpetuity. It is made available under aCC-BY 4.0 International license.

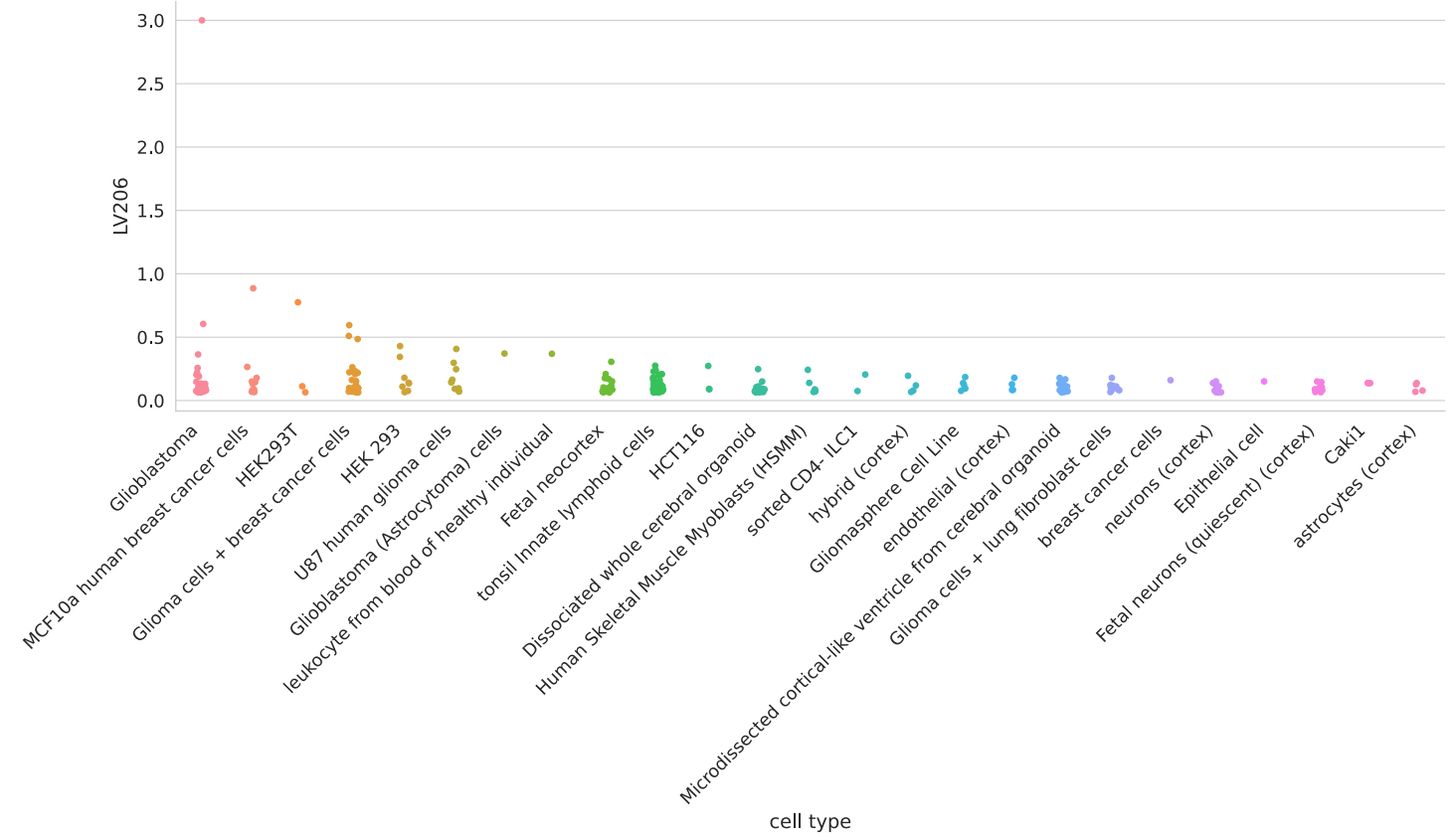

Figure 28: Cell types for LV206.

Table 46: Pathways aligned to LV206 from the MultiPLIER models.

\section{Pathway}

No pathways significantly enriched

Table 47: Significant trait associations of LV206 in PhenomeXcan.

\begin{tabular}{|l|l|l|l|l|}
\hline Trait description & Sample size & Cases & Partition / cluster & FDR \\
\hline CH2DB NMR & 24,154 & & $29 / 16$ & $5.04 \mathrm{e}-21$ \\
\hline HDL Cholesterol NMR & 19,270 & & $29 / 16$ & $5.20 \mathrm{e}-03$ \\
\hline
\end{tabular}

Table 48: Significant trait associations of LV206 in eMERGE.

\begin{tabular}{|l|l|l|l|l|}
\hline Phecode & Trait description & Sample size & Cases & FDR \\
\hline 458 & Hypotension & 51,341 & 4,432 & $3.06 \mathrm{e}-02$ \\
\hline 286.9 & Abnormal coagulation profile & 48,006 & 800 & $3.39 \mathrm{e}-02$ \\
\hline 458.9 & Hypotension NOS & 50,150 & 3,241 & $3.58 \mathrm{e}-02$ \\
\hline 428.2 & Heart failure NOS & 48,178 & 3,584 & 3.71 e-02 \\
\hline
\end{tabular}


bioRxiv preprint doi: https://doi.org/10.1101/2021.07.05.450786; this version posted August 5, 2021. The copyright holder for this preprint (which was not certified by peer review) is the author/funder, who has granted bioRxiv a license to display the preprint in perpetuity. It is made available under aCC-BY 4.0 International license.

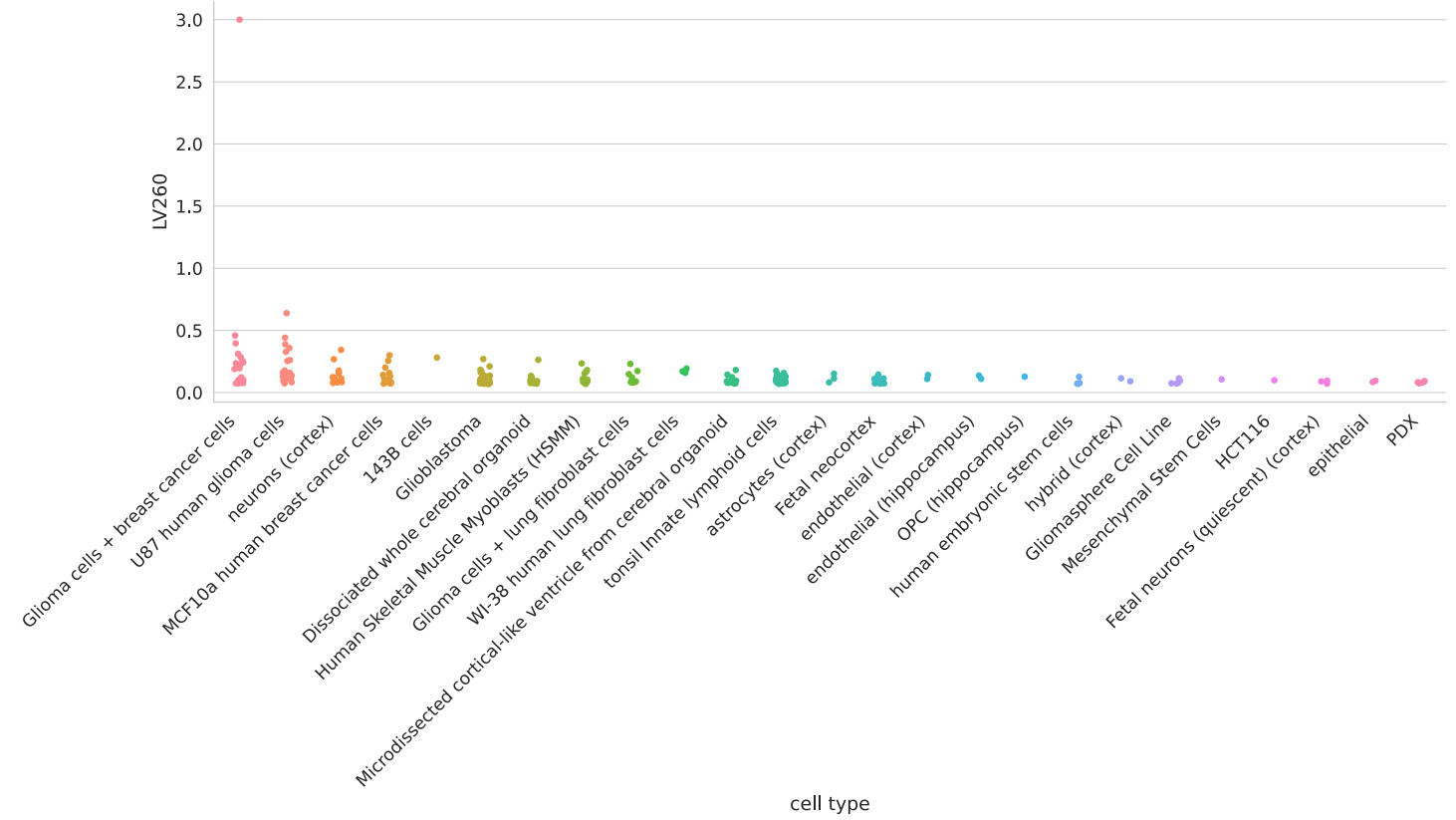

Figure 29: Cell types for LV260.

Table 49: Pathways aligned to LV260 from the MultiPLIER models.

\begin{tabular}{|l|l|l|}
\hline Pathway & AUC & FDR \\
\hline No pathways significantly enriched & & \\
\hline
\end{tabular}

Table 50: Significant trait associations of LV260 in PhenomeXcan.

\begin{tabular}{|l|l|l|l|l|}
\hline Trait description & Sample size & Cases & Partition / cluster & FDR \\
\hline CH2DB NMR & 24,154 & & $29 / 16$ & $4.35 \mathrm{e}-17$ \\
\hline HDL Cholesterol NMR & 19,270 & & $29 / 16$ & $1.88 \mathrm{e}-02$ \\
\hline
\end{tabular}

Table 51: Trait associations of LV260 in eMERGE.

\begin{tabular}{|l|l|l|l|l|}
\hline Phecode & Trait description & Sample size & Cases & FDR \\
\hline 427.6 & Premature beats & 31,575 & 2,453 & $7.90 \mathrm{e}-02$ \\
\hline
\end{tabular}

\section{LV21}


bioRxiv preprint doi: https://doi.org/10.1101/2021.07.05.450786; this version posted August 5, 2021. The copyright holder for this preprint (which was not certified by peer review) is the author/funder, who has granted bioRxiv a license to display the preprint in perpetuity. It is made available under aCC-BY 4.0 International license.

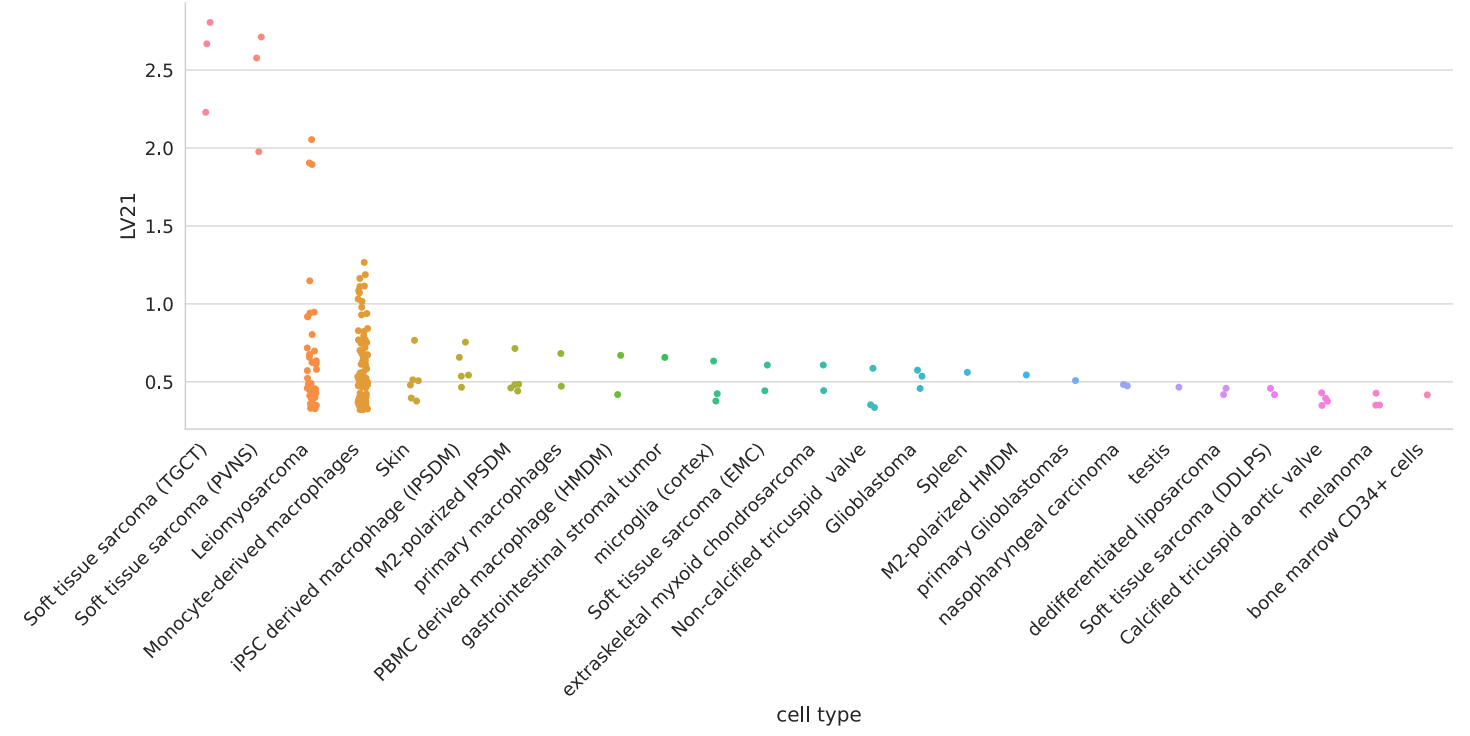

Figure 30: Cell types for LV21.

Table 52: Pathways aligned to LV21 from the MultiPLIER models.

\begin{tabular}{|l|l|l|}
\hline Pathway & AUC & FDR \\
\hline No pathways significantly enriched & & \\
\hline
\end{tabular}

Table 53: Significant trait associations of LV21 in PhenomeXcan.

\begin{tabular}{|l|l|l|l|l|}
\hline Trait description & Sample size & Cases & Partition / cluster & FDR \\
\hline Alzheimers Disease & 54,162 & 17,008 & $29 / 16$ & 1.11 e-19 \\
\hline LDL Cholesterol NMR & 13,527 & & $29 / 16$ & $9.53 \mathrm{e}-05$ \\
\hline Triglycerides NMR & 21,559 & $29 / 16$ & $1.74 \mathrm{e}-02$ \\
\hline
\end{tabular}

Table 54: Trait associations of LV21 in eMERGE.

\begin{tabular}{|l|l|l|l|l|}
\hline Phecode & Trait description & Sample size & Cases & FDR \\
\hline 573 & Other disorders of liver & 47,826 & 2,524 & $2.99 \mathrm{e}-02$ \\
\hline 577 & Diseases of pancreas & 60,538 & 1,795 & $5.51 \mathrm{e}-02$ \\
\hline
\end{tabular}

\section{LV5}


bioRxiv preprint doi: https://doi.org/10.1101/2021.07.05.450786; this version posted August 5, 2021. The copyright holder for this preprint (which was not certified by peer review) is the author/funder, who has granted bioRxiv a license to display the preprint in perpetuity. It is made available under aCC-BY 4.0 International license.

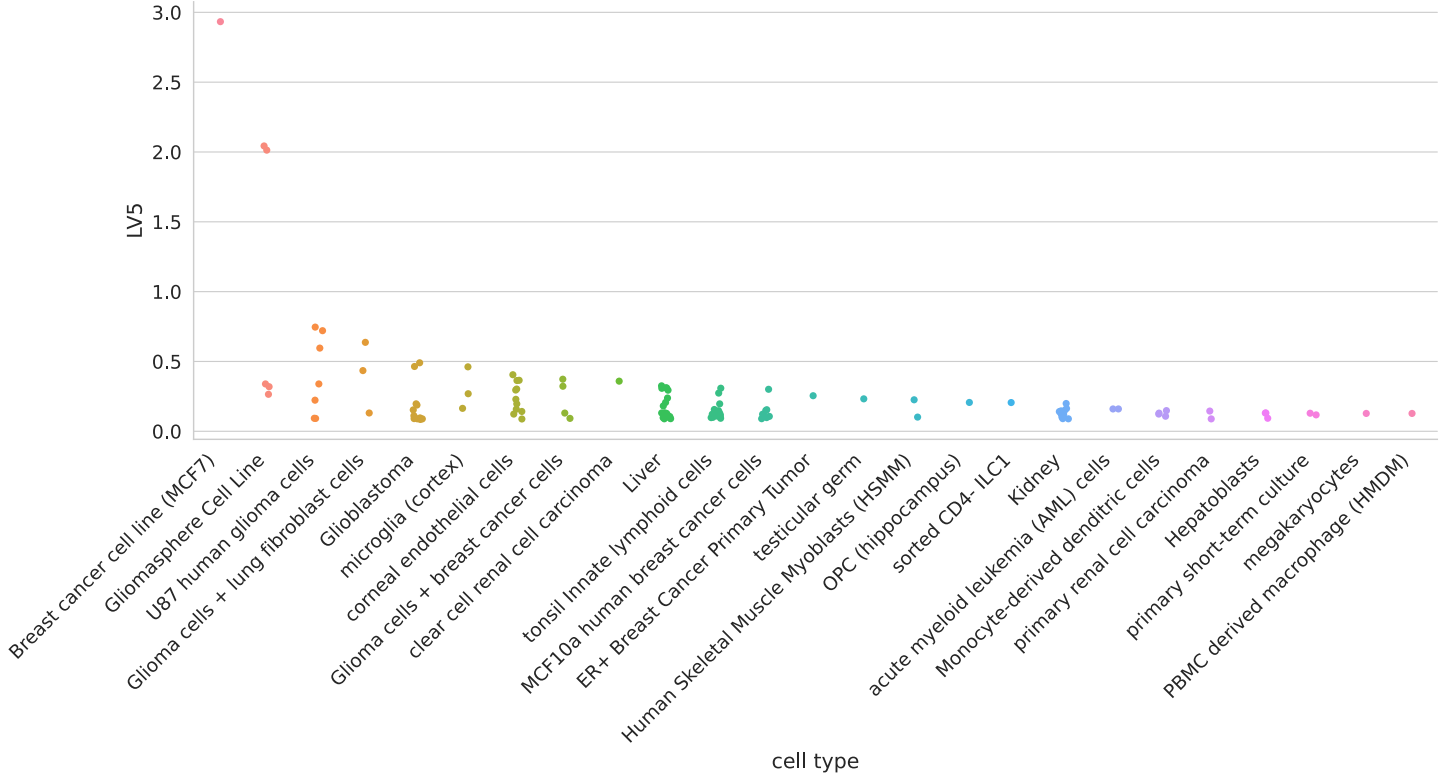

Figure 31: Cell types for LV5.

Table 55: Pathways aligned to LV5 from the MultiPLIER models.

\section{Pathway}

No pathways significantly enriched
AUC

FDR

Table 56: Significant trait associations of LV5 in PhenomeXcan.

\begin{tabular}{|c|c|c|c|c|}
\hline Trait description & $\begin{array}{l}\text { Sample } \\
\text { size }\end{array}$ & Cases & Partition / cluster & FDR \\
\hline LDL Cholesterol NMR & 13,527 & & $29 / 16$ & $1.44 \mathrm{e}-04$ \\
\hline Triglycerides NMR & 21,559 & & $29 / 16$ & $4.03 e-04$ \\
\hline Alzheimers Disease & 54,162 & $\begin{array}{l}17,00 \\
8\end{array}$ & $29 / 16$ & $2.47 \mathrm{e}-03$ \\
\hline Ever had prolonged feelings of sadness or depression & 117,763 & $\begin{array}{l}64,37 \\
4\end{array}$ & $29 / 27$ & $6.92 \mathrm{e}-03$ \\
\hline Medication for depression & 117,763 & $\begin{array}{l}28,35 \\
1\end{array}$ & $29 / 27$ & $8.24 \mathrm{e}-03$ \\
\hline Recent feelings of depression & 117,656 & & $29 / 27$ & $1.05 \mathrm{e}-02$ \\
\hline Ever contemplated self-harm & 117,610 & & $29 / 27$ & $1.50 \mathrm{e}-02$ \\
\hline Recent lack of interest or pleasure in doing things & 117,757 & & $29 / 27$ & $1.65 \mathrm{e}-02$ \\
\hline Amount of alcohol drunk on a typical drinking day & 108,256 & & $29 / 27$ & $2.77 e-02$ \\
\hline $\begin{array}{l}\text { Ever sought or received professional help for mental } \\
\text { distress }\end{array}$ & 117,677 & $\begin{array}{l}46,02 \\
0\end{array}$ & $29 / 27$ & $3.08 \mathrm{e}-02$ \\
\hline General happiness & 117,442 & & $29 / 27$ & $3.73 e-02$ \\
\hline Depression (diagnosed by a professional) & 117,782 & $\begin{array}{l}25,08 \\
7\end{array}$ & $29 / 27$ & $4.03 e-02$ \\
\hline
\end{tabular}

Table 57: Trait associations of LV5 in eMERGE.

\begin{tabular}{|l|l|l|l|l|}
\hline Phecode & Trait description & Sample size & Cases & FDR \\
\hline 241 & Nontoxic nodular goiter & 47,842 & 3,158 & $1.92 \mathrm{e}-02$ \\
\hline
\end{tabular}


bioRxiv preprint doi: https://doi.org/10.1101/2021.07.05.450786; this version posted August 5, 2021. The copyright holder for this preprint (which was not certified by peer review) is the author/funder, who has granted bioRxiv a license to display the preprint in perpetuity. It is made available under aCC-BY 4.0 International license.

\begin{tabular}{|l|l|l|l|l|}
\hline Phecode & Trait description & Sample size & Cases & FDR \\
\hline 241.1 & Nontoxic uninodular goiter & 47,125 & 2,441 & $6.84 \mathrm{e}-02$ \\
\hline
\end{tabular}

\section{LV434}

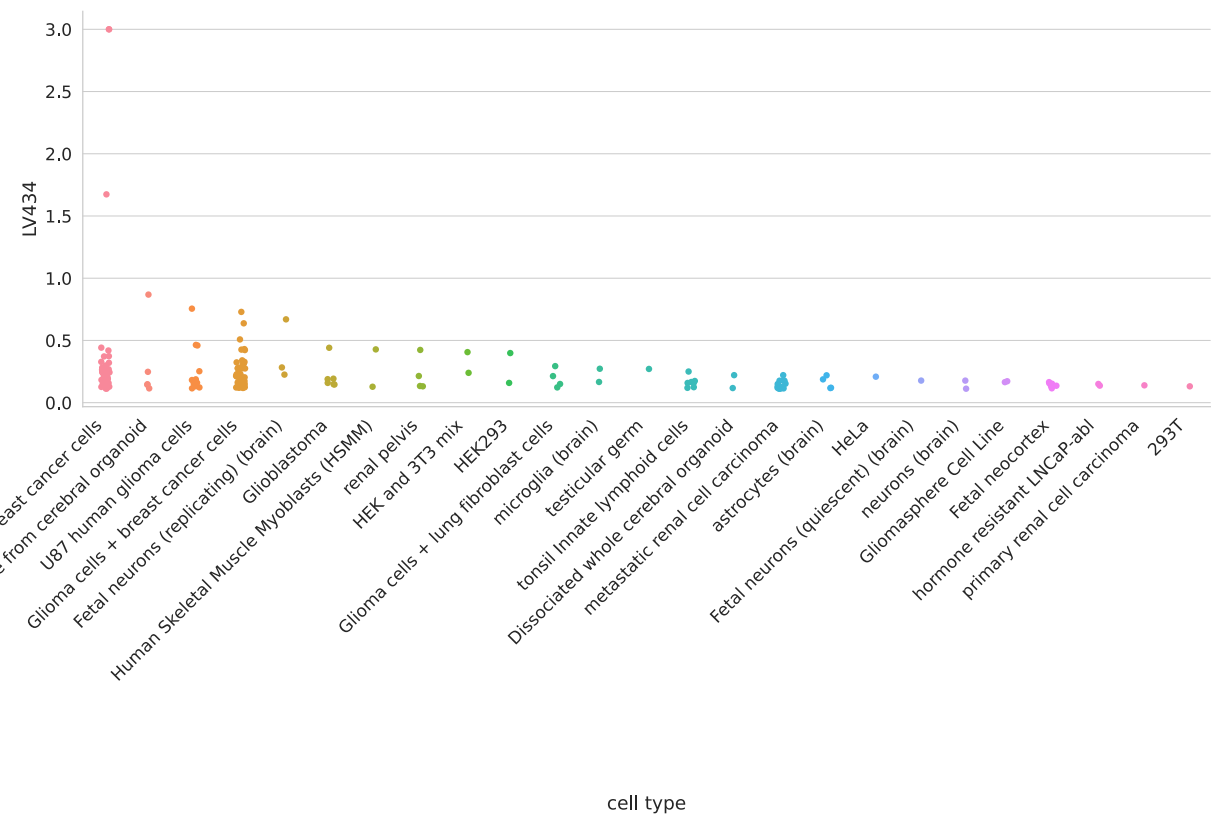

Figure 32: Cell types for LV434. HEK293 is a cell line derived from human embryonic kidney cells; 3 T3 is a cell line derived from mouse embryonic fibroblasts.

Table 58: Pathways aligned to LV434 from the MultiPLIER models.

\begin{tabular}{|l|l|l|}
\hline Pathway & AUC & FDR \\
\hline No pathways significantly enriched & \\
\hline
\end{tabular}

Table 59: Significant trait associations of LV434 in PhenomeXcan.

\begin{tabular}{|l|l|l|l|l|}
\hline Trait description & Sample size & Cases & Partition / cluster & FDR \\
\hline Attention Deficit Hyperactivity Disorder & 53,293 & 19,099 & $29 / 21$ & $5.62 e-03$ \\
\hline
\end{tabular}

Table 60: Significant trait associations of LV434 in eMERGE.

\begin{tabular}{|l|l|l|l|l|}
\hline Phecode & Trait description & Sample size & Cases & FDR \\
\hline 722 & Intervertebral disc disorders & 47,659 & 7,458 & $1.44 \mathrm{e}-02$ \\
\hline 721 & Spondylosis and allied disorders & 47,517 & 7,316 & $1.64 \mathrm{e}-02$ \\
\hline 250.4 & Abnormal glucose & 45,220 & 4,947 & $2.23 \mathrm{e}-02$ \\
\hline 721.1 & Spondylosis without myelopathy & 47,315 & 7,114 & $2.66 \mathrm{e}-02$ \\
\hline 720 & Spinal stenosis & 44,807 & 4,606 & $3.99 \mathrm{e}-02$ \\
\hline
\end{tabular}

